UNIVERSIDADE DE SÃO PAULO

ESCOLA DE EDUCAÇÃO FÍSICA E ESPORTE

\title{
ANÁLISE CINEMÁTICA DA FASE DE APOIO DA CORRIDA EM ADULTOS E IDOSOS CORREDORES
}

Reginaldo Kisho Fukuchi

SÃo PAULO 


\section{ANÁLISE CINEMÁTICA DA FASE DE APOIO DA CORRIDA EM ADULTOS E IDOSOS CORREDORES}

REGINALDO KISHO FUKUCHI

Dissertação apresentada à Escola de Educação Física e Esporte da Universidade de São Paulo, como requisito parcial para obtenção do grau de Mestre em Educação Física. 


\section{AGRADECIMENTOS}

Muitas pessoas participaram efetivamente deste trabalho. É inevitável que minha memória falível vacile neste momento tão importante. Aqui faço uma singela homenagem aqueles que direta ou indiretamente contribuíram para que chegasse nesse momento.

Ao Prof. Dr. Marcos Duarte pelo incentivo, ensinamentos e paciência durante todas as etapas do trabalho, além da confiança depositada em mim. Apesar da diferença de nossas formações, continuo me espelhando em seu trabalho.

Aos meus pais Sylvio e Eliza e a minha irmã Cintia que apesar de terem tido poucas chances de estudar, sempre me incentivaram e me deram todas as condições para que concluísse esta etapa.

Ao amigo Alexandre Dias Lopes por ter sido um dos principais incentivadores no início da minha vida em São Paulo.

Aos amigos do CETE (UNIFESP), principalmente ao Leo e ao Reynaldo, por terem me acolhido na minha chegada a cidade "grande".

Aos amigos e professores do curso de Fisioterapia da UNINOVE, em especial ao Markinho por ter depositado toda a confiança em meu trabalho.

Aos amigos da SONAFE, especialmente ao Claudinho e ao Forgas que sempre me apoiaram e admiraram o meu trabalho.

Aos membros do Instituto Vita, em especial ao Rogério Hirata e Mauro Dinato.

Não podia me esquecer das minhas raízes, portanto sou eternamente grato aos Professores do Curso de Fisioterapia da UCDB que souberam aconselhar seus alunos a buscarem sempre a formação continuada.

Aos amigos e colegas Seu Jorge, Boguinha ("meu cunhado"), Bruninho, Wallace, Magôo e Moisés "Kotó", que sempre me incentivaram a seguir batalhando em busca do meu sonho na cidade grande. 
Ao meu amor, que chegou na etapa final do trabalho mas que foi imprescindível para que eu conseguisse superar as dificuldades. Sempre procurando me ajudar e me entender em todos os momentos de desâmino que surgiram nesta etapa do trabalho. Didinha, serei eternamente grato a você.

Aos meus tios Ademir e Nancy que sempre se preocuparam com a qualidade da minha formação.

Aos membros atuais e aos ex-membros do LoB, Sandra, Silvana, Sandro, Paulo, Rogério, Janina, Rozi, Wilson, Daniel, Bel, André, Bruno, Tiago, Fernanda, Fernando, Cristina e Raquel.

Ao Laboratório de Hemodinâmica da Atividade Motora (LAHAM), principalmente a Profa. Dra. Cláudia Forjaz e ao Dr. Luis Riani pelo apoio durante a coleta de dados.

Ao responsável maior por este momento: Deus! 
LISTA DE TABELAS

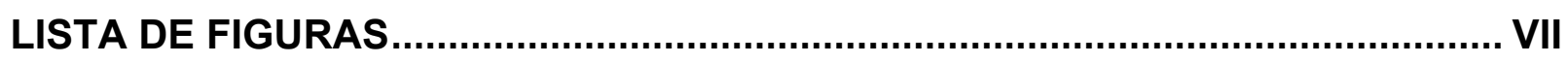

LISTA DE SIGLAS, ABREVIAÇÕES E SÍMBOLOS ........................................... X

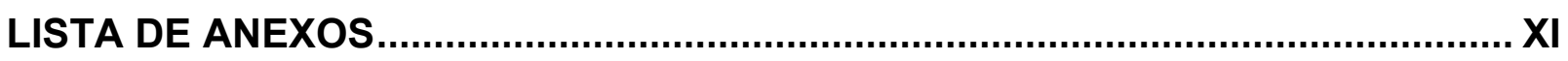

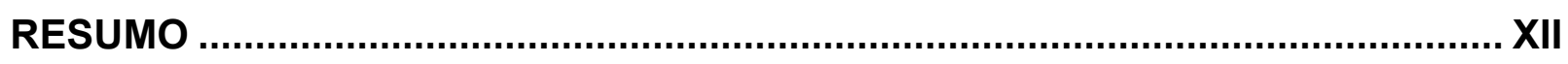

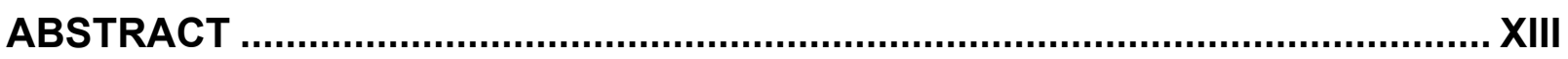

1. INTRODUÇÃO

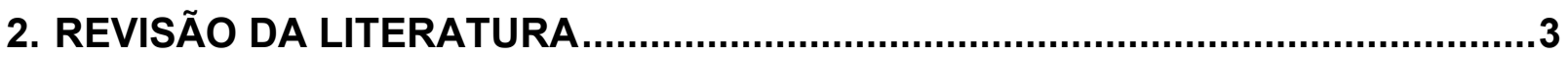

2.1. MOVIMENTO DO COMPLEXO DO TORNOZELO....................................................... 3

2.1.1. Flexão Plantar e Dorsiflexão …………………….................................. 7

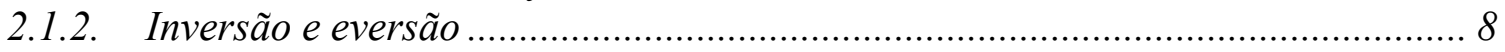

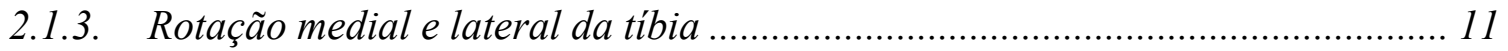

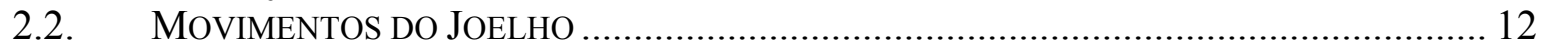

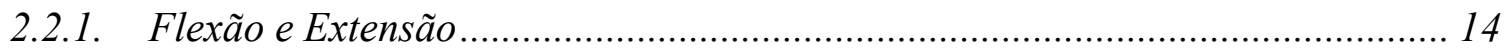

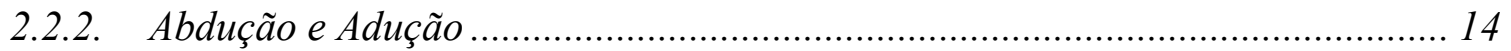

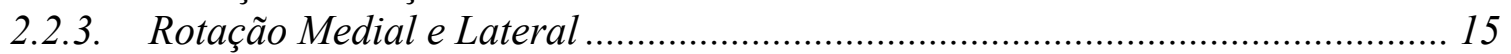

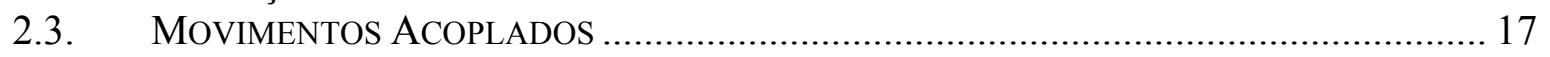

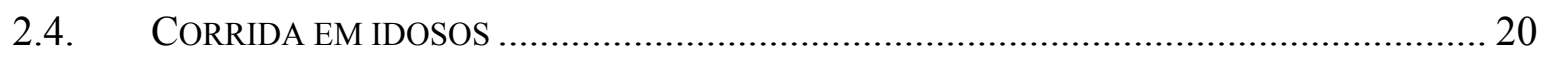

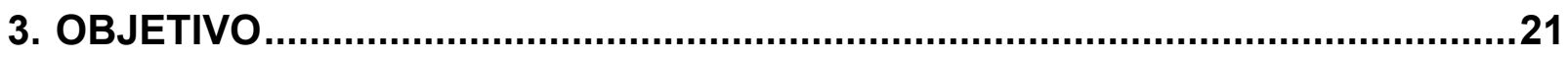

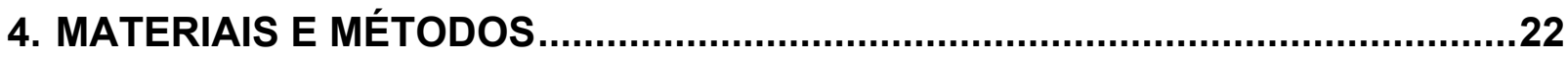

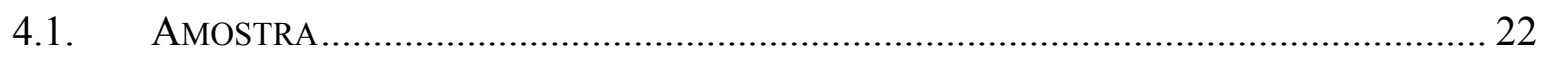

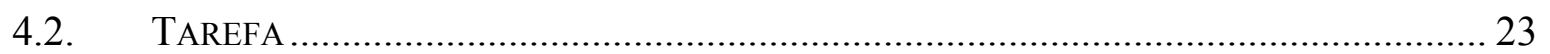

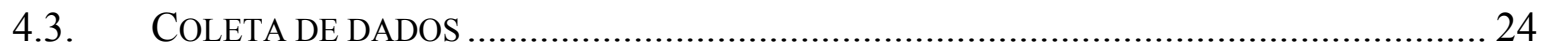

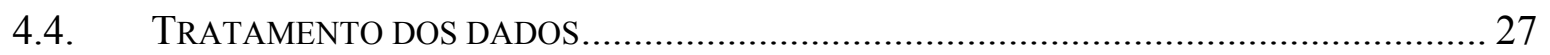

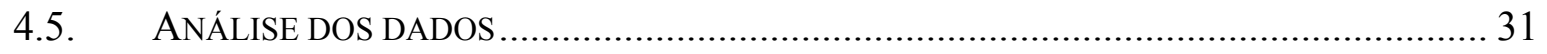

4.5.1. Análise estatística …………………………………………………… 33

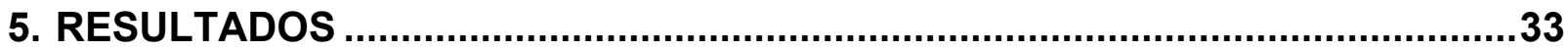

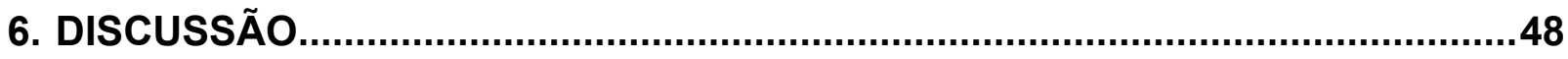

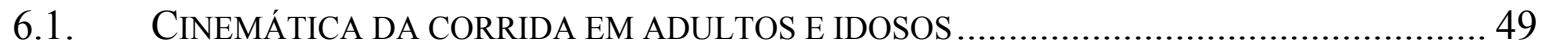

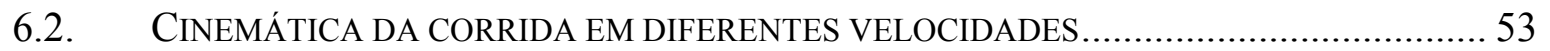

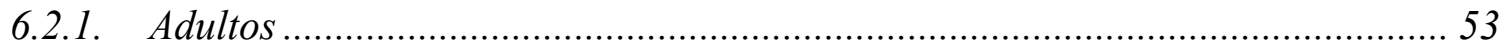

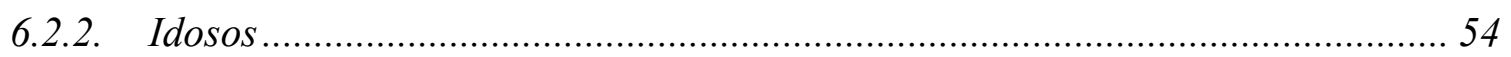

7. CONCLUSÃO

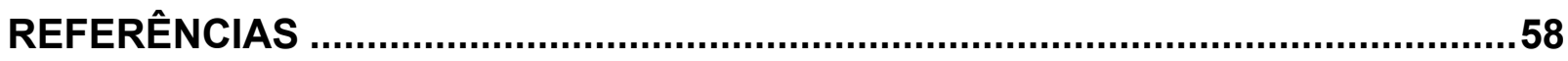




\section{LISTA DE TABELAS}

TABELA 1. Comparação da Cinemática angular para os parâmetros de movimento do pé e do joelho entre os adultos e os idosos. 34

TABELA 2. Comparação das excursões e dos parâmetros de acoplamento entre os adultos e os idosos. 


\section{LISTA DE FIGURAS}

FIGURA 1. Divisão anatômica do pé representando os ossos e articulações do retropé (pé posterior). Reproduzido de NEUMANN (2002).

FIGURA 2. Orientação do eixo médio-lateral da articulação talocrural. Reproduzido de NEUMANN (2002).

FIGURA 3. Orientação do eixo oblíquo da articulação talocrural. Dados extraídos de NEUMANN (2002). 6

FIGURA 4. Gráfico representando o movimento do complexo do tornozelo no plano sagital. Dados retirados de BUS (2003) onde a linha contínua representa os corredores mais velhos e a linha tracejada representa os adultos.

FIGURA 5. Dados de MCCLAY e MANAL (1998a). A linha contínua representa o ângulo de inversão e eversão em sujeitos normais e a linha tracejada representa os dados de sujeitos hiperpronadores. 10

FIGURA 6. Alinhamento do membro inferior direito durante as fases de heel strike, apoio médio e apoio final da corrida. Extraído de DELEO et. al. (2004).

FIGURA 7. Dados que representam o ângulo de flexão-extensão do joelho durante o apoio na corrida em sujeitos hiperpronadores e normais. A linha contínua representa os sujeitos normais e a linha tracejada os hiperpronadores (MCCLAY \& MANAL, 1998a).

FIGURA 8. Dados que representam o ângulo de abdução e adução do joelho durante a corrida em sujeitos que desenvolveram a síndrome do trato iliotibial (ITBS) e em sujeitos assintomáticos (Control) (NOEHREN, DAVIS \& HAMILL, 2007)

FIGURA 9. Dados que representam o ângulo de rotação medial e lateral do joelho durante a fase de apoio da corrida. A linha tracejada representa os sujeitos portadores de síndrome patelofemoral (pfps) e linha contínua representa os sujeitos assintomáticos (Control). A barra horizontal representa a série temporal da fase de apoio da corrida. Extraído de WILLSON \& DAVIS (no prelo). 16 
FIGURA 10. Modelo do acoplamento que existe entre a tíbia e o pé. Extraído de INMAN (1976).

FIGURA 11. Ângulos articulares do membro inferior durante a fase de apoio da corrida: (a) inversão (IN)/eversão (EV) do retropé, (b) rotação medial (TIR)/lateral (TER) da tíbia, (c) flexão (FLX)/extensão (EXT) do joelho e (d) rotação medial (HIR) e lateral (HER) do quadril. Extraído de DELEO et. al. (2004). 19

FIGURA 12. Ciclograma demonstrando o padrão de acoplamento entre os movimentos de eversão do retropé versus rotação medial da tíbia durante a fase de apoio da corrida: do heel strike (HS) ao toe-off (TO). Dados extraídos de ESLAMI et. al.(2007).

FIGURA 13. Representação esquemática do arranjo experimental com as quatro câmeras e esteira para a aquisição de dados cinemáticos.

FIGURA 14. Sistema de Coordenadas Articulares do Joelho …...........................28

Figura 15. Sistema de Coordenadas articulares do Tornozelo .............................29

FIGURA 16. Posicionamento dos clusters, das marcas anatômicas (esquerda) e a convenção adotada para medir os ângulos articulares (direita).

FIGURA 17. Média da série temporal dos movimentos do retropé e do joelho e o ciclograma da flexão do joelho vs. eversão do retropé durante a fase de apoio da corrida a $11 \mathrm{~km} / \mathrm{h}$.

FIGURA 18. Ciclograma que representa a média dos movimentos de INV/EV versus FLXJ/EXTJ.

FIGURA 19. Média e erro padrão do ângulo do joelho no plano sagital durante a fase de apoio em adultos (A) e idosos (B) nas duas velocidades analisadas......40 FIGURA 20. Média e erro padrão do ângulo do joelho no plano frontal durante a fase de apoio em adultos (A) e idosos (B) nas duas velocidades analisadas......41 FIGURA 21. Média e erro padrão do ângulo do joelho no plano frontal durante a fase de apoio em adultos (A) e idosos (B) nas duas velocidades analisadas......42 FIGURA 22. Média e erro padrão do ângulo do retropé no plano sagital durante a fase de apoio em adultos (A) e idosos (B) nas duas velocidades analisadas......43

FIGURA 23. Média e erro padrão do ângulo do retropé no plano frontal durante a fase de apoio em adultos (A) e idosos (B) nas duas velocidades analisadas......44 
FIGURA 24. Média e erro padrão do ângulo do retropé no plano transverso durante a fase de apoio em adultos $(A)$ e idosos $(B)$ nas duas velocidades analisadas... 45 FIGURA 25. Ciclograma que representa a média dos movimentos de eversão versus flexão do joelho para os adultos $(A)$ e idosos $(B)$ analisados. 46

FIGURA 26. Ciclograma que representa a média dos movimentos de eversão versus rotação medial da tíbia para os adultos $(A)$ e idosos $(B)$ analisados. 47

FIGURA 27. Ciclograma que representa a média dos movimentos de eversão versus rotação medial do joelho para os adultos $(A)$ e idosos $(B)$ analisados. ....48

FIGURA 28. Marcas anatômicas utilizadas no segmento coxa.............................71

FIGURA 29. Marcas anatômicas utilizadas no segmento perna............................72

FIGURA 30. Marcas anatômicas utilizadas no segmento pé.............................73

FIGURA 31 - Exemplo de um Sistema de Referência Global (SRG). ...................74

FIGURA 32 - Sistema de referência local (SRL) localizado dentro de um Sistema de

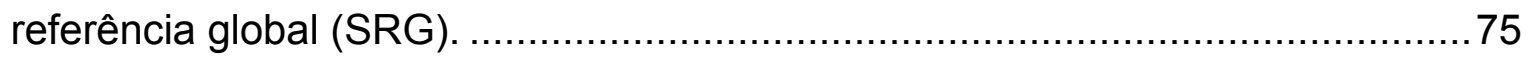

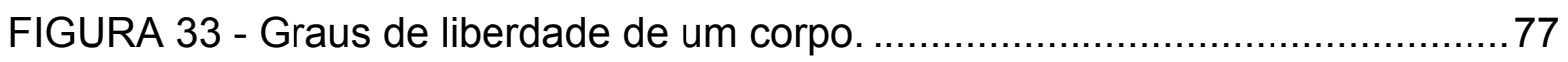

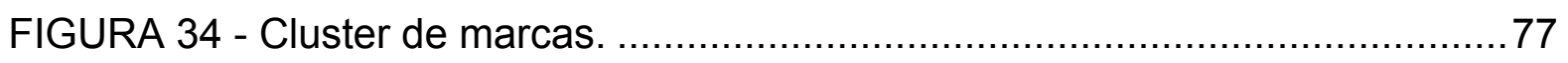

FIGURA 35 - Colocação das marcas anatômicas sobre os segmentos e os respectivos clusters para utilização do CAST. 78

FIGURA 36 - Vetores-posição (em branco) das marcas anatômicas em relação ao

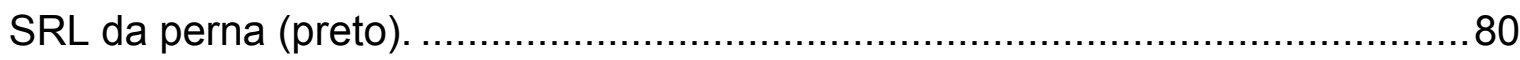

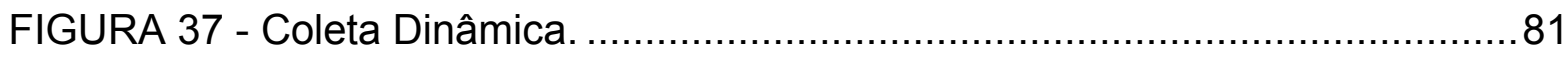

FIGURA 38. Posição relativa do Centro Articular do Quadril .................................. 82 


\section{LISTA DE SIGLAS, ABREVIAÇÕES E SÍMBOLOS}

\begin{tabular}{|c|c|}
\hline ABREV. & DESCRIÇÃO \\
\hline DFT & $\begin{array}{l}\text { Dorsiflexão do tornozelo: movimento relativo entre o calcâneo e a tíbia } \\
\text { no plano sagital. }\end{array}$ \\
\hline EV & $\begin{array}{l}\text { Eversão do retropé: movimento relativo entre o calcâneo e a tíbia no } \\
\text { plano frontal. }\end{array}$ \\
\hline ABD & $\begin{array}{l}\text { Abdução do retropé: movimento relativo entre o calcâneo e a tíbia no } \\
\text { plano transversal. }\end{array}$ \\
\hline RIT & $\begin{array}{l}\text { Rotação medial da tíbia: rotação da tíbia em relação ao calcâneo no } \\
\text { plano transversal. }\end{array}$ \\
\hline FLXJ & $\begin{array}{l}\text { Flexão do joelho: movimento relativo entre a tíbia e o fêmur no plano } \\
\text { sagital. }\end{array}$ \\
\hline ADU/ABD & $\begin{array}{l}\text { Adução/Abdução: movimento relativo entre a tíbia e o fêmur no plano } \\
\text { frontal. }\end{array}$ \\
\hline RIJ & $\begin{array}{l}\text { Rotação medial do joelho: movimento relativo entre a tíbia e o femur } \\
\text { no plano transversal. }\end{array}$ \\
\hline EV/RIT & $\begin{array}{l}\text { Razão entre a excursão de eversão do retropé com a excursão de } \\
\text { rotação medial da tíbia. }\end{array}$ \\
\hline $\begin{array}{l}\text { FLX-EV } \\
\text { tempo }\end{array}$ & $\begin{array}{l}\text { Diferença entre o tempo para atingir do pico da flexão do joelho e o } \\
\text { pico da eversão do retropé (em segundos). }\end{array}$ \\
\hline $\begin{array}{l}\text { RIJ-EV } \\
\text { tempo }\end{array}$ & $\begin{array}{l}\text { Diferença entre o tempo para atingir do pico da rotação medial do } \\
\text { joelho e o pico da eversão do retropé (em segundos). }\end{array}$ \\
\hline$\% \mathrm{EV}$ & Porcentagem do apoio em que ocorre o pico de eversão do retropé. \\
\hline$\%$ FLXJ & Porcentagem do apoio em que ocorre o pico de flexão de joelho. \\
\hline$\%$ RIJ & $\begin{array}{l}\text { Porcentagem do apoio em que ocorre o pico de rotação medial do } \\
\text { joelho. }\end{array}$ \\
\hline$\alpha$ & $\begin{array}{l}\text { Ângulos articulares do joelho e retropé no plano sagital: valores } \\
\text { positivos indicam flexão do joelho e dorsiflexão; valores negativos } \\
\text { indicam extensão do joelho e flexão plantar. }\end{array}$ \\
\hline$\beta$ & $\begin{array}{l}\text { Ângulos articulares do joelho e retropé no plano frontal: valores } \\
\text { positivos representam a inversão do retropé e adução do joelho e } \\
\text { valores negativos a eversão do retropé e a abdução do joelho. }\end{array}$ \\
\hline$\gamma$ & $\begin{array}{l}\text { Ângulo joelho no plano transversal: valores positivos representam a } \\
\text { rotação medial e valores negativos a rotação lateral. }\end{array}$ \\
\hline$\gamma \mathrm{m}$ & $\begin{array}{l}\text { Ângulo da tíbia no plano transversal: valores positivos representam a } \\
\text { rotação medial e valores negativos a rotação lateral. }\end{array}$ \\
\hline
\end{tabular}




\section{LISTA DE ANEXOS}

ANEXO 1-QUESTIONÁRIO COM DADOS PESSOAIS DOS SUJEITOS.................65

ANEXO 2- CARTA DE APROVAÇÃO DO COMITÊ DE ÉTICA .............................66

ANEXO 3- TERMO DE CONSENTIMENTO LIVRE E ESCLARECIDO ..................67

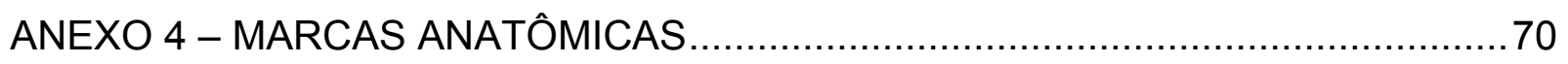

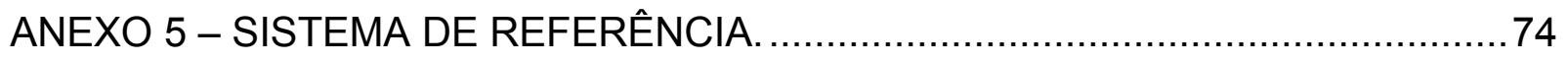

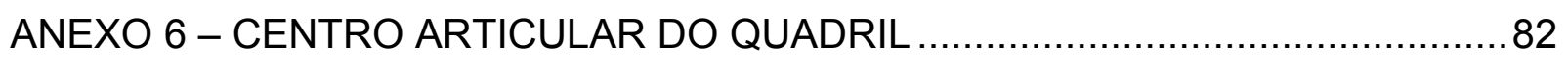




\title{
RESUMO
}

\section{ANÁLISE CINEMÁTICA DA FASE DE APOIO DA CORRIDA EM ADULTOS E IDOSOS CORREDORES}

\author{
Autor: Reginaldo Kisho Fukuchi \\ Orientador: Prof. Dr. Marcos Duarte
}

O crescente aumento da expectativa de vida tem culminado na constante preocupação com qualidade de vida na população idosa. A corrida de rua é um dos esportes que mais adquiriu adeptos dessa faixa etária. Alguns estudos têm reportado um aumento no número de lesões associado a este aumento do número de praticantes. As alterações teciduais decorrentes do envelhecimento biológico podem alterar a mecânica da corrida nos idosos e deixá-los mais susceptíveis a lesões. Contudo, ainda é desconhecido se tais efeitos realmente provocam esses resultados. O objetivo do presente estudo foi comparar a cinemática da corrida em

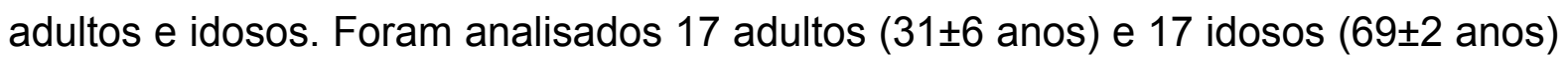
recrutados voluntariamente para o estudo. Os sujeitos correram em uma esteira ergométrica nas velocidades de 8 e 11 km/h (idosos) e 11 e 14 km/h (idosos). Os sujeitos foram filmados por quatro câmeras de vídeo com freqüência de $120 \mathrm{~Hz}$ durante a corrida em esteira. Foram realizadas a digitalização e reconstrução das coordenadas dos pontos digitalizados no espaço real a partir das imagens das quatro câmeras e da calibração pelo método DLT. Os idosos apresentaram menor excursão de movimentos de flexão do joelho e de rotação medial da tíbia. Aparentemente os idosos apresentaram maior assincronia entre os movimentos do retropé e do joelho em relação aos adultos. Esses resultados sugerem que os idosos adotam padrões de movimentos diferentes dos adultos durante a fase de apoio da corrida. A prescrição de exercícios e as estratégias de prevenção de lesões em idosos corredores devem considerar essas diferenças.

Palavras-chave: cinemática, corrida, envelhecimento 


\section{ABSTRACT}

\section{KINEMATICS ANALYSIS DURING THE STANCE PHASE OF RUNNING IN ADULTS AND ELDERLY \\ Author: Reginaldo Kisho Fukuchi \\ Advisor: Prof. Dr. Marcos Duarte}

The growing increase of the life expectancy has been culminating in the constant preoccupation in quality of life in the elderly people. Running is one of the sports that has gained more participants in this age group. Some studies have shown an increase of the number of injuries associated with the increasing number of runners. The tissues changes resulting from the aging can alter the mechanics of the elderly running and leave them more susceptible to injuries. Nevertheless it is still unknown if such effects really cause changes in the mechanics of running in the elderly population. The objective of the present study is to compare the kinematics of the adults and elderly runner. Seventeen adults and 17 elderly runners participated in this study. The subjects ran in a treadmill at two different speeds: 8 and $11 \mathrm{~km} / \mathrm{h}$ for elderly and 11-14 for adults. The subjects were filmed by four camcorders at $120 \mathrm{~Hz}$. The digitizing and reconstruction of the coordinates of the digitized points were made at APAS System and calibrated with the DLT method. The elderly runners have showed a lower knee flexion excursion and lower tibial internal rotation excursion. It seems that elderly runners presented more asynchrony between rearfoot and knee joint movement than young adults. These results suggest that elderly runners adopted different movement patterns when compared with adults during the stance phase of running. The prescriptions of physical activities and strategies for injury prevention in elderly runners must consider the findings of the present study.

Keywords: kinematics, running, aging 


\section{INTRODUÇÃO}

Durante o envelhecimento, uma série de disfunções podem acometer os idosos como a osteoporose, diabetes melito, a hipertensão arterial e outras doenças cardiovasculares (YOUNG \& DINAN, 2005). A prática regular de atividade física ajuda a prevenir ou postergar o aparecimento dessas disfunções e ajuda a melhorar a qualidade de vida. Além desses benefícios a atividade física regular diminui os efeitos deletérios da imobilidade, comuns nessa idade e é uma ótima oportunidade de sociabilização (WANG, RAMEY, SCHETTLER, HUBERT \& FRIES, 2002; YOUNG \& DINAN, 2005). A corrida de rua é uma das atividades que mais despertou adeptos desta faixa etária segundo dados da maior associação de corredores do estado de São Paulo, a CORPORE, que registrou um aumento de $52 \%$ do número de atletas com mais de 65 anos que participaram das provas organizadas pela entidade nos últimos três anos. A prática de atividade física tem sido um importante componente para os idosos envelhecerem com qualidade de vida. Além de todos os benefícios fisiológicos, a corrida tem sido o esporte de escolha por causa da sua conveniência e natureza econômica (TAUNTON, RYAN, CLEMENT, MCKENZIE, LLOYD-SMITH \& ZUMBO, 2002).

Infelizmente, o aumento da prática de corrida tem levado ao conseqüente aumento do número de lesões. Nos Estados Unidos, estima-se que, anualmente, cerca de metade dos corredores amadores e profissionais apresentam lesões que alteram suas performances (NOVACHECK, 1998). MCKEAN et al. (2006) encontrou uma incidência de $46 \%$ de lesões em corredores jovens e veteranos, sendo que as múltiplas lesões foram mais freqüentes em veteranos. Esse achado demonstra semelhança com outro achado reportado previamente na literatura (VAN MECHELEN, 1992). Estes autores encontraram diferença significativa da taxa de lesões entre corredores veteranos ( $\geq 40$ anos) e adultos jovens, com os mais velhos apresentando maior taxa. HOGAN \& CAPE (1984) reportaram uma incidência de $46,9 \%$ de lesões em maratonistas com mais de 60 anos. Ambos os indivíduos jovens e os mais velhos são frequentemente expostos a lesões sendo que a incidência anual de lesões se encontra entre $37 \%$ e $56 \%$ em ambos os grupos (MARTI, VADER, MINDER \& ABELIN, 1988). Note que os corredores mais velhos apresentam preocupantes $19 \%$ a mais de incidência de lesão que os corredores 
jovens. O aumento da incidência de lesões evidencia a falta de compreensão dos mecanismos que causam as lesões crônicas, particularmente em corredores mais velhos. O maior acometimento dos idosos por lesões pode ser devido às degenerações teciduais resultantes do processo de envelhecimento biológico (VANDERVOORT \& MCCOMAS, 1986); e por eventuais mudanças nos padrões de movimento utilizados na corrida (BUS, 2003).

Os movimentos excessivos da região do tornozelo têm sido atribuídos como causas de lesões musculoesqueléticas,principalmente na articulação do joelho em corredores (HINTERMANN \& NIGG, 1998; STOVITZ \& COETZEE, 2004). Infelizmente existe uma confusão terminológica em relação aos movimentos, principalmente àqueles que ocorrem nas articulações talocrural e subtalar. Os movimentos da articulação subtalar não podem ser avaliados por métodos nãoinvasivos devido a impossibilidade de determinar a posição do tálus. Portanto, os movimentos avaliados pela maioria dos estudos são uma combinação entre os movimentos das articulações talocrural e subtalar, onde se avalia os movimentos entre a perna e o calcâneo. A articulação entre esses dois ossos tem sido frequentemente referida como articulação do retropé (MCCLAY \& MANAL, 1999). Na maioria dos estudos que investiga a biomecânica da corrida, o principal componente do movimento de pronação/supinação é a eversão/inversão. Sendo assim, esses pares de termos frequentemente são empregados de maneira contrária (GREINER, 2007). Esta confusão foi reforçada pelos estudos anteriores, onde apenas o plano frontal de movimento do retropé era realizado por meio de análises cinemáticas bidimensionais (MCCLAY \& MANAL, 1998b; NOVACHECK, 1998). Neste tipo de análise apenas um componente da pronação/supinação pode ser observado.

Embora a cinemática dos membros inferiores durante a fase de apoio da corrida tenha sido relativamente investigada em adultos jovens (AREBLAD, NIGG, EKSTRAND, OLSSON \& EKSTROM, 1990; ENGSBERG \& ANDREWS, 1987; NOVACHECK, 1998); em idosos esses estudos são inexistentes. BUS (2003) não encontrou diferenças significativas nos padrões cinemáticos da corrida entre adultos e corredores mais velhos (entre 55 e 65 anos). Porém este autor não investigou idosos corredores, portanto ainda é desconhecido o comportamento biomecânico de idosos durante a corrida. 
É possível que em virtude das alterações no corpo humano relacionadas ao envelhecimento, os corredores idosos apresentem alterações na cinemática dos membros inferiores durante a corrida em comparação aos adultos. O maior conhecimento da cinemática do idoso corredor pode, de forma geral, contribuir para melhor prescrição da atividade física, melhor orientação quanto ao uso de calçado esportivo e na prevenção e tratamento de lesões relacionadas.

O presente trabalho relata um estudo sobre esta temática onde se investigou a cinemática de corredores jovens e idosos. A seguir, o objetivo do presente trabalho é detalhado e em seguida é descrita uma revisão de literatura sobre a temática investigada, para após serem apresentados os materiais e métodos utilizados, os resultados obtidos, a discussão sobre estes resultados e a conclusão do trabalho.

\section{REVISÃO DA LITERATURA}

A cinemática do movimento dos membros inferiores durante a corrida em adultos tem sido estudada de maneira extensiva pela literatura. Algumas referências principais serviram de guia para este trabalho, o livro The Biomechanics of Distance Running (CAVANAGH, 1990) e as revisões de NOVACHECK (1998) e de DELEO (2004).

\subsection{Movimento do Complexo do Tornozelo}

A região do pé e tornozelo é composta por cerca de 28 ossos e 30 articulações, que estão unidos por muitos ligamentos, tendões, músculos e outros tecidos moles (ENGSBERG \& ANDREWS, 1987). Anatomicamente o pé é dividido em três regiões: retropé, médiopé e antepé. Essa classificação divide o pé segundo os ossos contidos em cada região. O retropé é formado pelo tálus e o calcâneo, constituindo as articulações talocrural e subtalar. O médiopé é constituído pelo navicular, cubóide e os ossos cuneiformes. O antepé é formado pelos metatarsos e pelas falanges (NEUMANN, 2002). A FIGURA 1 ilustra os ossos do pé com suas respectivas divisões. 


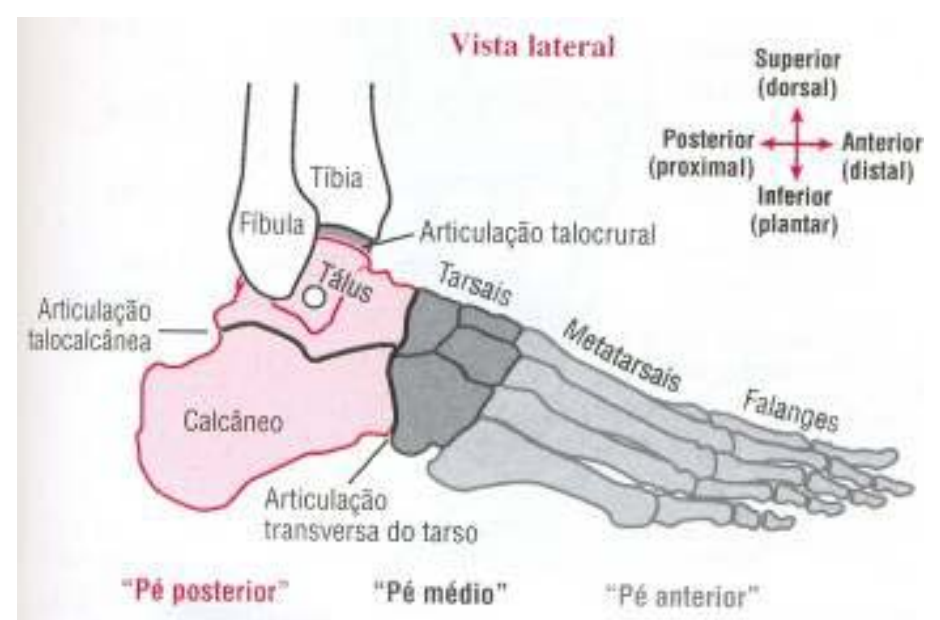

FIGURA 1. Divisão anatômica do pé representando os ossos e articulações do retropé (pé posterior). Reproduzido de NEUMANN (2002).

Segundo a terminologia proposta pela Sociedade Internacional de Biomecânica, o complexo articular do tornozelo é composto pelas articulações talocrural e subtalar (WU, SIEGLER, ALLARD, KIRTLEY, LEARDINI, ROSENBAUM, WHITTLE, D'LIMA, CRISTOFOLINI, WITTE, SCHMID \& STOKES, 2002). A falta de distinção nos estudos se deve ao fato de que a maioria dos trabalhos utilizaram marcas externas para avaliar os movimentos dessas articulações, portanto, avaliaram o movimento existente entre a perna e o calcâneo (AREBLAD et al., 1990; DE WIT, DE CLERCQ \& AERTS, 2000; MCCLAY \& MANAL,1998b; MCCLAY \& MANAL,1999; NAWOCZENSKI, SALTZMAN \& COOK, 1998; NIGG, COLE \& NACHBAUER, 1993).

A articulação talocrural (tornozelo) é compreendida pela junção da perna (tíbia e fíbula) e o tálus. A articulação subtalar (talocalcaneana) é a junção entre o tálus e o calcâneo (INMAN, 1976). Devido à dificuldade de mensurar os movimentos do tálus utilizando marcas externas, este complexo tem sido simplificado como uma articulação simples do tipo bola e soquete, realizando três rotações (REINSCHMIDT, 1996). Utilizando esta simplificação, o movimento do tornozelo, da articulação subtalar e da articulação transversa do tálus são mensurados e reportados como uma articulação simples (CZERNIECKI, 1988). MCCLAY \& MANAL (1999) definiram articulação do retropé como a junção entre o calcâneo e a tíbia. No presente estudo foi utilizado esta definição para descrever os movimentos do retropé. 
A articulação talocrural possui um grau de liberdade, realizando os movimentos de flexão plantar e dorsiflexão. O eixo dessa articulação está ligeiramente desalinhado em relação ao eixo médio-lateral puro. A divergência desse eixo está por volta de dez graus no plano frontal e seis graus no plano transversal (CZERNIECKI, 1988). A orientação do eixo da articulação talocrural está demonstrada na FIGURA 2.

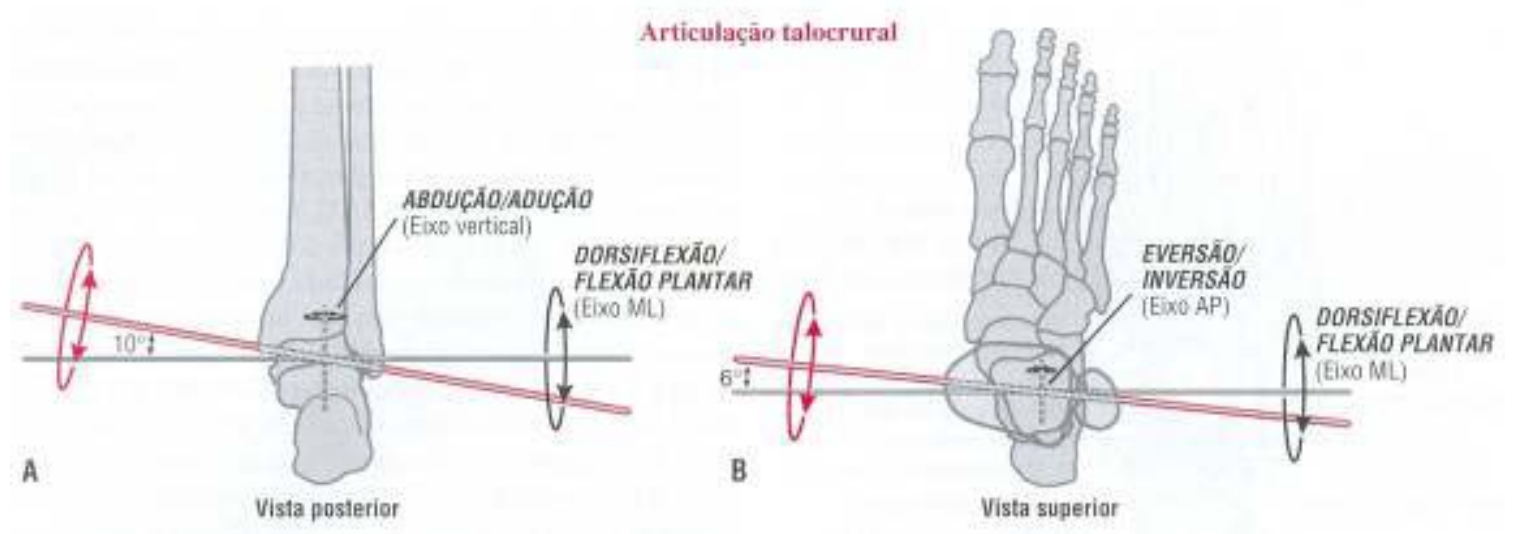

FIGURA 2. Orientação do eixo médio-lateral da articulação talocrural. Reproduzido de NEUMANN (2002).

Em conseqüência dessa orientação, durante a marcha, quando o pé se encontra fixo no solo durante a fase de apoio, a dorsiflexão é associada com uma leve abdução e eversão, e a flexão plantar com leve adução e inversão (CZERNIECKI, 1988).

A articulação subtalar também possui um eixo oblíquo que não é paralelo a nenhum dos eixos anatômicos. Este eixo está orientado em cerca de 42 graus acima do plano transversal e 16 graus medialmente ao plano sagital como demonstrado na FIGURA 3 (CZERNIECKI, 1988). 


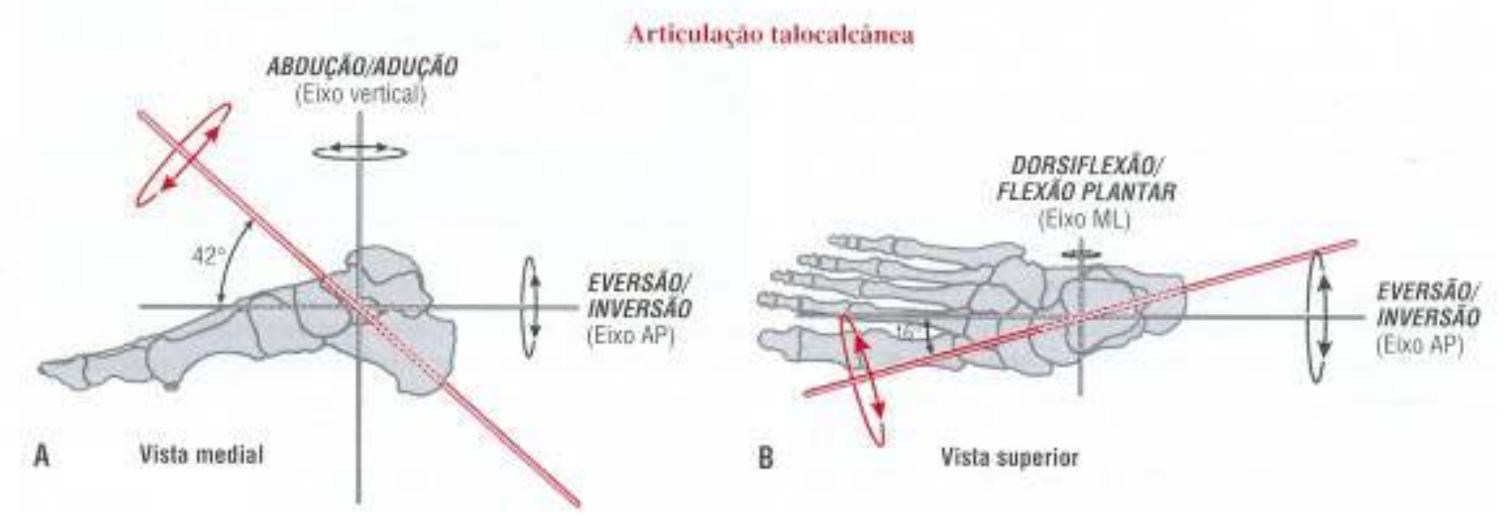

FIGURA 3. Orientação do eixo oblíquo da articulação talocrural. Dados extraídos de NEUMANN (2002).

Devido a esta orientação, dois dos três componentes da pronação e supinação ficam mais evidentes nesta articulação: eversão e abdução e inversão e adução. Os movimentos de flexão plantar e dorsiflexão possuem pequena amplitude nesta articulação (CZERNIECKI, 1988; NEUMANN, 2002).

A impossibilidade de mensurar os movimentos da articulação subtalar por métodos não-invasivos, a pronação e supinação acabam sendo consideradas como movimentos combinados que ocorrem na articulação do retropé, ou seja entre o calcâneo e a tíbia. Sendo que a supinação/ pronação é resultado da inversão/eversão da articulação subtalar, flexão plantar/dorsiflexão da articulação talocrural e adução/abdução da articulação subtalar (GREINER, 2007).

Os termos eversão e inversão têm sido utilizados para se referirem aos movimentos de pronação e supinação respectivamente, devido a dificuldade em mensurar esse movimento combinado (CLARKE, FREDERICK \& HAMILL, 1983; NOVACHECK, 1998).

Existe certa confusão existente devido à numerosa terminologia necessária para descrever os movimentos do pé, sendo que a supinação/pronação e a inversão/eversão são as mais frequentemente confundidas (GREINER, 2007). No presente estudo foi adotada a terminologia mais utilizada pela literatura especializada, para representar os movimentos analisados (Veja (CZERNIECKI, 
1988) e (GREINER, 2007) para uma descrição mais completa dos movimentos do pé e do tornozelo).

\subsubsection{Flexão Plantar e Dorsiflexão}

Os movimentos do complexo do tornozelo no plano sagital (flexão plantar e dorsiflexão) são totalmente dependentes do estilo adotado pelo corredor no contato inicial (heel strike). Cerca de $80 \%$ dos corredores de fundo realizam o contato inicial com o retropé (rearfoot strikers), sendo que o restante realiza o toque inicial com o médiopé e o antepé (NOVACHECK, 1998). À medida que a velocidade da corrida aumenta, a tendência natural é realizar o contato inicial mais com o antepé (CLARKE, FREDERICK \& HAMILL, 1984). Os rearfoot strikers realizam uma flexão plantar no início do apoio. Por volta de $20 \%$ da fase de apoio ocorre uma dorsiflexão até cerca de $50 \%$ da fase de apoio. Desse ponto em diante acontece uma rápida flexão plantar até o momento em que o pé perde o contato com o solo (AREBLAD et al., 1990). O comportamento angular do complexo do tornozelo no plano sagital é demonstrado no gráfico abaixo (FIGURA 4).

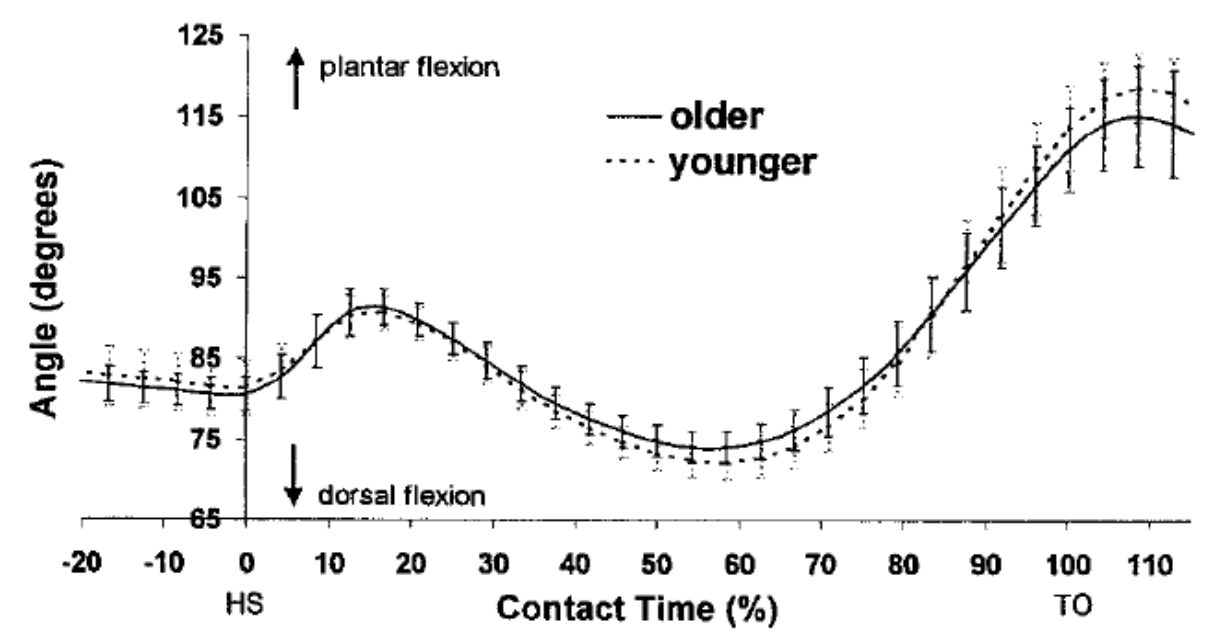

FIGURA 4. Gráfico representando o movimento do complexo do tornozelo no plano sagital. Dados retirados de BUS (2003) onde a linha contínua representa os corredores mais velhos e a linha tracejada representa os adultos. 


\subsubsection{Inversão e eversão}

Os movimentos de inversão e eversão do retropé têm sido amplamente estudados devido a grande ligação que alguns estudos fazem entre a excessiva pronação e a ocorrência de lesões (HINTERMANN \& NIGG, 1998; JAMES, BATES \& OSTERNIG, 1978; MESSIER \& PITTALA, 1988; STOVITZ \& COETZEE, 2004). Esse movimento está muito relacionado com a ocorrência de fraturas por estresse da extremidade inferior (LYSHOLM \& WIKLANDER, 1987; SLOCUM \& JAMES, 1968). A pronação excessiva e/ou prolongada exerce tensão nas estruturas anatômicas mediais do pé e do tornozelo, levando a sobrecarga dessas estruturas (MCCLAY \& MANAL, 1998a). Devido aos problemas já mencionados anteriormente, a eversão foi utilizada no presente estudo para descrever a pronação do retropé. Outros estudos também utilizaram esse mesmo procedimento para descrever a pronação (MCCLAY \& MANAL, 1997,, 1998a,, 1999; STERGIOU \& BATES, 1997).

No contato inicial durante a marcha o retropé entra em contato com o solo em inversão, então a pronação ocorre no membro de apoio durante a fase de absorção de choque. A pronação destrava a articulação transversa do tálus aumentando a flexibilidade do pé e permitindo uma função mais efetiva de absorção de choque (CZERNIECKI, 1988; NOVACHECK, 1998). O pico de pronação normalmente ocorre por volta de $40 \%$ da fase de apoio, logo em seguida o pé começa a supinar e atinge a posição neutra por volta de $70 \%$ da fase de apoio. $O$ hiperpronador inicia a supinação e atinge a posição neutra com atraso, já na fase de geração de potência, deixando a propulsão do pé ineficiente (NOVACHECK, 1998).

Até o início dos anos 90 a maioria dos estudos haviam mensurado o movimento do retropé utilizando técnicas de análise cinemática bidimensional. Neste tipo de análise os ângulos de inversão e eversão do calcâneo são utilizados para designar os movimentos de pronação e supinação da subtalar (CLARKE, FREDERICK \& HAMILL, 1983; EDINGTON, FREDERICK \& CAVANAGH, 1990; HRELJAC, MARSHALL \& HUME, 2000). Esses dois pares de termos (inversão/eversão e pronação/supinação) têm sido utilizados como sinônimos pela literatura (NOVACHECK, 1998). 
AREBLAD et al. (1990) demonstraram que o ângulo de eversão é o mais sensível a mudanças do alinhamento da câmera em relação ao movimento analisado quando realizada a técnica bidimensional de análise cinemática. Este estudo demonstrou alterações superiores a um grau para cada dois graus de mudança no alinhamento da câmera, comparado com dados de uma análise tridimensional.

O primeiro estudo encontrado na literatura que apresentou os ângulos de inversão e eversão de um grande número de sujeitos foi conduzido por NIGG et al. (1993). Neste estudo os autores encontraram um pico de eversão na magnitude de $28 \pm 7^{\circ}$ nos primeiros $55 \%$ do apoio, para 30 sujeitos analisados. Na segunda metade do apoio o pé começa a inverter, sendo que no final do apoio a amplitude de inversão do pé excede a de eversão em cerca de $7^{\circ}$. Os valores encontrados nesse estudo são altos se comparados com outros estudos (AREBLAD et al., 1990; NIGG, 1986). Os autores atribuem essas diferenças devido a técnica de mensuração utilizada (bidimensional vs. tridimensional) e ao protocolo de posicionamento das marcas anatômicas.

Dado sua importância para o entendimento da cinemática da fase de apoio, o ângulo de inversão e eversão tem sido utilizado para classificar a pisada em corredores, sendo que o pico de eversão é o valor escolhido para essa classificação. CLARKE et al. (1984) atribuíram como normais os indivíduos que possuíam pico de eversão entre $8^{\circ}-15^{\circ}$. MCCLAY e MANAL (1997) utilizaram essa mesma metodologia para classificar dois grupos de corredores. Neste estudo os sujeitos que possuíam valores de pico entre $8^{\circ}-15^{\circ}$ foram classificados como normais e os sujeitos com valores superiores a $18^{\circ}$ foram classificados como hiperpronadores. O gráfico na FIGURA 5 demonstra o comportamento angular de inversão e eversão do retropé durante a fase de apoio da corrida. 


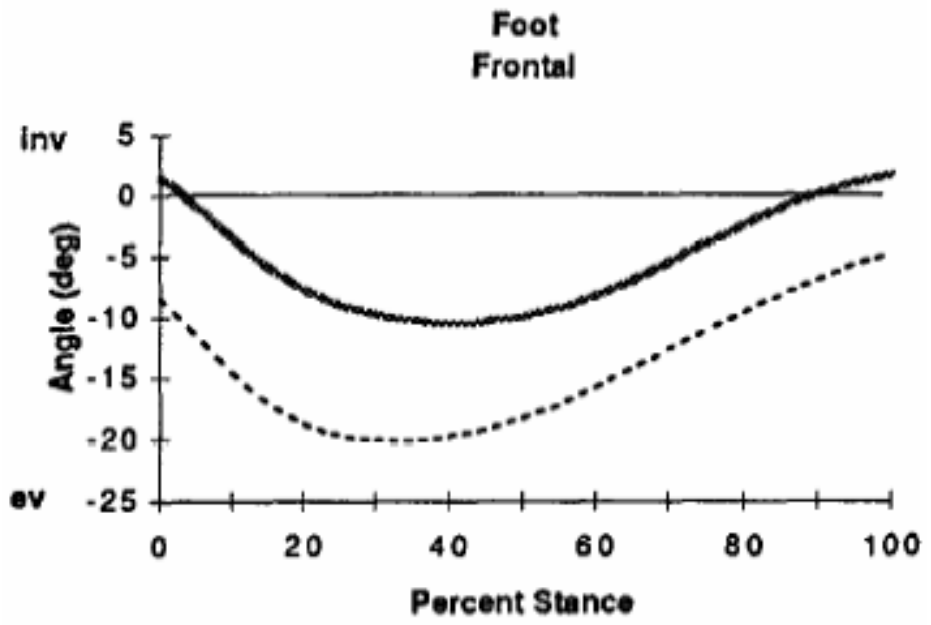

FIGURA 5. Dados de MCCLAY e MANAL (1998a). A linha contínua representa o ângulo de inversão e eversão em sujeitos normais e a linha tracejada representa os dados de sujeitos hiperpronadores.

Estudos demonstram que o máximo grau de pronação, o tempo de pronação ou a máxima velocidade de pronação constituem as variáveis determinantes para o prognóstico de lesões (CLARKE, FREDERICK \& HAMILL, 1984; EDINGTON, FREDERICK \& CAVANAGH, 1990).

A maioria dos estudos que investiga esses movimentos utilizou marcas externas fixadas a pele ou ao calçado do indivíduo (AREBLAD et al., 1990; BELLCHAMBER \& VAN DEN BOGERT, 2000; DE WIT, DE CLERCQ \& AERTS, 2000; ENGSBERG \& ANDREWS, 1987; MCCLAY \& MANAL, 1998a,, 1998b,, 1999; NAWOCZENSKI, SALTZMAN \& COOK, 1998; STERGIOU \& BATES, 1997; STERGIOU, BATES \& JAMES, 1999). Porém, sabe-se que em movimentos rápidos como na corrida, existe um movimento relativo entre as marcas e a estrutura óssea. Portanto, esses estudos não reproduzem com fidelidade o real movimento que ocorre nas articulações, como demonstrado por trabalhos anteriores (REINSCHMIDT, 1996; REINSCHMIDT, VAN DEN BOGERT, MURPHY, LUNDBERG \& NIGG, 1997b; REINSCHMIDT, VAN DEN BOGERT, NIGG, LUNDBERG \& MURPHY, 1997c). Apesar do conhecimento deste fato, ainda predominam estudos que utilizam marcas externas para análise do movimento, devido ao procedimento invasivo que o emprego de sínteses metálicas ósseas utilizam. 
Esta revisão da literatura demonstra a limitação do conhecimento a respeito dos movimentos do complexo do tornozelo, principalmente em idosos. Existe uma carência na literatura que traga dados cinemáticos do complexo do tornozelo de sujeitos normais e patológicos durante a corrida.

\subsubsection{Rotação medial e lateral da tíbia}

Durante a fase de apoio da corrida, a pronação do pé ocorre em cadeia cinética fechada. Portanto, o calcâneo fica impossibilitado de abduzir em relação ao tálus por ficar fixo no solo. Devido à configuração da articulação talocrural, a adução do tálus provoca uma rotação medial da tíbia. Esta rotação medial da perna perdura até o final da fase excêntrica ou de amortização da corrida. Na fase de propulsão, ocorre o movimento inverso, onde a tíbia roda lateralmente e o calcâneo inverte (TIBERIO, 1987). A seqüência deste movimento é demonstrada na FIGURA 6. Notem que à medida que o apoio do pé avança, a marca preta localizada na região da tuberosidade anterior da tíbia medializa indicando a ocorrência da rotação medial da tíbia (DELEO et al., 2004).
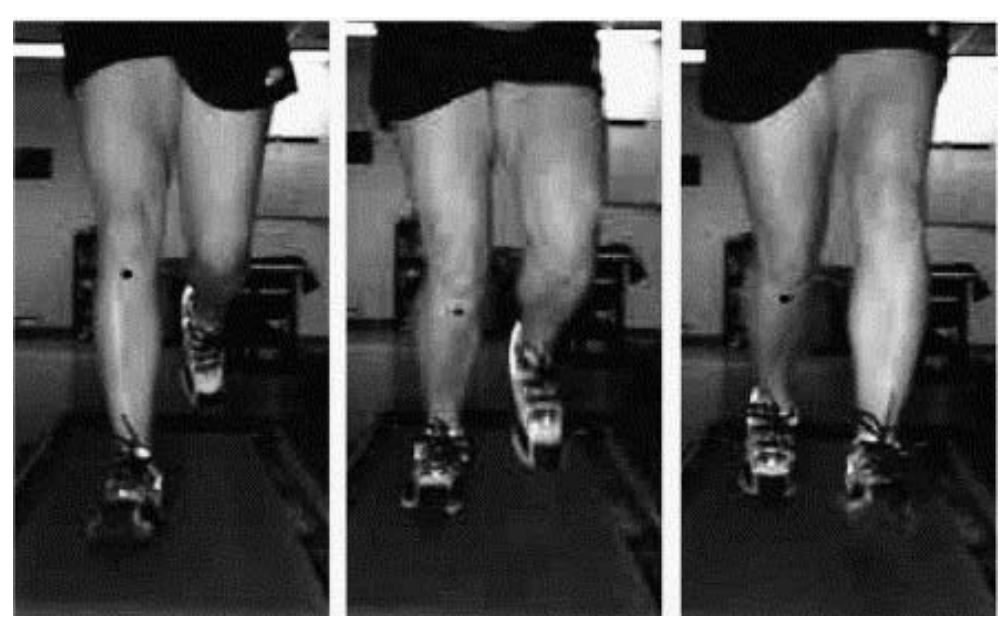

FIGURA 6. Alinhamento do membro inferior direito durante as fases de heel strike, apoio médio e apoio final da corrida. Extraído de DELEO et. al. (2004).

O movimento do pé no plano transverso, em cadeia cinética aberta, corresponde à abdução e a adução. Porém, quando o pé está fixo no solo, este 
componente de movimento ocorre na perna, ou seja, ocorre uma rotação da perna que acompanha os movimentos do pé (DELEO et al., 2004).

Aparentemente os movimentos da perna no plano transverso são resultantes do acoplamento existente entre a perna e o pé. Na seção de movimentos acoplados descreveremos com mais detalhes os movimentos da perna neste plano de movimento.

\subsection{Movimentos do Joelho}

A articulação tibiofemoral possui movimentos rotacionais: no plano sagital (flexão e extensão), no plano frontal (abdução e adução) e no plano transversal (rotação medial e lateral) e três translações: ântero-posterior, médio-lateral e distração e compressão (LAFORTUNE, CAVANAGH, SOMMER \& KALENAK, 1992; MARANS, JACKSON, GLOSSOP \& YOUNG, 1989; TAKEDA, XEROGEANES, LIVESAY, FU \& WOO, 1994). Esta terminologia de movimentos tem sido utilizada para melhorar a interpretação clínica. Devido a grande amplitude de movimento no plano sagital, o joelho é frequentemente simplificado como uma articulação simples (dobradiça).

Os movimentos de abdução e adução são limitados, possuindo uma amplitude de cerca de cinco graus, devido às restrições impostas pela geometria articular e estabilizadores estáticos. A rotação medial-lateral e a flexão-extensão do joelho possuem amplitudes de $35^{\circ}$ e $150^{\circ}$ respectivamente (FRANK \& SHRIVE, 1994).

Estudos anteriores se restringiam a realização de análises bidimensionais para descrever os movimentos do joelho (LAFORTUNE et al., 1992). Porém, para uma análise cinemática completa do joelho, é necessário analisá-lo de forma tridimensional, pois esta articulação possui seis graus de liberdade (três rotações e três translações) (BRANCH, HUNTER \& DONATH, 1989; BRANCH \& HUNTER, 1990).

A literatura a respeito da cinemática do joelho durante a corrida é escassa. Em se tratando de idosos, essa carência é ainda maior. Nesta revisão serão reportadas apenas os estudos que investigaram a cinemática do joelho durante a corrida. Apesar da existência de estudos que analisaram o joelho utilizando marcas 
externas, esta revisão irá descrever estudos que utilizaram mensuração direta, ou seja, pelo uso de marcas internas (sínteses metálicas), fixadas na estrutura óssea. Esse procedimento será adotado por considerar os erros inerentes associados com as outras técnicas de análise.

O conhecimento sobre as translações e rotações do joelho é limitado, principalmente os movimentos de abdução e adução, e rotação medial e lateral. VAILAS e PINK (1993) apontaram que as dificuldades de comparação entre os estudos que investigaram os movimentos do joelho no plano frontal e transversal se devem pelas variações de protocolos utilizados entre os experimentos. Outro fator que pode influenciar a magnitude das rotações secundárias do joelho são os problemas de alinhamento do sistemas de coordenadas (REINSCHMIDT et al., 1997b). 


\subsubsection{Flexão e Extensão}

Durante a corrida, o joelho apresenta-se em flexão de $10-20^{\circ}$ no heel strike e atinge cerca de $30-40^{\circ}$ de flexão por volta de $40 \%$ do período de apoio. Depois, o joelho estende-se na preparação para o toe-off, que consiste na fase em que o pé de apoio perde contato com o solo. A amplitude média de movimento do joelho foi de $21^{\circ}$ para três sujeitos analisados no estudo de MCCLAY (1990). A FIGURA 7 demonstra o comportamento cinemático do ângulo do joelho em sujeitos com pisada normal e hiperpronadores durante a fase de apoio da corrida.

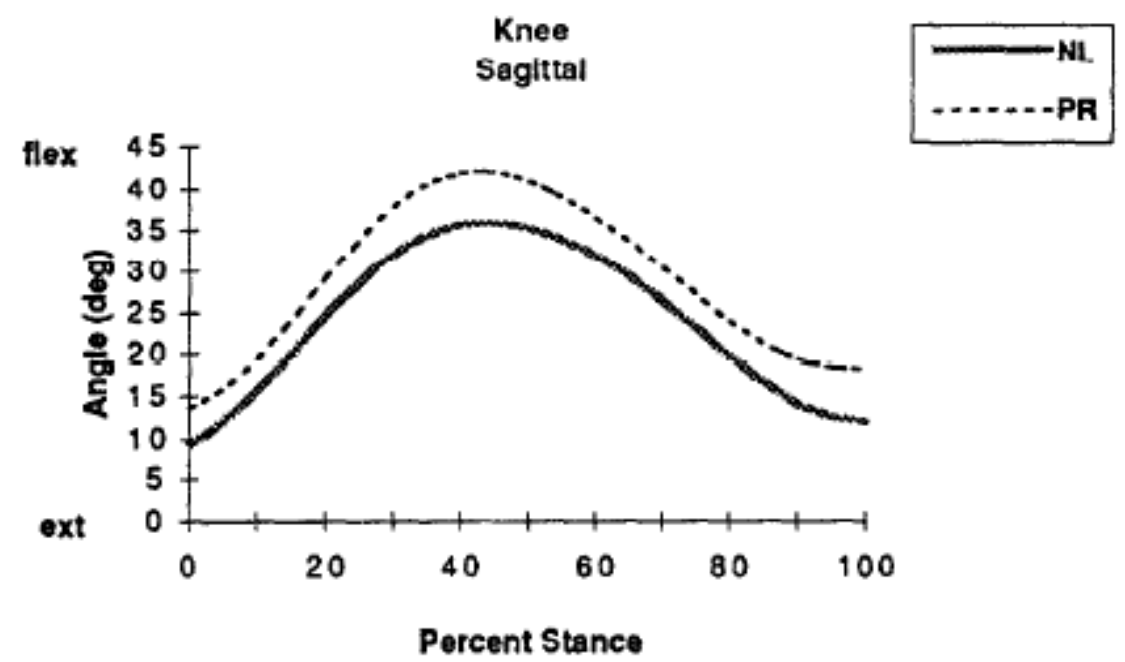

FIGURA 7. Dados que representam o ângulo de flexão-extensão do joelho durante o apoio na corrida em sujeitos hiperpronadores e normais. A linha contínua representa os sujeitos normais e a linha tracejada os hiperpronadores (MCCLAY \& MANAL, 1998a).

\subsubsection{Abdução e Adução}

Dados reportados por MCCLAY (1990) demonstraram que, do heel strike até $40 \%$ do período de apoio, a tíbia normalmente aduz $6^{\circ}$, seguida por uma gradual abdução de $8^{\circ}$ até o fim do período de apoio. Outro estudo que investigou tais movimentos reportou dados totalmente diferentes do estudo anterior, porém ambos os estudos demonstraram que a amplitude de movimento de abdução-adução está por volta de $5^{\circ}$. REINSCHMIDT (1996) atribui estas diferenças ao fato de utilizarem 
sistemas de coordenadas anatômicos distintos. Enquanto MCCLAY (1990) utilizou imagens radiográficas para calcular a posição das marcas anatômicas, REINSCHMIDT (1996) utilizou a calibração estática em posição neutra. Mesmo assim, é especulado que a pequena amplitude de movimento acrescido aos problemas de alinhamento dos sistemas de coordenadas resultam em cross-talk que podem mascarar o movimento real da articulação (RAMSEY \& WRETENBERG, 1999). A FIGURA 8 apresenta as curvas que representam os movimentos do joelho no plano frontal durante a corrida (NOEHREN, DAVIS \& HAMILL, 2007).

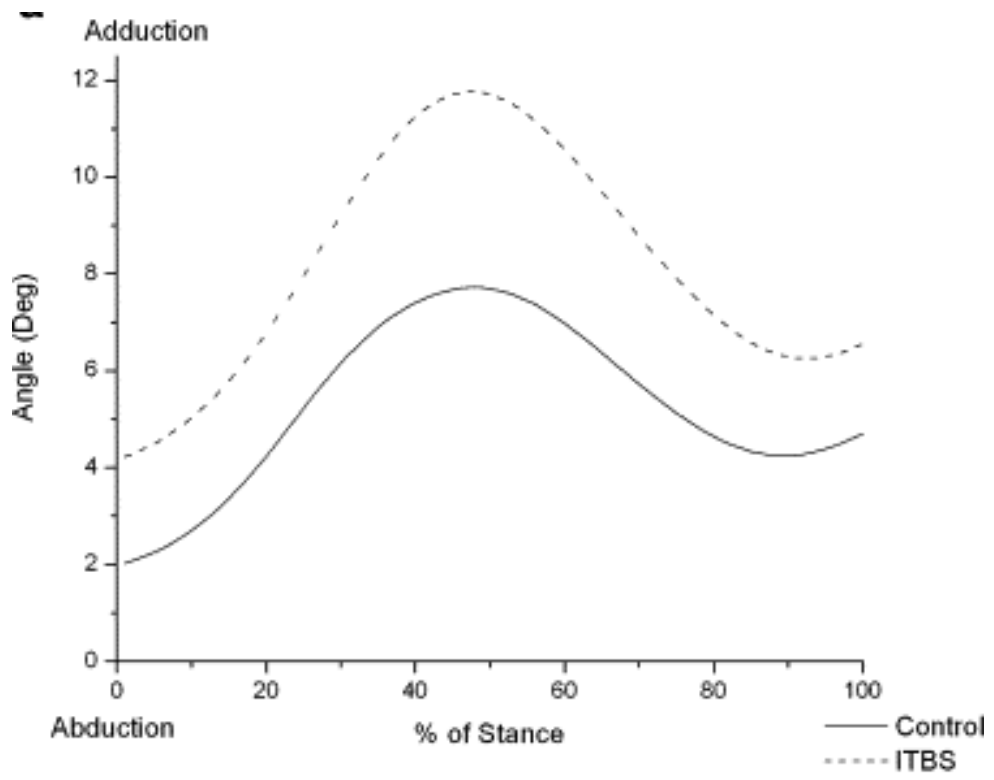

FIGURA 8. Dados que representam o ângulo de abdução e adução do joelho durante a corrida em sujeitos que desenvolveram a síndrome do trato iliotibial (ITBS) e em sujeitos assintomáticos (Control) (NOEHREN, DAVIS \& HAMILL, 2007).

\subsubsection{Rotação Medial e Lateral}

Em estudo realizado por MCCLAY (1990), o joelho roda medialmente por aproximadamente $10^{\circ}$ do contato inicial até o apoio médio, seguida por uma rotação lateral de mesma magnitude até o final do apoio. Os dados reportados por REINSCHMIDT (1996), demonstraram pouca consistência. Em seu estudo foram encontradas variações da rotação medial do joelho da ordem de $7-9^{\circ}$ até pequenas 
rotações de $2^{\circ}$. Assim como nos movimentos de abdução-adução, a pequena magnitude de movimentos, acoplado com problemas de alinhamento de sistemas de coordenadas podem resultar em cross-talk. Na FIGURA 9 são demonstrados os gráficos que representam os movimentos do joelho no plano transverso durante a corrida extraídos de um estudo. Notem a grande variabilidade da zona sombreada em ambos os grupos demonstrando que trata-se de uma medida ainda inconsistente e sujeitas a artefatos de medida como mencionado anteriormente.

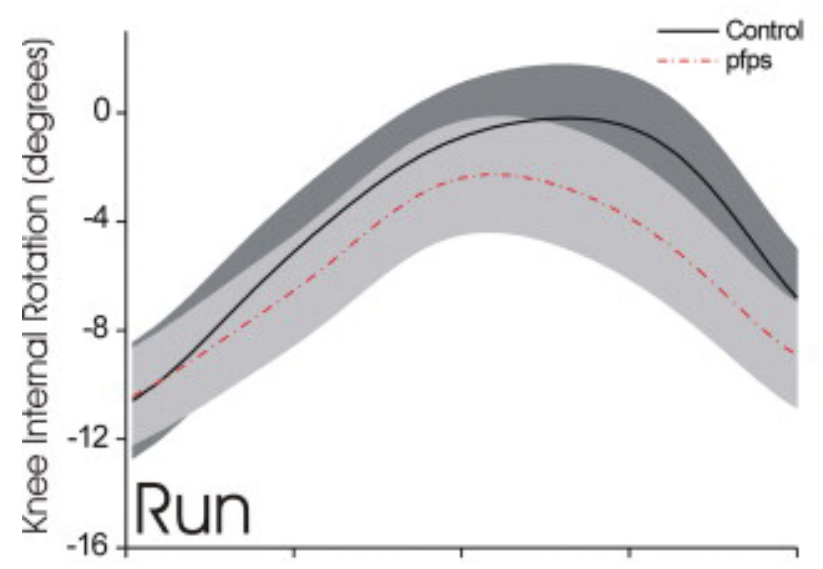

FIGURA 9. Dados que representam o ângulo de rotação medial e lateral do joelho durante a fase de apoio da corrida. A linha tracejada representa os sujeitos portadores de síndrome patelofemoral (pfps) e linha contínua representa os sujeitos assintomáticos (Control). A barra horizontal representa a série temporal da fase de apoio da corrida. Extraído de WILLSON \& DAVIS (no prelo)

Devido à carência de estudos que investigam estes padrões, torna-se difícil estimar quanta rotação secundária (abdução-adução, rotação medial/lateral) realmente existe ou quanto pode ser atribuído a estes problemas citados anteriormente (RAMSEY \& WRETENBERG, 1999). Os autores sugerem que mais estudos sejam realizados para estabelecer um sistema de coordenadas confiável que seja capaz de validar comparações entre os sujeitos. 


\subsection{Movimentos Acoplados}

Estudos anteriores que investigaram a mecânica da corrida estudaram o movimento das articulações isoladamente (AREBLAD et al., 1990; ENGSBERG \& ANDREWS, 1987). Estudos sobre acoplamento articular investigaram a simples relação envolvendo o tempo de pico de movimento no plano frontal do retropé e o movimento no plano sagital do joelho (HAMILL, BATES \& HOLT, 1992). Segundo STACOFF (2000b), movimento acoplado compreende a quantidade de movimento que ocorre sobre um eixo de rotação em relação a simultânea rotação sobre um segundo eixo. Em termos mecânicos, movimento acoplado descreve a razão da rotação de dois segmentos. INMAN (1976) utilizou o termo "mitered joint model" para demonstrar um acoplamento imutável entre a perna e o pé conforme demonstrado na FIGURA 10.

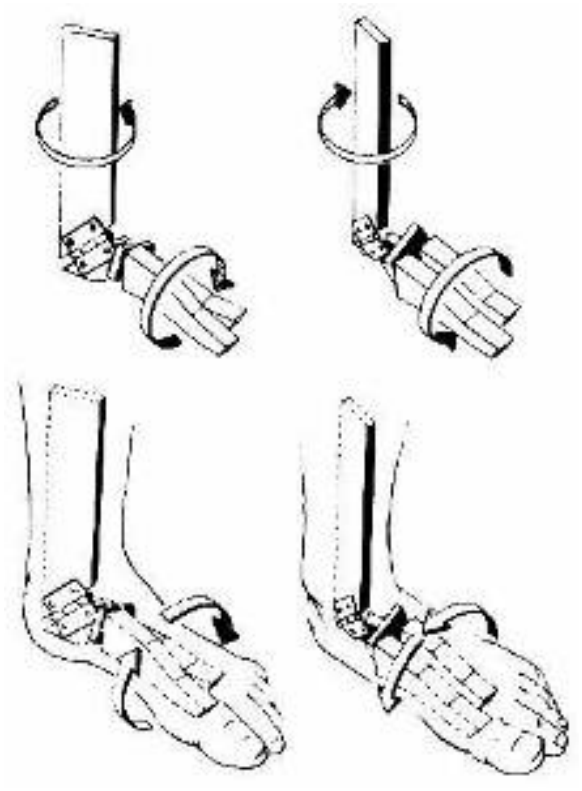

FIGURA 10. Modelo do acoplamento que existe entre a tíbia e o pé. Extraído de INMAN (1976).

As principais lesões decorrentes da prática da corrida acometem joelho, tornozelo e pé. Um estudo que avaliou retrospectivamente 2002 corredores foi observado que as lesões mais freqüentes foram: a síndrome patelofemoral, síndrome do trato iliotibial, fasceíte plantar, lesão meniscal, tendinite patelar e tendinite de Aquiles (TAUNTON et al., 2002). A pronação excessiva da articulação subtalar tem 
sido atribuída como uma das principais causas que podem predispor os corredores a tais lesões (JAMES, BATES \& OSTERNIG, 1978). O motivo pelo qual o desalinhamento do pé causa sobrecarga no joelho ainda é obscuro, porém alguns estudos atribuem a ligação mecânica existente entre o joelho e o pé através da tíbia, como demonstrado pelo modelo (DELEO et al., 2004).

Durante a fase de apoio da marcha, a pronação do pé, a rotação tibial medial e a flexão do joelho ocorrem relativamente ao mesmo tempo conforme demonstrado na FIGURA 11 (DELEO et al., 2004). Para verificar a sincronia dos movimentos do pé e da tíbia, os estudos têm avaliado o tempo de pico de eversão do pé com o tempo de pico de flexão de joelho (HAMILL, BATES \& HOLT, 1992). A literatura sugere que corredores com alta razão entre as excursões de eversão e de rotação medial da tíbia (EV/RIT) estariam mais susceptíveis a lesões do pé. Por outro lado corredores com baixa razão EV/RIT teriam maior risco para desenvolverem lesões do joelho (MCCLAY \& MANAL, 1997; NAWOCZENSKI, SALTZMAN \& COOK, 1998). Devido à existência de movimento acoplado, quanto maior a amplitude de pronação maior será a amplitude de rotação do joelho caso o fêmur não acompanhasse a rotação da tíbia. 


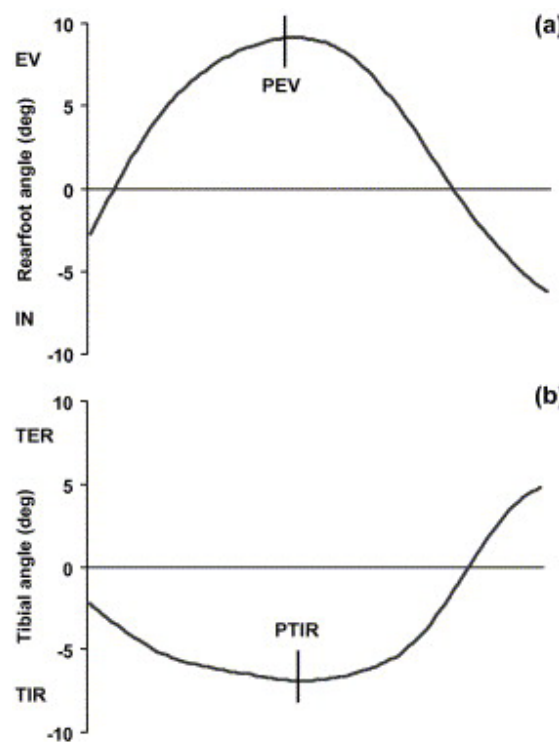

(a)

(b)

(c)

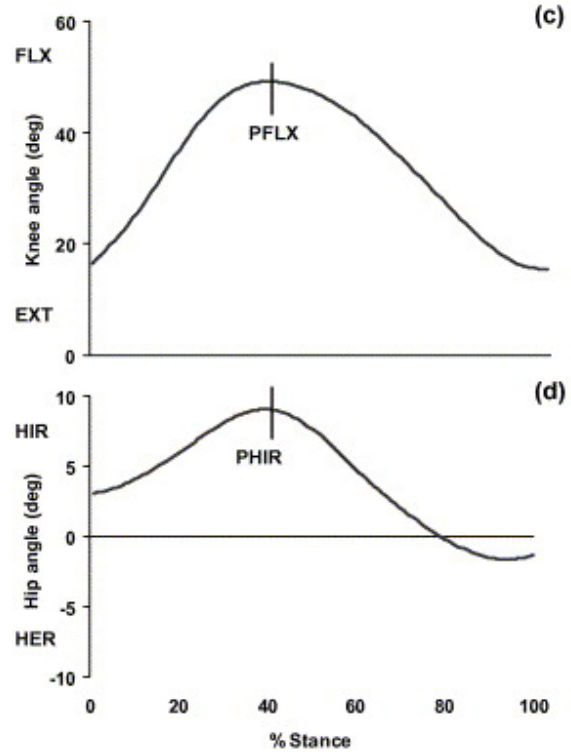

FIGURA 11. Ângulos articulares do membro inferior durante a fase de apoio da corrida: (a) inversão (IN)/eversão (EV) do retropé, (b) rotação medial (TIR)/lateral (TER) da tíbia, (c) flexão (FLX)/extensão $(E X T)$ do joelho e $(d)$ rotação medial (HIR) e lateral (HER) do quadril. Extraído de DELEO et. al. (2004).

Alguns modelos demonstram a ligação mecânica existente entre a região posterior do pé (retropé) e o joelho através da tíbia (INMAN, 1976). Portanto, os movimentos dos pés influenciam os movimentos do joelho. Alguns estudos experimentais demonstraram a existência de movimentos acoplados conforme 
sugerido por estes modelos anatômicos (MCCLAY \& MANAL, 1997; STACOFF et al., 2000b; STERGIOU \& BATES, 1997; STERGIOU, BATES \& JAMES, 1999), porém nenhum deles analisaram este comportamento durante a corrida nos idosos.

Uma das ferramentas utilizadas para observar o acoplamento entre duas estruturas são os ciclogramas (diagramas ângulo-ângulo). Apesar destes diagramas omitirem a série temporal, eles são úteis para determinar esse padrão de acoplamento (GOSWAMI, 1998). Alguns estudos têm utilizado os ciclogramas para demonstrar o acoplamento mecânico entre o pé e a perna durante a corrida (ESLAMI, BEGON, FARAHPOUR \& ALLARD, 2007; MCCLAY \& MANAL, 1997). Através destes gráficos podemos analisar a sincronia entre duas articulações como demonstrado na FIGURA 12.

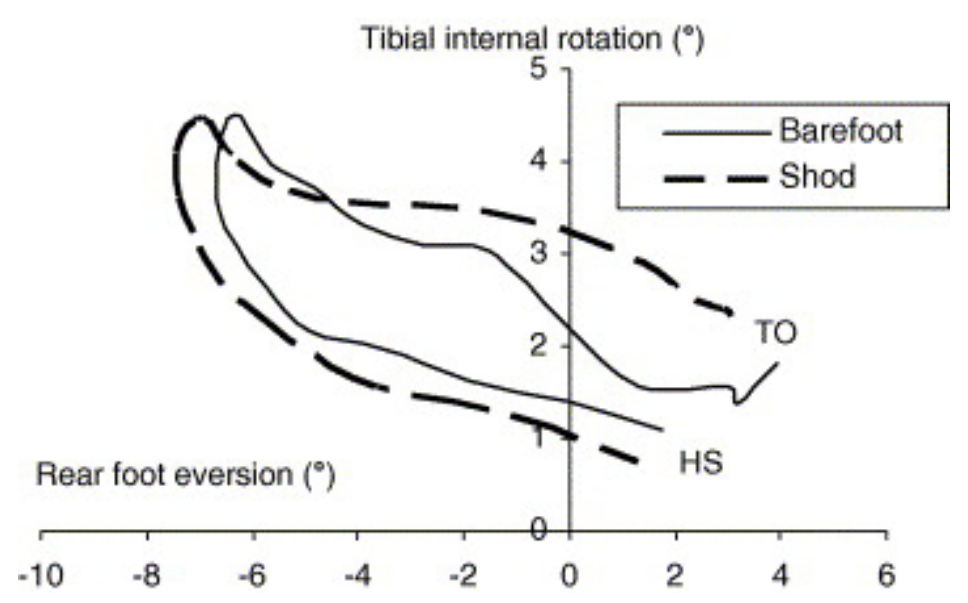

FIGURA 12. Ciclograma demonstrando o padrão de acoplamento entre os movimentos de eversão do retropé versus rotação medial da tíbia durante a fase de apoio da corrida: do heel strike (HS) ao toe-off (TO). Dados extraídos de ESLAMI et. al.(2007).

\subsection{Corrida em idosos}

Embora existam pesquisas relacionadas aos comportamentos fisiológicos de idosos corredores, estudos sobre a característica biomecânica desta população continuam escassos. BUS (2003) comparou a força de reação do solo e a cinemática durante a corrida em adultos e em indivíduos entre 55 e 65 anos de idade. Seus resultados não demonstraram diferença nos movimentos da articulação subtalar 
entre os grupos estudados. Apesar deste estudo analisar corredores mais velhos, a Organização Mundial da Saúde (OMS) define a população idosa como aquela a partir dos 60 anos de idade, mas faz uma distinção quanto ao local de residência dos idosos. Este limite é válido para os países em desenvolvimento, subindo para 65 anos de idade quando se trata de países desenvolvidos. Além disso, BUS (2003) não investigou as características do acoplamento entre as articulações do joelho e do retropé.

Alguns estudos demonstram maior acometimento dos idosos por lesões devido a prática de corrida (MARTI et al., 1988). Acrescido ao risco de lesão associado à prática da corrida, várias alterações musculoesqueléticas ocorrem no corpo devido ao envelhecimento, podendo resultar em alterações na mecânica da corrida. Algumas destas alterações são a perda de flexibilidade, que pode reduzir a amplitude de movimento articular dos membros inferiores durante a corrida (VANDERVOORT, CHESWORTH, CUNNINGHAM, PATERSON, RECHNITZER \& KOVAL, 1992), perda de flexibilidade da fáscia plantar (HSU, WANG, TSAI, KUO \& TANG, 1998), a progressiva fraqueza muscular e óssea (LARSSON, GRIMBY \& KARLSSON, 1979; RIGGS \& MELTON, 1986) e a perda de força e potência muscular também é evidente nos idosos (VANDERVOORT \& MCCOMAS, 1986), entre outros fatores. Apesar de existirem inúmeros estudos sobre mecânica da corrida como demonstra a revisão feita por (NOVACHECK, 1998), ainda permanece obscuro a relação entre mecânica dos membros inferiores e lesões em corredores (MCCLAY \& MANAL, 1997). Em se tratando de idosos corredores essa escassez torna-se muito maior.

\section{OBJETIVO}

O objetivo deste estudo é compreender melhor a maneira como idosos correm por meio de uma comparação descritiva da cinemática do membro inferior na corrida de adultos jovens e idosos praticantes de corrida de longa distância. Mais especificamente foram investigados os movimentos das articulações do joelho e do retropé, além dos movimentos acoplados entre estas duas articulações. Também foi investigada a influência da velocidade nos padrões de movimento durante a corrida. 


\section{MATERIAIS E MÉTODOS}

As tarefas que foram realizadas apresentaram mínimo risco à saúde dos sujeitos. O presente estudo foi aprovado pelo comitê de ética da Escola de Educação Física e Esporte da Universidade de São Paulo (ANEXO 2). Não há nenhum conflito de interesse entre os pesquisadores participantes deste projeto e fontes de financiamento ou grupos privados que possam ser privilegiados com o presente estudo.

\subsection{Amostra}

Participaram deste estudo 34 indivíduos (17 adultos e 17 idosos), todos praticantes assíduos de corrida de rua. Todos os sujeitos corriam entre 10-20 km por semana. O tempo médio que esses indivíduos praticavam corrida foi de cinco anos. A estatura média ( \pm um desvio padrão) dos adultos foi de $173 \pm 8 \mathrm{~cm}$, massa média de $71 \pm 10 \mathrm{~kg}$ e idade média de $31 \pm 6$ anos. A estatura média ( \pm um desvio padrão) dos idosos foi de $168 \pm 5 \mathrm{~cm}$, massa média de $65 \pm 9 \mathrm{~kg}$ e idade média de $69 \pm 2$ anos. Os idosos participantes do estudo tinham idade entre 67 e 73 anos.

Os idosos foram recrutados de uma lista cedida pela CORPORE (Corredores Paulistas Reunidos) que continha os melhores atletas classificados na faixa etária acima de 65 anos. O circuito de corridas da CORPORE envolve em média 14 corridas por ano com percursos entre cinco e $21 \mathrm{~km}$. A classificação utilizada pela CORPORE era baseada no tempo médio gasto para percorrer um quilômetro $(\mathrm{km})$, ou pace, durante as corridas organizadas pela entidade. Dentre os idosos que participaram do estudo, o que tinha a pior classificação nesse ranking possuía um pace de 5 minutos e 54 segundos, isto é, uma velocidade média de 10,2 $\mathrm{km} / \mathrm{h}$ durante as corridas. Isso demonstra que o nível de desempenho dos idosos era alto de maneira que todos pudessem tolerar bem as tarefas do estudo. Além disso, os idosos realizaram um exame ergoespirométrico para verificar a aptidão para realizar as tarefas. Só participaram do estudo os sujeitos que apresentaram boas condições para tal, devidamente atestadas pelo exame. Os exames ergoespirométricos foram realizados pela equipe da Dra. Cláudia Forjaz da Escola de Educação Física e Esporte da Universidade de São Paulo. 
Para os adultos, o principal critério de seleção foi o tempo gasto para percorrer uma distância de $10 \mathrm{~km}$. O tempo mínimo exigido para participar do estudo foi de 50 minutos, isto é, uma velocidade média de $12 \mathrm{~km} / \mathrm{h}$.

Outros critérios de inclusão e exclusão foram adotados. Os critérios de inclusão foram: aptidão física normal, familiaridade com a corrida na esteira, serem classificados como corredores que na pisada da corrida aterrissam primeiro com o calcanhar (rearfoot strikers), não utilizar nenhum tipo de órtese no calçado, desempenho na corrida e estado de saúde, que foi avaliado baseado nas respostas de um questionário (ANEXO 1). O critério de exclusão foi qualquer queixa de comprometimento musculoesquelético, cardiovascular, sensorial e/ou motor que pudesse comprometer o desempenho na corrida. É sabido que a maioria dos praticantes de corrida de rua fica susceptível a lesões por diversos motivos (NOVACHECK, 1998). Portanto, adotou-se o critério de excluir da amostra indivíduos que apresentassem lesões musculoesqueléticas no período de até três meses antes do experimento. Todos os sujeitos correram utilizando seu próprio calçado de corrida. Tal procedimento foi adotado visto que forçar o sujeito a utilizar um calçado novo que não é familiar poderia alterar o padrão de movimento da corrida. Todos os sujeitos só realizaram o experimento após assinarem um termo de consentimento de acordo com o comitê de ética local da Universidade de São Paulo (ANEXO 3).

\subsection{Tarefa}

Os sujeitos correram numa esteira ergométrica modelo Super ATL (Inbrasport). A escolha das velocidades utilizadas no experimento foi feita de maneira que elas provocassem esforços leves e moderados nos respectivos grupos estudados. EDINGTON et al. (1990) reportaram que nos estudos revisados por ele, existia tendência a utilizar a velocidade de $13.68 \mathrm{~km} / \mathrm{h}$ para estudar a cinemática do retropé. A escolha das velocidades empregadas no presente estudo foi subjetiva devido à falta de padrão encontrado na literatura em trabalhos da mesma natureza. Para os idosos a escolha da velocidade foi baseada no único estudo que utilizou um padrão semelhante de investigação (BUS, 2003). Propositalmente foi escolhida uma 
velocidade comum para os dois grupos $(11 \mathrm{~km} / \mathrm{h})$ que permitiu uma comparação direta entre os mesmos.

Até atingirem a velocidade de coleta das imagens, alguns procedimentos foram adotados e serão descritos a seguir:

1. Aquecimento: os sujeitos inicialmente foram instruídos a caminharem a velocidade de $5 \mathrm{~km} / \mathrm{h}$ por 5 minutos com o objetivo de se adaptarem até que fosse atingida a velocidade de teste.

2. Corrida: em seguida a velocidade da esteira foi progressivamente aumentada até que atingisse a velocidade de $8 \mathrm{~km} / \mathrm{h}$ nos idosos e 11 $\mathrm{km} / \mathrm{h}$ nos adultos. Os sujeitos permaneceram correndo nesta velocidade por 5 minutos para aquisição das imagens. Depois, a velocidade da esteira foi novamente aumentada, de forma gradual, até atingir $11 \mathrm{~km} / \mathrm{h}$ para os idosos e $14 \mathrm{~km} / \mathrm{h}$ para os adultos permanecendo assim por mais 5 minutos.

3. Desaquecimento: após o término da aquisição das imagens, a velocidade da esteira foi ajustada para aquela utilizada na primeira etapa do teste $(11 \mathrm{~km} / \mathrm{h}$ e $8 \mathrm{~km} / \mathrm{h}$, para os adultos e idosos, respectivamente) e permaneceu por 5 minutos, em seguida foi regulada para $5 \mathrm{~km} / \mathrm{h}$. Deste ponto a esteira foi progressivamente desacelerada até que parasse totalmente.

Durante todos os instantes da coleta, o experimentador observava 0 comportamento dos sujeitos para eventuais interrupções devido às intercorrências e pedia aos mesmos para reproduzirem o gesto da corrida natural sem se preocuparem com os procedimentos experimentais. Não houve episódios de desistência e/ou acidente durante as tarefas realizadas. Todos os sujeitos relataram que tal tarefa não provocou grandes esforços.

\subsection{Coleta de dados}

Para a análise cinemática tridimensional da corrida, foram utilizadas quatro câmeras digitais (GRDVL9800U, JVC Inc.) todas com freqüência de aquisição de 120 $\mathrm{Hz}$. O protocolo da análise cinemática dos membros inferiores foi padronizado dentro 
dos modelos internacionais propostos, procurando atingir os objetivos indicados no estudo da maneira mais acurada e menos invasiva possível.

A sincronização entre as câmeras foi feita por meio do software APAS (Ariel Inc.) que permite sincronizar os campos dos vídeos a partir de um evento sonoro captado simultaneamente pelas câmeras. Os campos são alinhados pelo software de tal forma a coincidirem o instante registrado da ocorrência deste evento sonoro. A FIGURA 13 ilustra uma representação do arranjo experimental para a aquisição de dados, demonstrando o posicionamento das câmeras e da esteira.

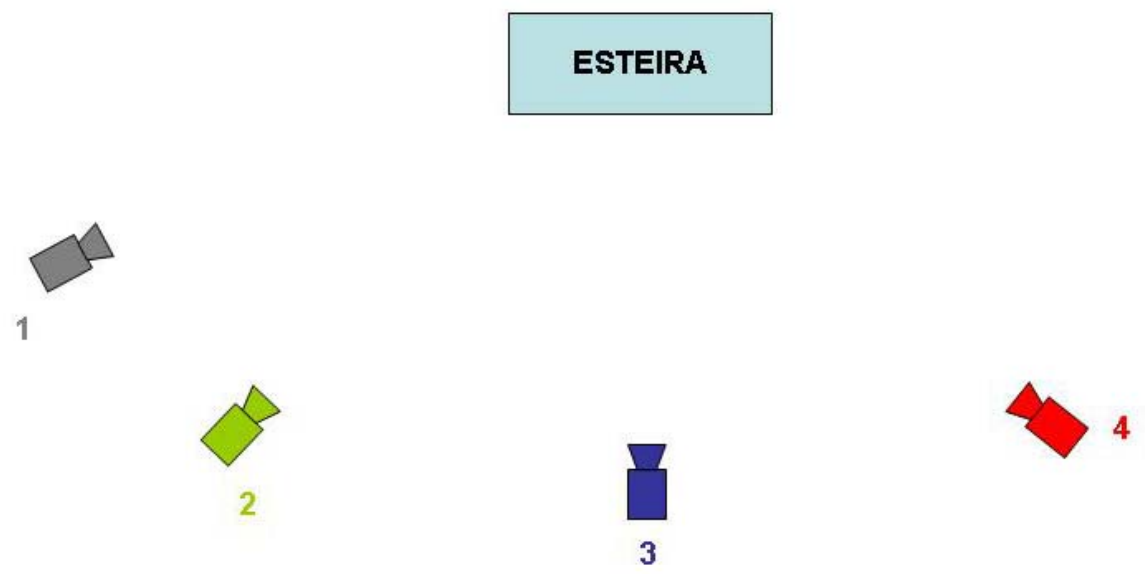

FIGURA 13. Representação esquemática do arranjo experimental com as quatro câmeras e esteira para a aquisição de dados cinemáticos.

Marcas retrorefletivas foram colocadas em proeminências anatômicas nas seguintes localizações do corpo no lado direito: espinha ilíaca ântero-superior direita e esquerda, trocânter maior, epicôndilo lateral e medial do fêmur, ápice da cabeça da fíbula, tuberosidade anterior da tíbia, ápice distal do maléolo lateral e medial, tuberosidade do calcâneo, cabeça do quinto metatarso, cabeça do segundo metatarso e cabeça do primeiro metatarso do membro inferior (CAPPOZZO, CATANI, CROCE \& LEARDINI, 1995). Detalhes que justificam a utilização de tais marcas podem ser vistos no ANEXO 4.

Para minimizar os erros de medição dos dados cinemáticos, utilizou-se a técnica de calibração do sistema anatômico (CAST) proposto por CAPPOZZO et al. (1995). Na utilização da técnica CAST, a primeira etapa da coleta consiste em uma calibração estática onde o sujeito permanecia parado na posição anatômica, alinhado 
com a esteira. Além das marcas anatômicas, os sujeitos utilizaram três clusters (CAPPOZZO, CAPPELLO, DELLA CROCE \& PENSALFINI, 1997), um na coxa, um na perna e um no pé. Os clusters da coxa e da perna possuíam quatro marcas refletivas e o cluster do pé possuía três marcas. Esse procedimento foi adotado para definir a posição das marcas em relação à base dos clusters. Uma vez definidas as posições das marcas elas foram retiradas e os sujeitos correram utilizando apenas os clusters (mais detalhes, ver ANEXO 5).

Assumindo que os segmentos coxa, perna e pé são corpos rígidos e que os clusters não se mexem em relação às marcas dos respectivos segmentos, o vetor posição das marcas em relação ao respectivo cluster não muda em função do movimento do segmento. Assim, com a calibração estática, todos os vetores posição das marcas da coxa, da perna e do pé são determinados e descritos a partir do sistema de coordenada local (cluster) possibilitando a retirada das marcas durante a tentativa dinâmica (quando o indivíduo corre sem as marcas anatômicas). Na tentativa dinâmica, apenas os clusters são utilizados no segmento coxa, perna e pé. A partir dos clusters, as posições das marcas retiradas foram reconstruídas virtualmente por meio de rotinas computacionais escritas em ambiente Matlab (versão 6.5, Mathworks inc) utilizando os vetores posição obtidos na calibração estática. Os clusters foram construídos especificamente para este experimento. A base dos três clusters era de acrílico, sendo que para a coxa e para a pena, essa base foi fixada em uma cinta elástica que tinha 15 centímetros de largura. Tiras de Velcro $^{\circledR}$ foram costuradas nesta cinta e proporcionaram boa fixação aos segmentos. Além disso, para melhorar a fixação, ataduras elásticas foram colocadas por cima dos clusters, sem que elas cobrissem as marcas refletivas. Eles ficaram posicionados na região distal do segmento. Em seu estudo MANAL et al. (2000) reportaram que estes cuidados podem melhorar a acurácia da técnica de medição. O cluster do pé também possuía uma base de acrílico que foi fixada diretamente no contraforte do calçado dos sujeitos com o uso de uma fita dupla face de espuma Scotch-Mount ${ }^{\mathrm{MR}}$, que proporcionava ótima fixação ao calçado do sujeito. A coleta das imagens iniciouse cinco minutos após os sujeitos atingirem a velocidade alvo do teste, sendo que o tempo de filmagem foi de 15 segundos. Esse tempo será necessário para fins de adaptação dos sujeitos às velocidades estabelecidas. 
O presente estudo não investigou assimetrias nos membros inferiores e somente o membro inferior direito foi analisado; procedimento similar a outros estudos (BUS, 2003; MCCLAY \& MANAL, 1997,, 1998a,, 1998b,, 1999; NAWOCZENSKI, SALTZMAN \& COOK, 1998; NIGG, COLE \& NACHBAUER, 1993).

\subsection{Tratamento dos dados}

A digitalização das posições das marcas foi realizada no software APAS (Ariel Inc.) e a reconstrução tridimensional foi feita utilizando o algoritmo transformação linear direta (DLT) (ABDEL-AZIZ \& KARARA, 1971) implementado em uma rotina computacional no ambiente Matlab. Para alisamento dos dados cinemáticos foi utilizado um filtro Butterworth de $4^{\mathrm{a}}$ ordem, passa baixa com freqüência de corte de $20 \mathrm{~Hz}$ em ambiente Matlab. Foram digitalizadas cinco fases de apoio do membro inferior direito de cada sujeito. O início (heel strike) e o fim do apoio (toe off) foi reconhecido visualmente por um observador experiente, através de imagens obtidas pela câmera melhor posicionada para visualizar estes eventos.

Foi determinada a posição dos eixos e planos articulares (base anatômica) como descrito por CAPPOZZO et al. (1995). Para definição dos eixos articulares, foi necessário a determinação dos centros das articulações do quadril, joelho e tornozelo. As coordenadas do centro articular do quadril ( $x_{c}, y_{c}$ e $\left.z_{c}\right)$ foram determinadas pelo método híbrido reportado por TYLKOWSKI et al. (1982) e ANDRIACCHI et al. (1980), os detalhes desse procedimento são descritos no ANEXO 6. O centro articular do joelho foi considerado como o ponto médio entre os epicôndilos do fêmur e o centro articular do tornozelo como sendo o ponto médio entre o maléolo lateral e medial.

O Sistema de Coordenadas Articulares (SCA) foi primeiramente proposto para descrever o movimento da articulação do joelho (GROOD \& SUNTAY, 1983) e tem sido aplicada para outras articulações da extremidade inferior (ROBERTSON, 2004). Este método foi desenvolvido para que as três rotações entre os segmentos anatômicos tenham um significado clínico e funcional. O Sistema de Coordenadas Articulares é construído utilizando um eixo de cada Sistema de Coordenadas Local (SCL) dos dois segmentos que constituem a articulação. No joelho, este sistema é construído utilizando o eixo longitudinal do SCL da perna e o eixo lateral do SCL da 
coxa $(\mathrm{Zt})$. O terceiro eixo deste novo sistema é um eixo flutuante (floating) que é o produto vetorial do eixo longitudinal com o eixo lateral. Os eixos vertical e lateral deste sistema não são necessariamente perpendiculares, portanto, o SCA não é um sistema ortogonal. O SCA para a articulação do joelho é demonstrado esquematicamente na FIGURA 14.

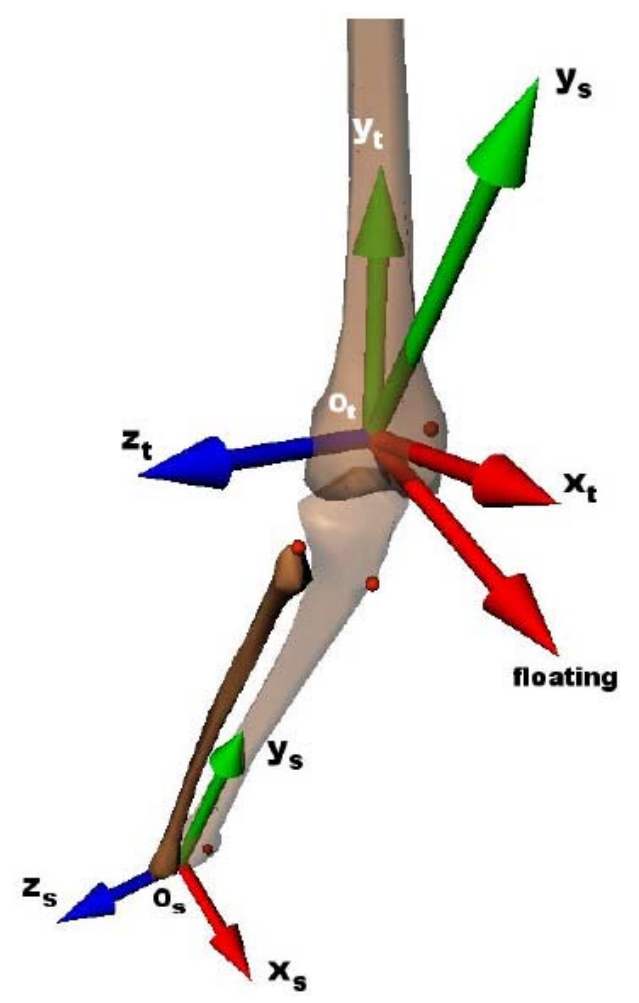

FIGURA 14. Sistema de Coordenadas Articulares do Joelho

O SCA para o pé foi construído de maneira similar ao proposto por SOUTAS-LITTLE et al. (1987). Porém foram utilizadas as proeminências anatômicas baseadas no Virtual Animation of the Kinematics of the Human for Industrial, Educational and Research Purposes - VAKHUM (http://www.ulb.ac.be/project/vakhum/). Trata-se de um projeto europeu que se preocupou em padronizar protocolos de análise cinemática para os membros inferiores dentro dos modelos internacionais propostos, procurando diminuir a variabilidade destes entre os diferentes estudos. Os detalhes da construção do SCL do segmento perna e do segmento pé encontram-se no ANEXO 5. 
Para a obtenção do SCA do tornozelo foi utilizado o eixo longitudinal do $S C L$ do pé (Yf) e eixo lateral do SCL da coxa (Zs). O terceiro eixo deste novo sistema é um eixo flutuante (FA) que é o produto vetorial do eixo longitudinal e lateral dos segmentos distal e proximal respectivamente. O SCA para a articulação do tornozelo é demonstrado esquematicamente na Figura 15.

Sabe-se que os movimentos de inversão/eversão e abdução/adução são referidos primariamente à articulação subtalar (CZERNIECKI, 1988; MCCLAY \& MANAL, 1997). Porém, torna-se difícil analisá-la com as técnicas de análise de movimento convencionais com marcadores superficiais devido à impossibilidade de colocar marcas externas no tálus. Portanto, a grande maioria dos estudos que analisam o movimento desta articulação posiciona os marcadores na tíbia e no calçado do sujeito, resultando em uma medida de movimentos combinados entre a articulação subtalar e a articulação talocrural (MCCLAY \& MANAL, 1997,, 1998a; NIGG, COLE \& NACHBAUER, 1993). No presente estudo, os movimentos do retropé serão mensurados entre o calcâneo e a tíbia e os ângulos do joelho serão medidos entre a tíbia e o fêmur.

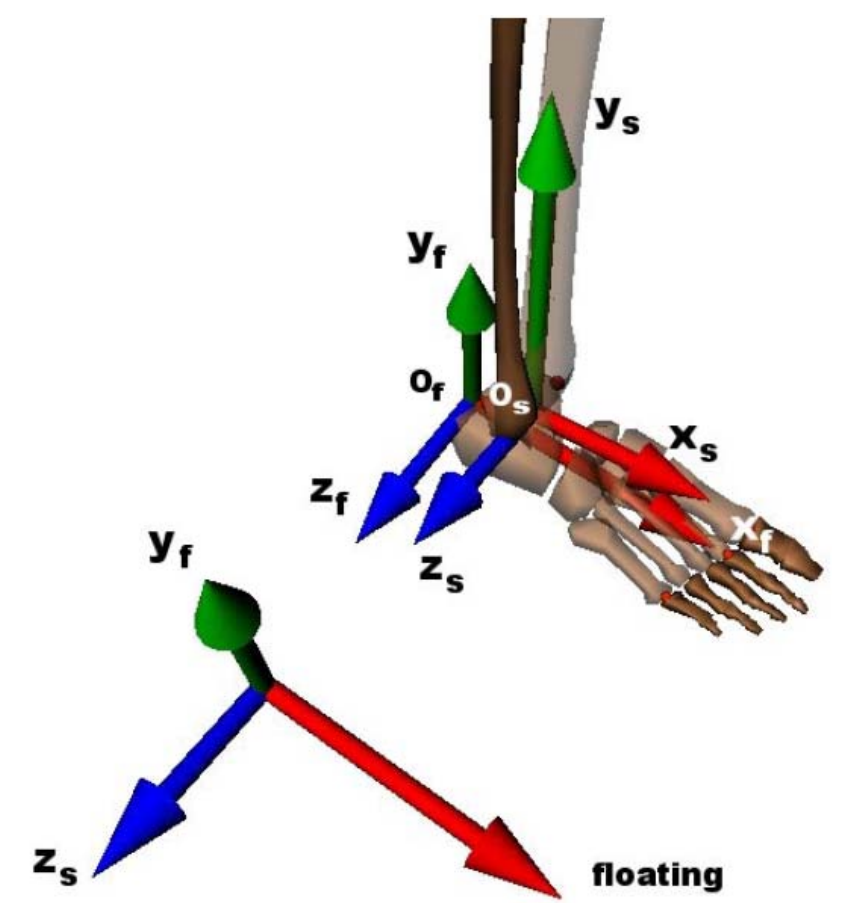

Figura 15. Sistema de Coordenadas articulares do Tornozelo 
Os ângulos do membro inferior direito dos sujeitos serão calculados pelas seguintes equações (ROBERTSON, 2004)

Ângulos articulares no plano sagital:

$\alpha=90-\arccos ($ Yproximal $\otimes F A)$

Equação 1

Ângulos articulares no plano frontal:

$\beta=-90-\arccos ($ Ydistal $\otimes$ Zproximal $)$

Equação 2

Ângulos articulares no plano transversal:

$\gamma=90-\arccos ($ Zdistal $\otimes F A)$

Equação 3

Um outro SCA foi construído para calcular os ângulos de rotação da tíbia no plano transversal, assim como proposto por NIGG et al. (1993). Para a construção desse novo sistema de coordenadas foi utilizado o eixo mediolateral do SCL do pé (Zf) e o eixo longitudinal do SCL da perna. O terceiro eixo deste novo sistema é um eixo flutuante (floating) que é o produto vetorial do eixo mediolateral com o eixo longitudinal. O ângulo de rotação da tíbia no plano transversal foi calculado utilizando a seguinte equação:

$$
\gamma m=90-\arccos (\text { Zproximal } \otimes F A)
$$

Equação 4

Todos os ângulos foram calculados em relação a posição estática, ou seja, as variáveis da tentativa dinâmica foram referenciadas em relação à calibração anatômica. A FIGURA 16 demonstra a posição das marcas retrofletivas posicionadas nas proeminências anatômicas dos sujeitos, bem como os três clusters utilizados em cada segmento e a convenção adotada no presente estudo para medir os ângulos articulares. 

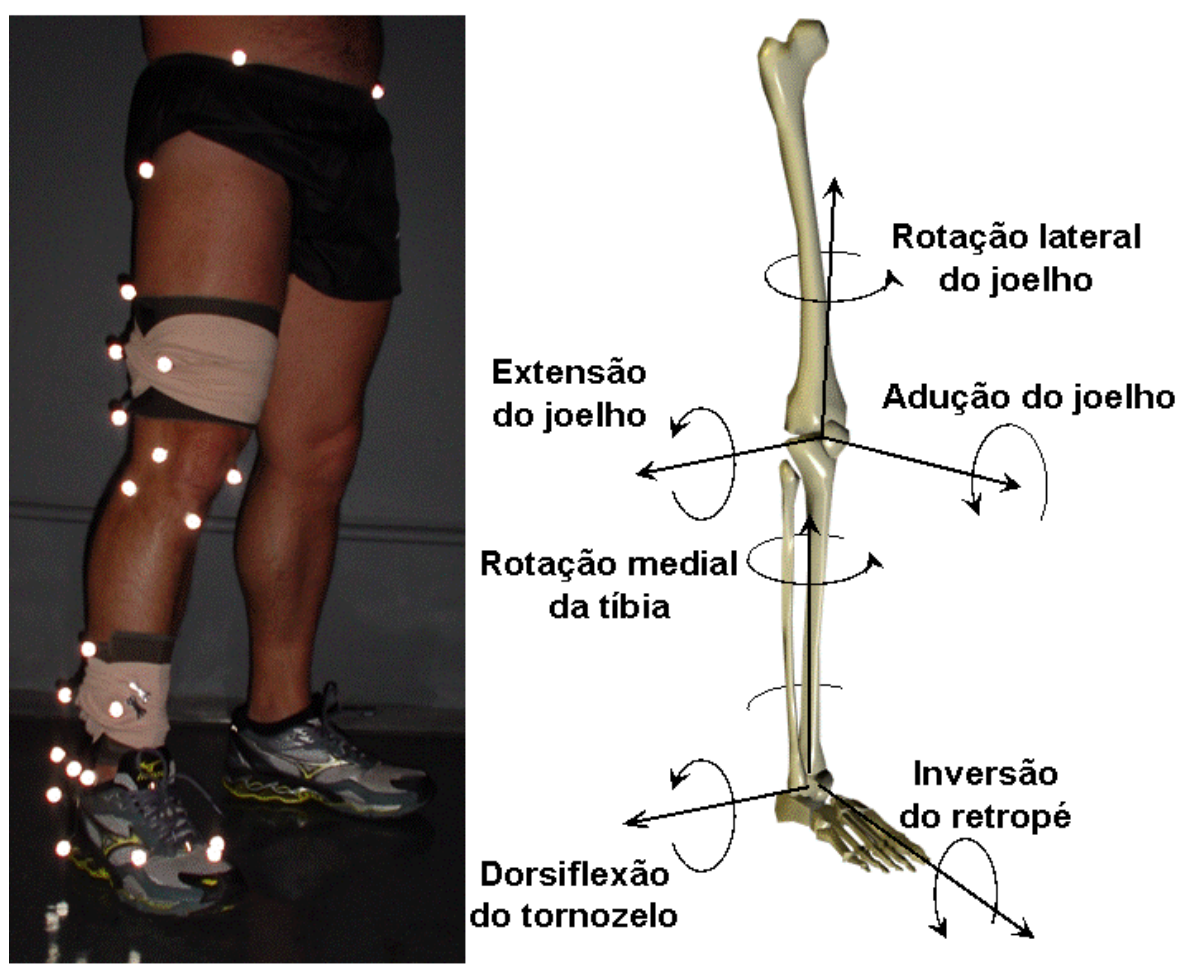

FIGURA 16. Posicionamento dos clusters, das marcas anatômicas (esquerda) e a convenção adotada para medir os ângulos articulares (direita).

\subsection{Análise dos dados}

O presente estudo é o primeiro a investigar de forma detalhada a cinemática de corredores idosos. Com um caráter exploratório, selecionamos as principais variáveis reportadas em diversos trabalhos similares sobre adultos para permitir uma maior caracterização do grupo de idosos. Sendo assim, a partir da obtenção dos ângulos articulares, conforme descrito anteriormente, obtivemos os valores de pico para os movimentos de dorsiflexão, eversão e rotação medial da tíbia referente a articulação do retropé e para os movimentos flexão, adução e rotação medial referente a articulação do joelho. Esses valores representam o grau máximo de amplitude de movimento atingida durante a fase de apoio. O tempo que levava para atingir este pico também foi calculado, assim como a porcentagem do período de apoio em que esses picos aconteciam. Essas variáveis são importantes, pois fornecem informações sobre fase de amortização da corrida, onde ocorre atenuação 
de carga e acomodação do pé ao solo (DELEO et al., 2004). Essas variáveis podem ser comparadas com os achados de outros estudos (DE WIT, DE CLERCQ \& AERTS, 2000; HAMILL, BATES \& HOLT, 1992; STERGIOU \& BATES, 1997; STERGIOU, BATES \& JAMES, 1999). Para avaliar a coordenação entre os movimentos do retropé e o joelho, o tempo gasto para ocorrer os picos de eversão do retropé, flexão e rotação medial do joelho foi determinado. As diferenças entre os tempos para os picos de eversão do retropé-flexão do joelho e para os picos de eversão-rotação medial do joelho foram calculadas. Valores positivos para essas variáveis significam que o pico da eversão do retropé ocorreu antes do pico da flexão do joelho e da rotação medial do joelho.

As excursões dos movimentos de dorsiflexão, eversão e rotação medial da tíbia referente a articulação do retropé e da flexão, adução e rotação medial referente a articulação do joelho foram calculadas. A excursão foi representada pela diferença entre o valor máximo e o valor mínimo de cada variável analisada durante todo o período de apoio.

A razão entre as excursões de eversão do retropé e de rotação medial da tíbia foi calculada. Foi utilizado a rotação medial da tíbia ao invés da rotação medial do joelho, pois a rotação do joelho é totalmente influenciada pelo movimento do fêmur, sendo que a rotação da tíbia é uma medida mais direta da transferência de movimento da articulação subtalar.

Para a análise das séries temporais, o período de apoio do pé foi normalizada para um período correspondente ao intervalo de 0 a $100 \%$, sendo que o início $(0 \%)$ representava o instante em que o indivíduo tocava a esteira (heel strike) e o fim $(100 \%)$ o instante em que o indivíduo perdia contato com a esteira.

A posição angular dessas articulações foi demonstrada por meio de ciclogramas. Como mencionado anteriormente, estes diagramas têm sido utilizados para demonstrar o padrão de acoplamento entre duas articulações ou entre dois segmentos analisados (GOSWAMI, 1998). No presente estudo eles foram empregados para observar o acoplamento entre os movimentos de eversão do retropé-rotação medial do joelho, eversão do retropé-rotação medial da tíbia e eversão do retropé-flexão do joelho. 


\subsubsection{Análise estatística}

Foi realizada uma análise exploratória dos dados antes de ser aplicado o teste estatístico para verificar sua distribuição. Foi utilizado o teste-t pareado para identificar diferenças entre as velocidades dentro do mesmo grupo e o test-t não pareado para identificar diferenças entre os grupos. Foi utilizado um nível de significância de 0.01 para diminuir a chance de erro tipo I em virtude das múltiplas análises realizadas. O software utilizado foi o Matlab 6.5 (Mathworks inc).

\section{RESULTADOS}

Todos os participantes do estudo conseguiram desempenhar as tarefas do experimento sem dificuldades. A TABELA 1 e a TABELA 2 apresentam a média, o desvio padrão e o valor de $p$ para a comparação entre as velocidades analisadas e para os grupos. 
TABELA 1. Comparação dos parâmetros de acoplamento entre as articulações do retropé e do joelho entre os adultos e idosos.

\begin{tabular}{|c|c|c|c|c|c|c|c|}
\hline \multirow[b]{2}{*}{ Variáveis analisadas } & \multicolumn{3}{|c|}{ ADULTO } & \multicolumn{3}{|c|}{ IDOSO } & \multirow{2}{*}{$\begin{array}{c}\text { ADULTO/IDOSO } \\
(11 \mathrm{Km} / \mathrm{h}) \\
\text { Valor }^{(2)} \\
\end{array}$} \\
\hline & $\begin{array}{c}11 \mathrm{~km} / \mathrm{h} \\
\text { Média(DP) }\end{array}$ & $\begin{array}{c}14 \mathrm{~km} / \mathrm{h} \\
\text { Média(DP) }\end{array}$ & $\begin{array}{l}\text { Valor } \\
p^{(1)}\end{array}$ & $\begin{array}{c}\text { 8km/h } \\
\text { Média(DP) }\end{array}$ & $\begin{array}{c}11 \mathrm{~km} / \mathrm{h} \\
\text { Média(DP) }\end{array}$ & $\begin{array}{l}\text { Valor } \\
p^{(1)}\end{array}$ & \\
\hline Tempo para o pico EV & $0,11 \pm 0,03$ & $0,11 \pm 0,02$ & 0,51 & $0,09 \pm 0,02$ & $0,09 \pm 0,02$ & 0,39 & 0,02 \\
\hline$\%$ EV & $42 \pm 9$ & $47 \pm 8$ & 0,003 & $27 \pm 6$ & $34 \pm 7$ & $<0,001$ & 0,02 \\
\hline Tempo para o pico RIJ & $0,13 \pm 0,04$ & $0,12 \pm 0,03$ & 0,28 & $0,13 \pm 0,03$ & $0,12 \pm 0,03$ & 0,13 & 0,64 \\
\hline$\%$ RIJ & $47 \pm 12$ & $52 \pm 10$ & 0,127 & $41 \pm 9$ & $47 \pm 9$ & $<0,001$ & 0,86 \\
\hline Tempo para o pico de FLXJ & $0,14 \pm 0,02$ & $0,12 \pm 0,02$ & 0,003 & $0,15 \pm 0,02$ & $0,13 \pm 0,01$ & $<0,001$ & 0,25 \\
\hline$\%$ FLXJ & $51 \pm 7$ & $55 \pm 7$ & 0,002 & $46 \pm 5$ & $49 \pm 4$ & $<0,001$ & 0,37 \\
\hline FLX-EV tempo & $0,03 \pm 0,03$ & $0,02 \pm 0,02$ & 0,03 & $0,06 \pm 0,02$ & $0,04 \pm 0,02$ & $<0,001$ & 0,10 \\
\hline RIJ-EV tempo & $0,02 \pm 0,03$ & $0,01 \pm 0,02$ & 0,58 & $0,04 \pm 0,03$ & $0,03 \pm 0,02$ & 0,08 & 0,13 \\
\hline EV/TIR & $1,1 \pm 0,3$ & $1,2 \pm 0,4$ & 0,12 & $1,3 \pm 0,4$ & $1,2 \pm 0,4$ & 0,24 & 0,26 \\
\hline
\end{tabular}

(1) Comparação intra-grupo para fator velocidade

(2) Comparação inter-grupo (fator idade) na velocidade de $11 \mathrm{~km} / \mathrm{h}$ 
TABELA 2. Comparação da cinemática angular para os parâmetros de movimento do retropé e do joelho entre os adultos e os idosos.

\begin{tabular}{|c|c|c|c|c|c|c|c|}
\hline \multirow[b]{2}{*}{ Variáveis analisadas } & \multicolumn{3}{|c|}{ ADULTO } & \multicolumn{3}{|c|}{ IDOSO } & \multirow{2}{*}{$\begin{array}{c}\text { ADULTO/IDOSO } \\
(11 \mathrm{Km} / \mathrm{h}) \\
\text { valor } \mathrm{p}^{(2)}\end{array}$} \\
\hline & $\begin{array}{c}11 \mathrm{~km} / \mathrm{h} \\
\text { Média(DP) }\end{array}$ & $\begin{array}{c}14 \mathrm{~km} / \mathrm{h} \\
\text { Média(DP) }\end{array}$ & valor $p^{(1)}$ & $\begin{array}{c}8 \mathrm{~km} / \mathrm{h} \\
\text { Média(DP) }\end{array}$ & $\begin{array}{c}11 \mathrm{~km} / \mathrm{h} \\
\text { Média(DP) }\end{array}$ & valor $p^{(1)}$ & \\
\hline \multicolumn{8}{|l|}{ Contato Inicial } \\
\hline $\mathrm{Cl}$ DFT & $0.5 \pm 2.5$ & $0.4 \pm 3.7$ & 0.82 & $1.1 \pm 4.8$ & $0.4 \pm 5.3$ & 0.23 & 0.93 \\
\hline Cl EV & $2 \pm 4$ & $3 \pm 5$ & 0.05 & $-2 \pm 5$ & $-1 \pm 6$ & 0.09 & 0.12 \\
\hline Cl RIT & $-2 \pm 3$ & $-2 \pm 4$ & 0.19 & $0.5 \pm 3.3$ & $-0.3 \pm 3.3$ & 0.01 & 0.07 \\
\hline Cl FLXJ & $5 \pm 6$ & $9 \pm 7$ & $<0.001$ & $9 \pm 6$ & $10 \pm 6$ & 0.39 & 0.04 \\
\hline $\mathrm{Cl} A B D$ & $-1 \pm 2$ & $-2 \pm 3$ & 0.003 & $0.1 \pm 2.4$ & $0.1 \pm 2.3$ & 0.94 & 0.09 \\
\hline CI RIJ & $-4 \pm 5$ & $-4 \pm 5$ & 0.73 & $-8 \pm 5$ & $-8 \pm 4$ & 0.47 & 0.05 \\
\hline \multicolumn{8}{|l|}{ Pico de Movimento } \\
\hline Pico de DFT & $20 \pm 3$ & $21 \pm 2$ & 0,66 & $17 \pm 4$ & $18 \pm 4$ & 0,015 & 0,13 \\
\hline Pico de EV & $-10 \pm 5$ & $-11 \pm 6$ & 0,79 & $-12 \pm 6$ & $-12 \pm 6$ & 0,63 & 0,47 \\
\hline Pico de RIT & $9 \pm 3$ & $9 \pm 3$ & 0,18 & $8 \pm 3$ & $9 \pm 3$ & 0,14 & 0,95 \\
\hline Pico de FLXJ & $37 \pm 5$ & $38 \pm 5$ & 0,12 & $34 \pm 7$ & $35 \pm 7$ & 0,09 & 0,30 \\
\hline Pico ADJ & $2 \pm 4$ & $2 \pm 4$ & 0.03 & $0.5 \pm 2.8$ & $0.2 \pm 2.7$ & 0.12 & 0.06 \\
\hline Pico ABD & $-1 \pm 4$ & $-2 \pm 4$ & 0.02 & $-4 \pm 3$ & $-5 \pm 5$ & 0.63 & 0.06 \\
\hline Pico de RIJ & $7 \pm 7$ & $8 \pm 7$ & $<0,001$ & $3 \pm 4$ & $4 \pm 3$ & 0,03 & 0,07 \\
\hline \multicolumn{8}{|l|}{ Excursões } \\
\hline Excursão de DFT & $23 \pm 4$ & $24 \pm 4$ & 0,14 & $20 \pm 2$ & $22 \pm 2$ & $<0,001$ & 0,409 \\
\hline Excursão de EV & $13 \pm 3$ & $14 \pm 5$ & 0,19 & $11 \pm 2$ & $11 \pm 3$ & 0,50 & 0,15 \\
\hline Excursão de RIT & $12 \pm 2$ & $12 \pm 3$ & 0,89 & $9 \pm 2$ & $9 \pm 2$ & 0,03 & 0,003 \\
\hline Excursão de FLXJ & $33 \pm 5$ & $31 \pm 5$ & 0,002 & $26 \pm 4$ & $27 \pm 3$ & 0,56 & $<0,001$ \\
\hline Excursão de RIJ & $13 \pm 8$ & $13 \pm 8$ & 0,23 & $11 \pm 3$ & $12 \pm 4$ & 0,85 & 0,63 \\
\hline Excursão ABDJ & $4 \pm 2$ & $3 \pm 2$ & 0.68 & $4 \pm 2$ & $4 \pm 3$ & 0.22 & 0.47 \\
\hline
\end{tabular}

(1) Comparação intra-grupo para fator velocidade

(2) Comparação inter-grupo (fator idade) na velocidade de $11 \mathrm{~km} / \mathrm{h}$ 
A FIGURA 17 demonstra a média das séries temporais dos ângulos de flexão do joelho, adução do joelho, rotação medial do joelho, dorsiflexão do retropé, eversão do retropé e rotação medial da tíbia durante a corrida na velocidade de $11 \mathrm{~km} / \mathrm{h}$.

A dorsiflexão do retropé demonstrou um padrão muito similar entre os grupos. A única diferença notável entre os grupos foi que os idosos atingiram a máxima dorsiflexão cerca de $10 \%$ da fase de apoio antes dos adultos e consequentemente iniciaram a flexão plantar mais precocemente.

O padrão de movimento no plano frontal também foi similar entre os grupos. Os adultos jovens aterrissaram em inversão do retropé e rapidamente realizaram a eversão atingindo seu máximo por volta de $40 \%$ do apoio. Enquanto os idosos iniciaram o contato já em eversão e atingiram seu máximo cerca de $10 \%$ antes dos adultos. No plano transverso, os adultos jovens aterrissaram em rotação lateral da tíbia, na seqüência iniciaram a rotação medial, atingindo seu máximo por volta de metade do período de apoio e retornaram a realizar a rotação lateral até perderem o contato com o solo (toe off). Os idosos apresentaram um padrão similar embora tenham aterrissado já em rotação medial. Essa diferença resultou em uma significativa redução da excursão deste movimento nos idosos (veja a Tabela 1).

Ambos os grupos adotaram uma leve flexão do joelho ao aterrissarem, sendo que o máximo de flexão foi atingida por volta de $50 \%$ do período de apoio. Apesar da máxima flexão não ter sido diferente, os idosos apresentaram menor excursão deste movimento pois iniciaram o apoio com o joelho mais flexionado do que os adultos. No plano frontal, o ângulo de adução/abdução do joelho foi o único gráfico que demonstrou diferença aparente entre os grupos. Os adultos jovens aterrissaram com uma leve abdução do joelho e rapidamente mudaram para uma pequena adução, enquanto os idosos aterrissaram com uma pequena adução do joelho para rapidamente realizarem a abdução ao contrário dos adultos.

Embora tais resultados devem ser interpretados com precaução, ambos os grupos apresentaram uma excursão de adução/abdução de somente quatro graus, existiu grande variabilidade entre os sujeitos como pode ser observado pelo grande erro padrão e desvio padrão demonstrado na FIGURA 17 e na TABELA 2, respectivamente. 
O movimento do joelho no plano transverso também foi similar entre os grupos. Ambos iniciaram o apoio em rotação lateral do joelho seguida por uma rotação medial até cerca de $50 \%$ da fase de apoio. Em seguida realizaram novamente a rotação lateral até o final do período de apoio. Apesar de nãosignificativa, os idosos apresentaram menor rotação medial do que os adultos. 

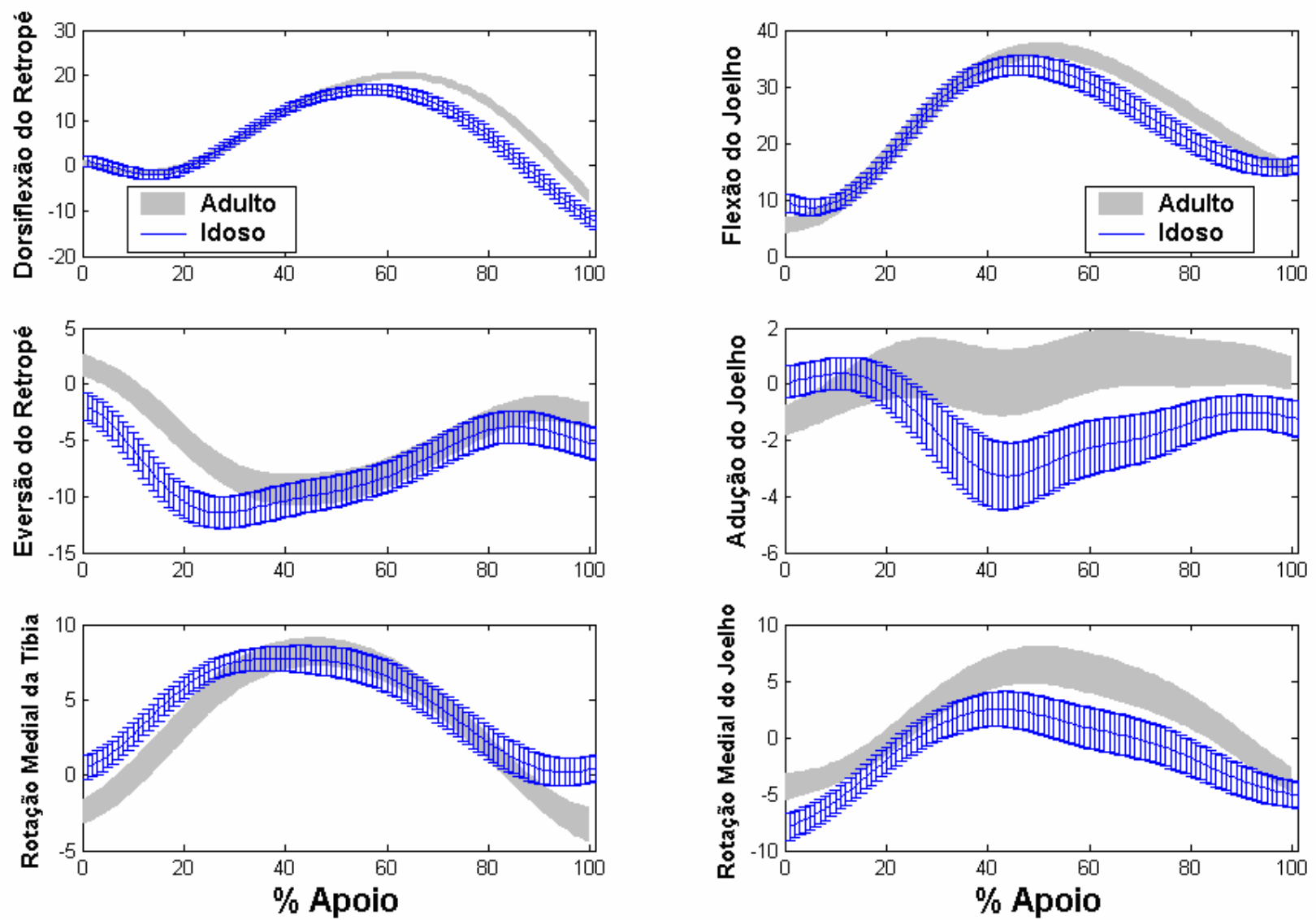

FIGURA 17. Média da série temporal dos movimentos do retropé e do joelho e o ciclograma da flexão do joelho vs. eversão do retropé durante a fase de apoio da corrida a $11 \mathrm{~km} / \mathrm{h}$. 
Os ciclogramas apresentados na FIGURA 18 demonstram a média do ângulo de eversão versus a média do ângulo de rotação medial e de flexão do joelho e de rotação medial da tíbia para cada grupo analisado. Podemos notar que o pico de movimento dos pares: rotação medial do joelho/eversão do retropé e rotação medial da tíbia/eversão do retropé aproximadamente coincidem para os adultos mas não para os idosos (reparem na curva mais fechada no gráfico dos adultos e mais aberta nos idosos).

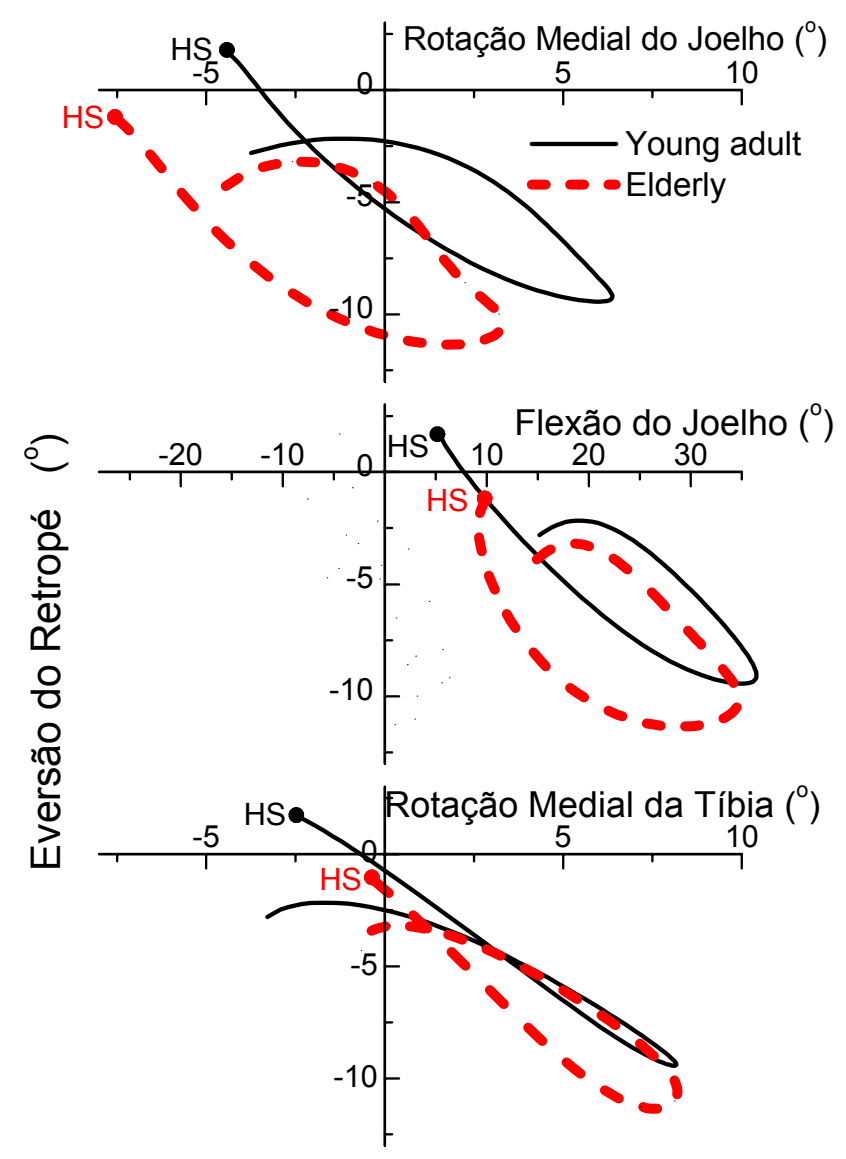

FIGURA 18. Ciclograma que representa a média dos movimentos de INV/EV versus FLXJ/EXTJ.

A FIGURA 19 demonstra a média do comportamento angular do joelho no plano sagital nos adultos durante a corrida nas velocidades de 11 e $14 \mathrm{~km} / \mathrm{h}$ e nos idosos nas velocidades de 8 e $11 \mathrm{~km} / \mathrm{h}$. Os adultos apresentaram diferença significativa $(p<0,001)$ no heel strike. O aumento da velocidade $(14 \mathrm{~km} / \mathrm{h})$ de corrida 
fez com que estes sujeitos aterrissassem com os joelhos mais flexionados (9 graus) em relação a velocidade mais baixa (5 graus). Outra diferença marcante foi que ambos os grupos alcançaram o pico de flexão mais cedo quando corriam na velocidade mais alta: $14 \mathrm{~km} / \mathrm{h}$ para os adultos e $8 \mathrm{~km} / \mathrm{h}$ para os idosos.

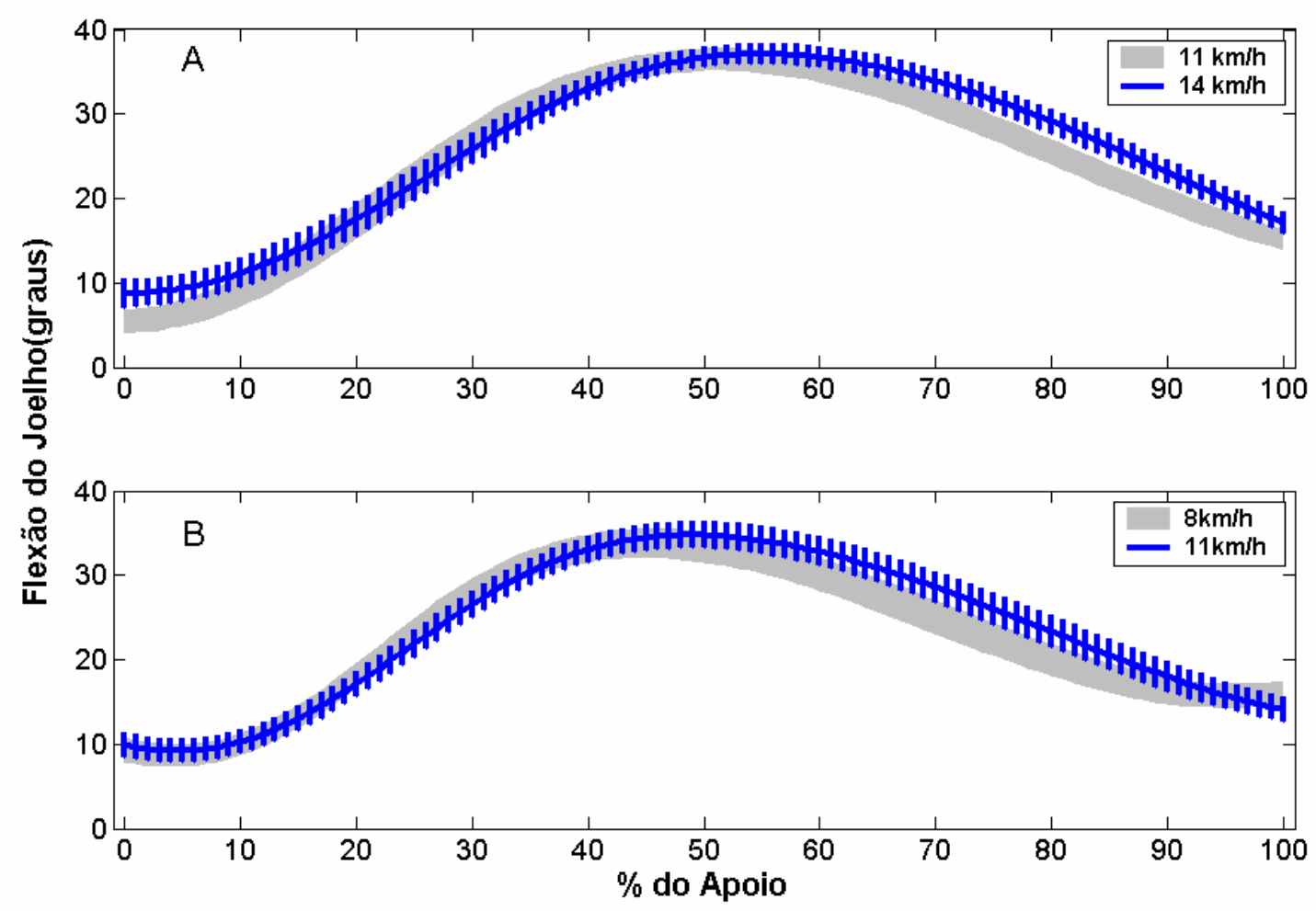

FIGURA 19. Média e erro padrão do ângulo do joelho no plano sagital durante a fase de apoio em adultos (A) e idosos (B) nas duas velocidades analisadas.

A FIGURA 20 demonstra respectivamente a média do comportamento angular do joelho no plano frontal e no transverso para os adultos durante a corrida nas velocidades de 11 e $14 \mathrm{~km} / \mathrm{h}$ e nos idosos nas velocidades de 8 e $11 \mathrm{~km} / \mathrm{h}$. Ambos os grupos apresentaram padrão muito similar dos dois movimentos (plano frontal e transverso) nas diferentes velocidades analisadas. 


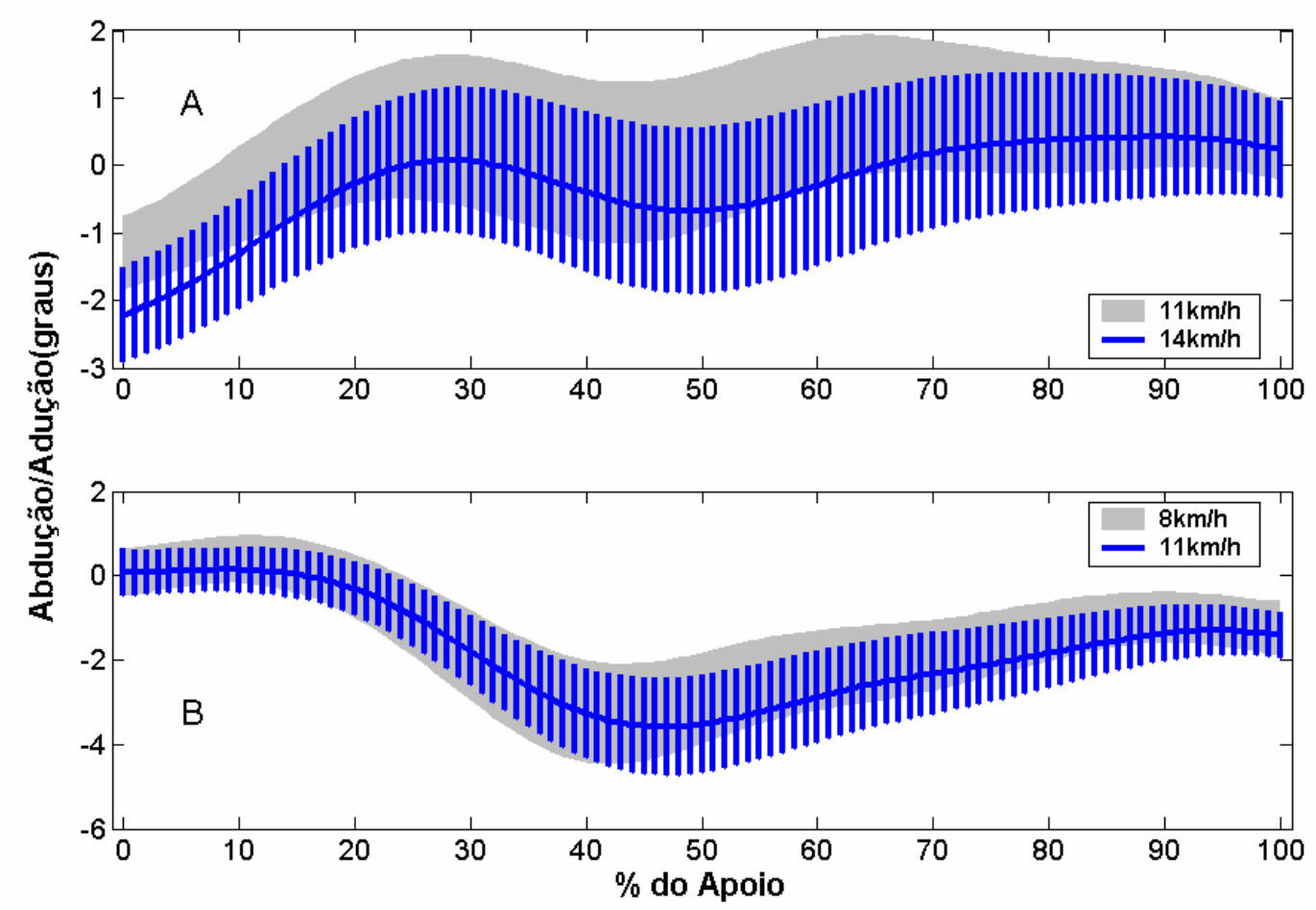

FIGURA 20. Média e erro padrão do ânqulo do joelho no plano frontal durante a fase de apoio em adultos (A) e idosos (B) nas duas velocidades analisadas.

A FIGURA 21 demonstra respectivamente a média do comportamento angular do joelho no plano frontal e no transverso para os adultos durante a corrida nas velocidades de 11 e $14 \mathrm{~km} / \mathrm{h}$ e nos idosos nas velocidades de 8 e $11 \mathrm{~km} / \mathrm{h}$. Ambos os grupos atingiram o pico de rotação medial do joelho mais precocemente quando correram na velocidade mais alta sendo que para os idosos essa diferença foi significativa $(p<0,001)$. 


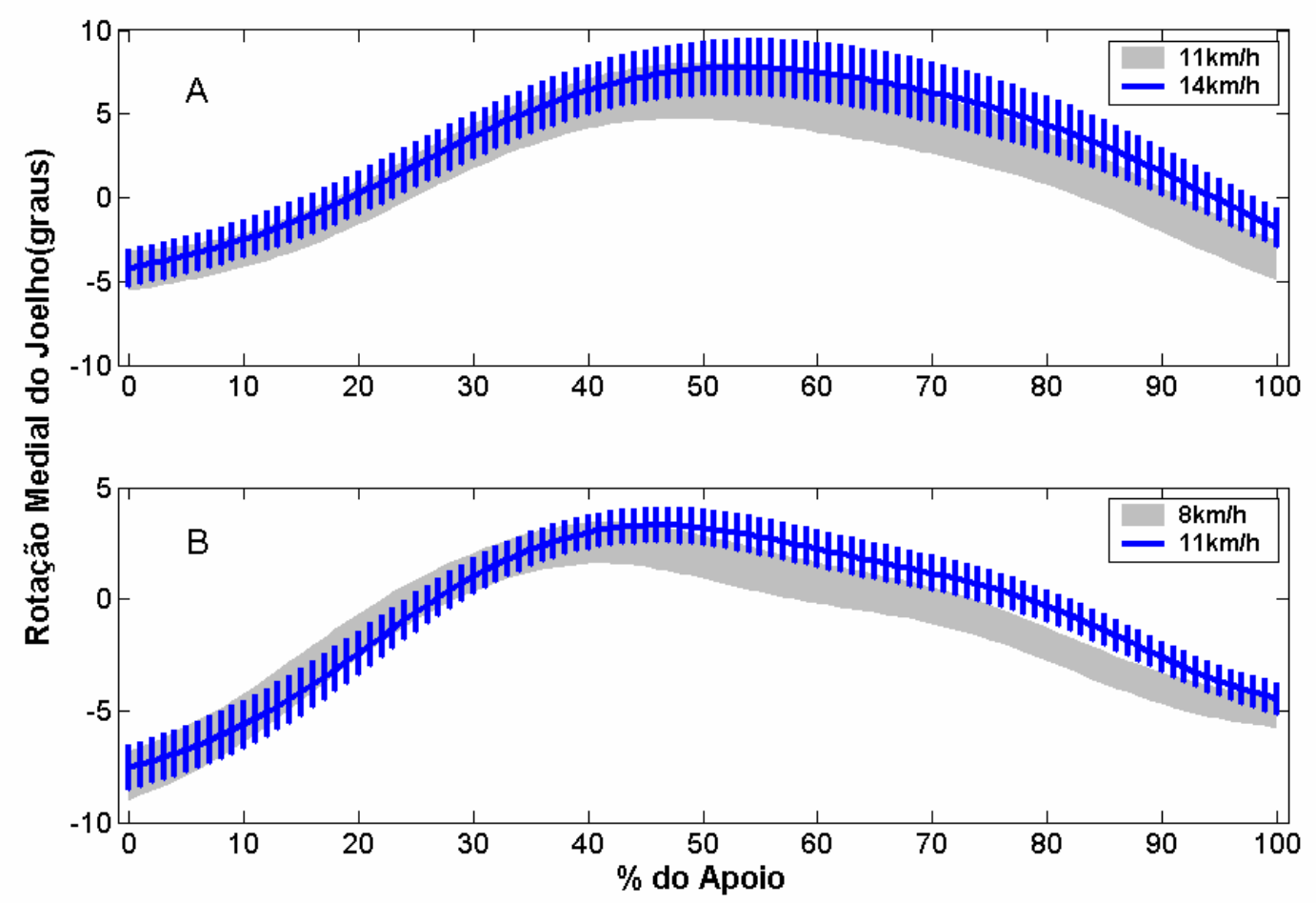

FIGURA 21. Média e erro padrão do ângulo do joelho no plano frontal durante a fase de apoio em adultos (A) e idosos (B) nas duas velocidades analisadas.

A FIGURA 22 demonstra a média do comportamento angular do retropé no plano sagital nos adultos durante a corrida nas velocidades de 11 e $14 \mathrm{~km} / \mathrm{h}$ e nos idosos nas velocidades de 8 e $11 \mathrm{~km} / \mathrm{h}$. Os idosos apresentaram aumento significativo $(p<0,001)$ da excursão de dorsiflexão durante a fase de apoio quando correram a $11 \mathrm{~km} / \mathrm{h}$ (22 graus) quando comparado a velocidade mais baixa (20 graus). 


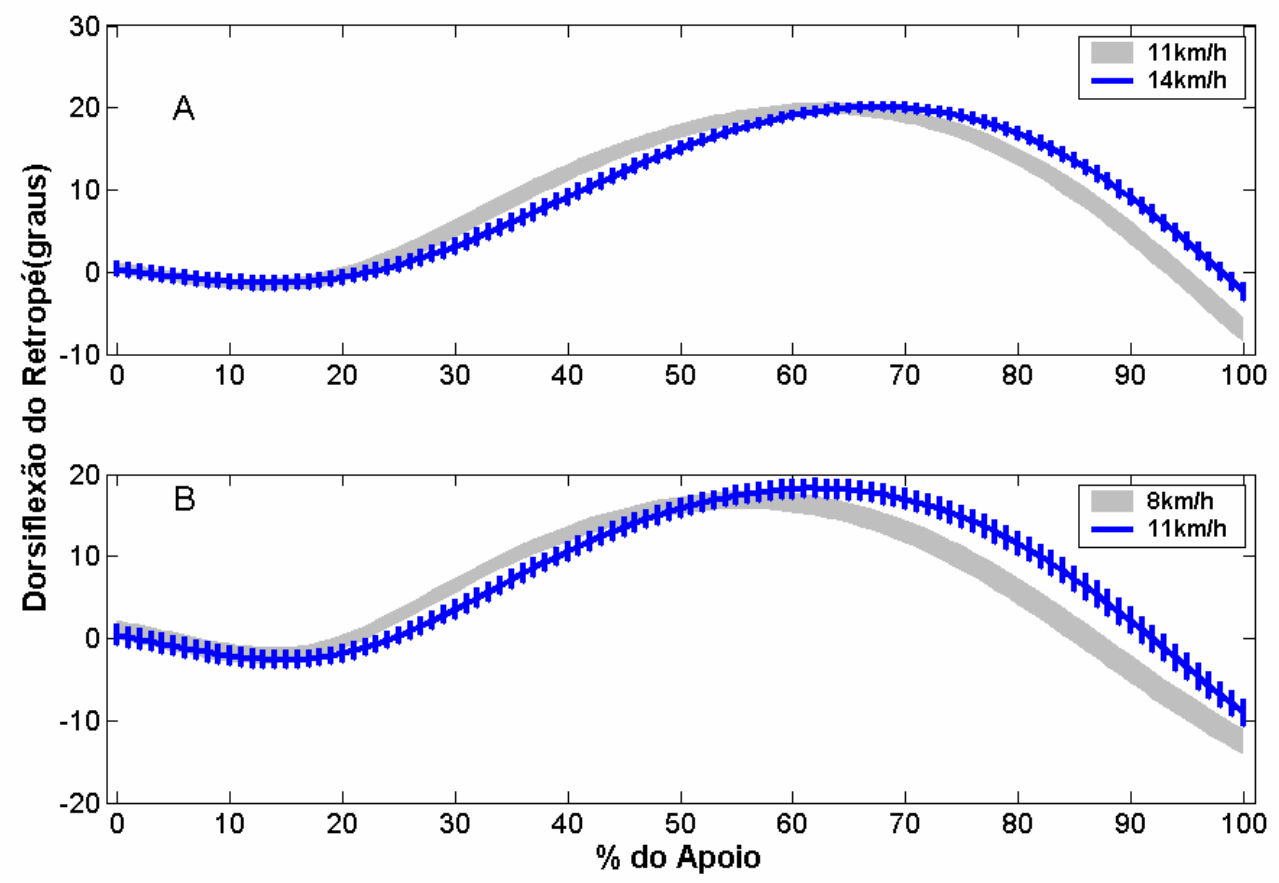

FIGURA 22. Média e erro padrão do ângulo do retropé no plano sagital durante a fase de apoio em adultos (A) e idosos (B) nas duas velocidades analisadas.

A FIGURA 23 demonstra a média do comportamento angular do retropé no plano frontal nos adultos durante a corrida nas velocidades de 11 e $14 \mathrm{~km} / \mathrm{h}$ e nos idosos nas velocidades de 8 e $11 \mathrm{~km} / \mathrm{h}$. Aparentemente ambos os grupos demonstraram padrões similares de movimento nas diferentes velocidades analisadas. A única diferença notável foi que ambos os grupos atingiram o pico de eversão mais precocemente quando a velocidade de corrida foi aumentada. 


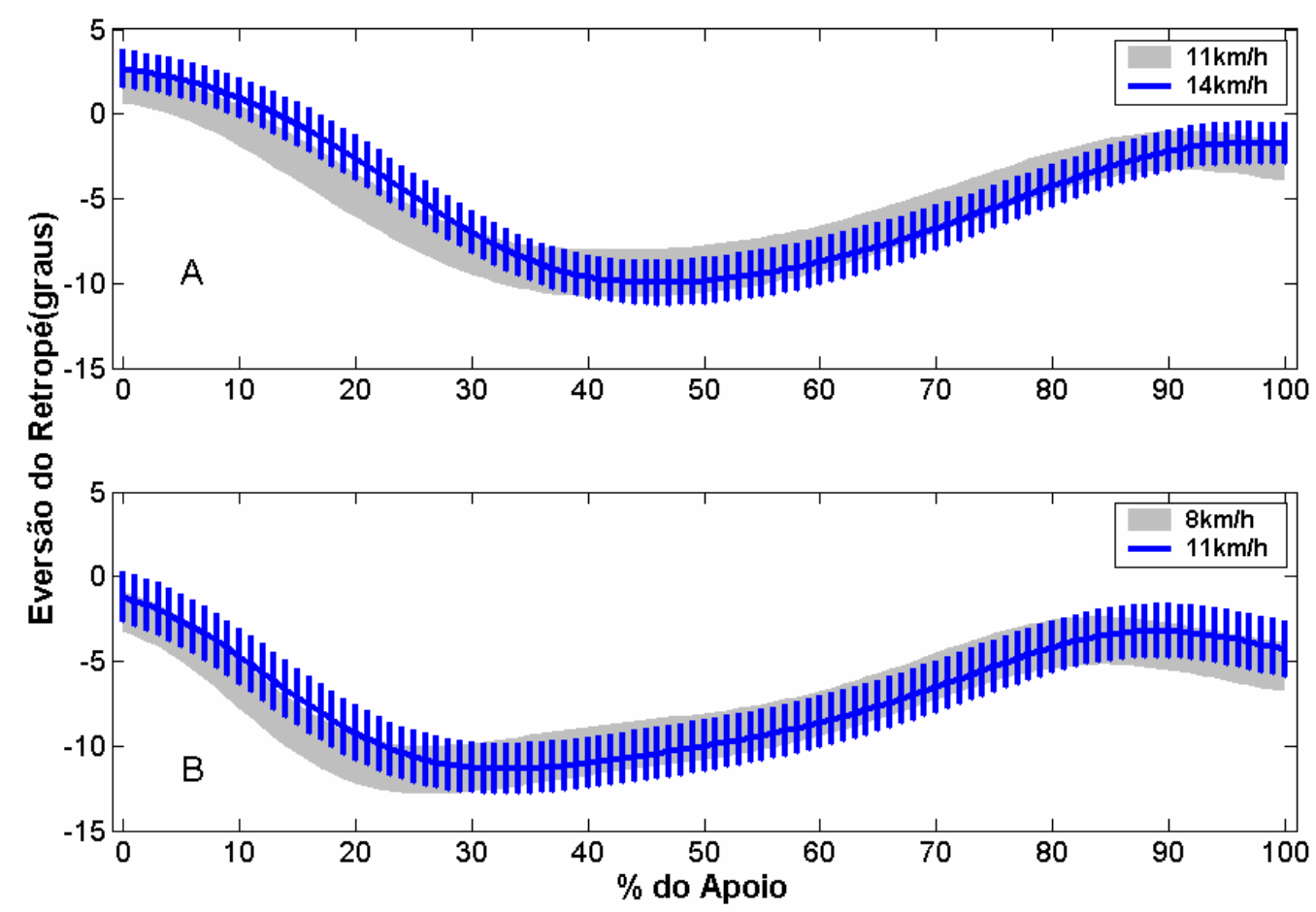

FIGURA 23. Média e erro padrão do ângulo do retropé no plano frontal durante a fase de apoio em adultos (A) e idosos (B) nas duas velocidades analisadas.

A FIGURA 24 demonstra a média do comportamento angular do retropé no plano transverso nos adultos durante a corrida nas velocidades de 11 e $14 \mathrm{~km} / \mathrm{h}$ e nos idosos nas velocidades de 8 e $11 \mathrm{~km} / \mathrm{h}$. Aparentemente ambos os grupos demonstraram padrões similares de movimento nas diferentes velocidades analisadas. O aumento da velocidade fez com que os idosos adotassem maior rotação lateral da tíbia ao aterrissarem (-0,3 grau) comparado a velocidade mais baixa $(0,5$ grau). 


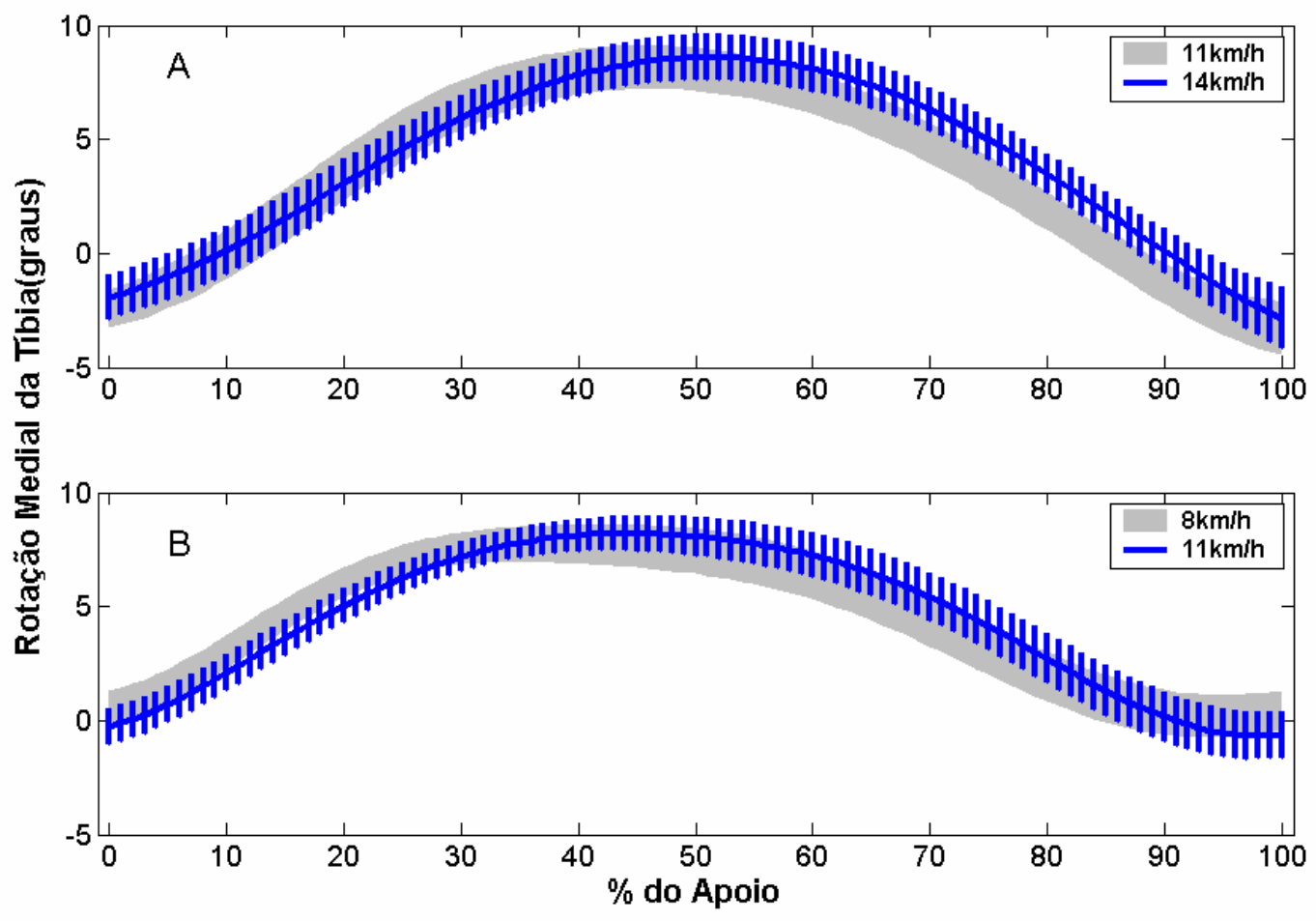

FIGURA 24. Média e erro padrão do ângulo do retropé no plano transverso durante a fase de apoio em adultos (A) e idosos (B) nas duas velocidades analisadas.

$\mathrm{Na}$ FIGURA 25, está representada a média dos movimentos de inversão/eversão em relação aos movimentos de flexão/extensão para os adultos analisados nas velocidades de 11 e $14 \mathrm{~km} / \mathrm{h}$ e para os idosos nas velocidades de 8 e $11 \mathrm{~km} / \mathrm{h}$. Aparentemente os adultos aterrissaram com maior flexão de joelho no apoio observado pela distância entre as duas curvas no heel strike (HS) na velocidade de $14 \mathrm{~km} / \mathrm{h}$. Já os idosos apresentaram maior pico de flexão de joelho na velocidade de $11 \mathrm{~km} / \mathrm{h}$ observado pela curva mais a direita do gráfico nesta velocidade. 


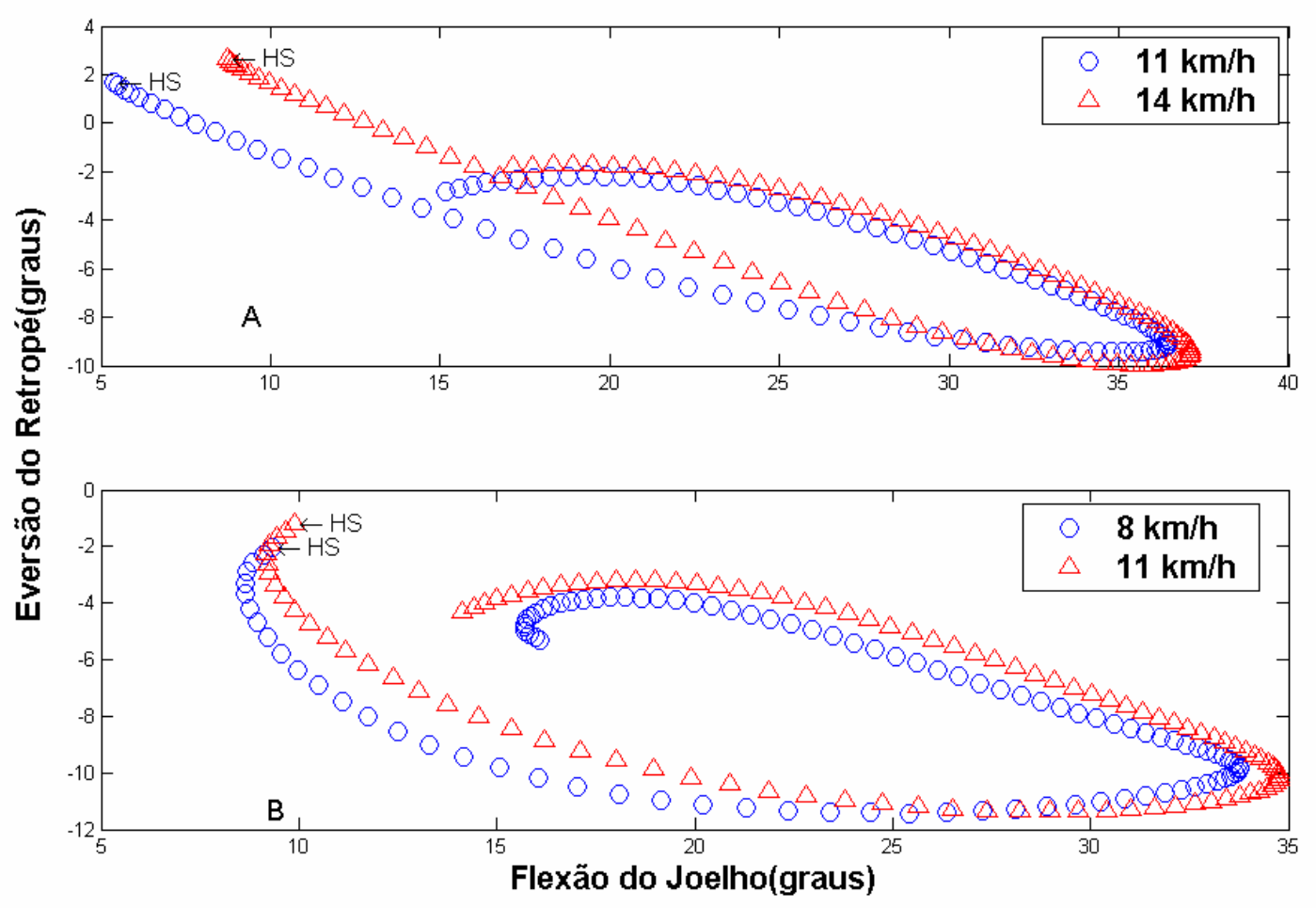

FIGURA 25. Ciclograma que representa a média dos movimentos de eversão versus flexão do joelho para os adultos (A) e idosos (B) analisados.

$\mathrm{Na}$ FIGURA 26, está representada a média dos movimentos de inversão/eversão em relação aos movimentos de rotação medial/rotação lateral da tíbia para os adultos analisados nas velocidades de 11 e $14 \mathrm{~km} / \mathrm{h}$ e para os idosos nas velocidades de 8 e $11 \mathrm{~km} / \mathrm{h}$. Aparentemente os idosos aterrissaram em maior rotação lateral da tíbia e atingiram maior rotação medial durante a fase de apoio na velocidade mais alta $(8 \mathrm{~km} / \mathrm{h})$. Flexão de joelho no apoio observado pela distância entre as duas curvas no heel strike (HS) na velocidade de $14 \mathrm{~km} / \mathrm{h}$. Já os idosos apresentaram maior pico de flexão de joelho na velocidade de $11 \mathrm{~km} / \mathrm{h}$ observado pela curva mais a direita do gráfico nesta velocidade. 


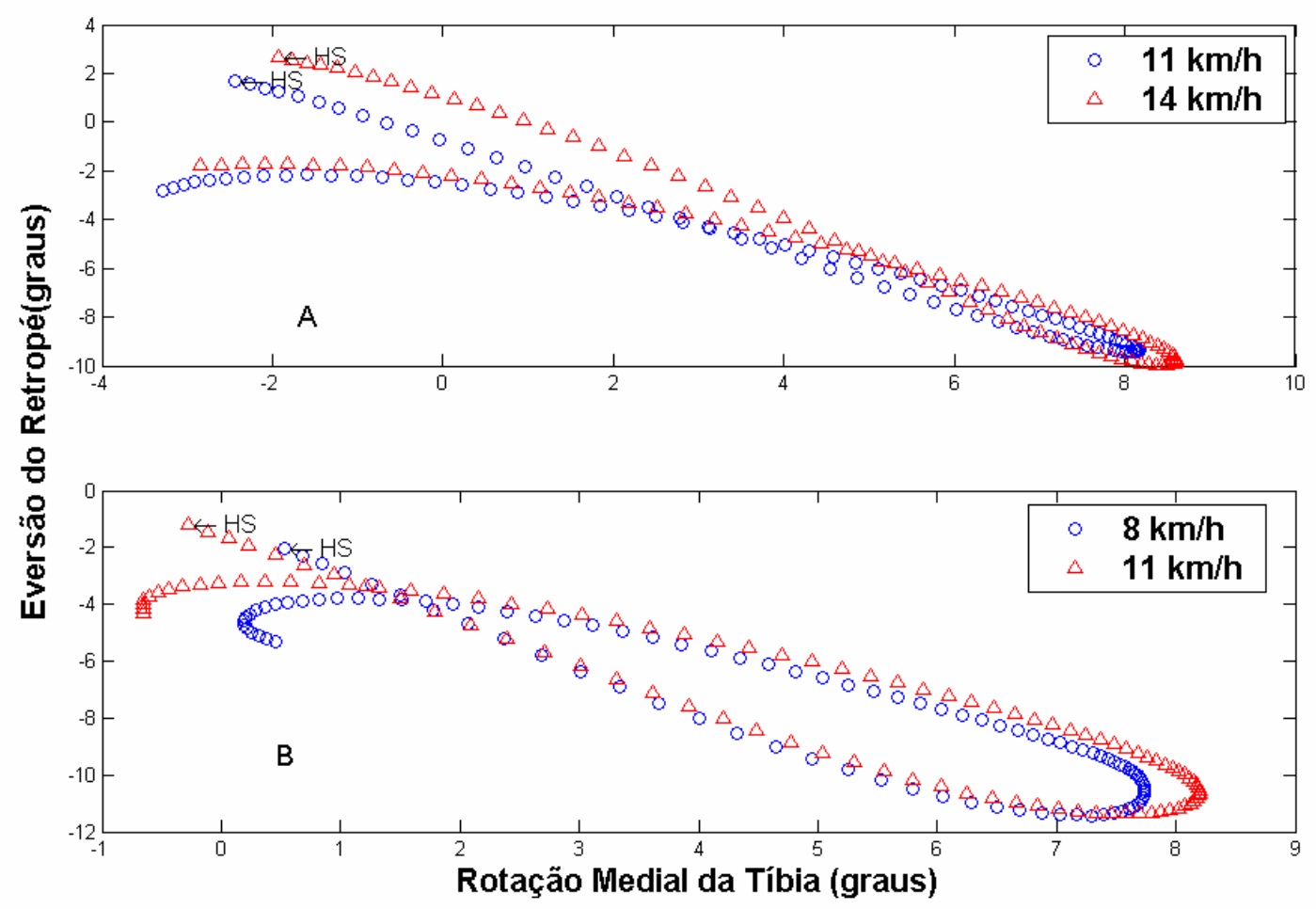

FIGURA 26. Ciclograma que representa a média dos movimentos de eversão versus rotação medial da tíbia para os adultos $(A)$ e idosos $(B)$ analisados.

Na FIGURA 27, está representada a média dos movimentos de inversão/eversão em relação aos movimentos de rotação medial/rotação lateral do joelho para os adultos analisados nas velocidades de 11 e $14 \mathrm{~km} / \mathrm{h}$ e para os idosos nas velocidades de 8 e $11 \mathrm{~km} / \mathrm{h}$. Tanto os adultos quanto os idosos aparentemente apresentaram aumento do pico de rotação medial do joelho quando correram na velocidade mais elevada (14 e $11 \mathrm{~km} / \mathrm{h}$ respectivamente). O deslocamento para direita da curva que representa essas velocidades demonstra tal achado. 


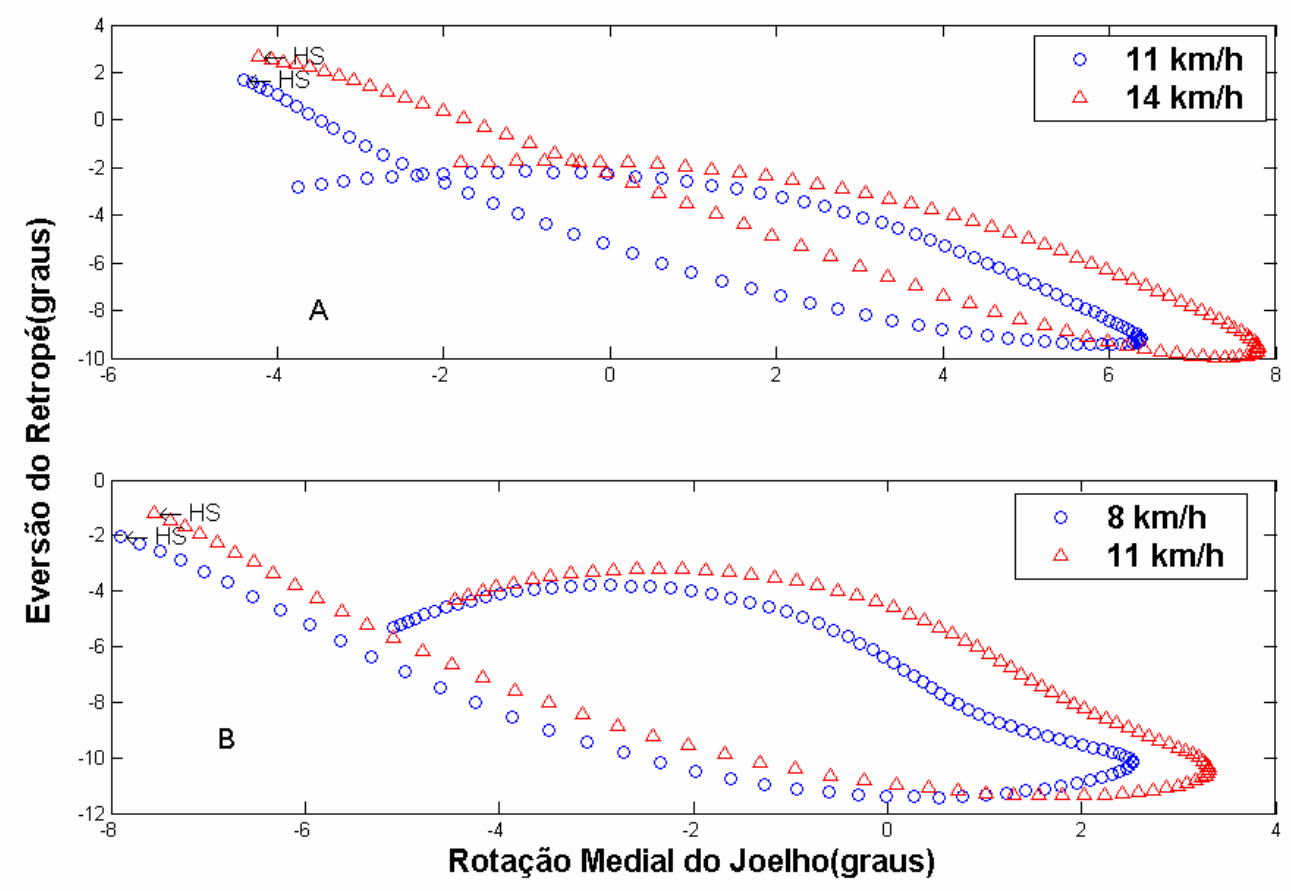

FIGURA 27. Ciclograma que representa a média dos movimentos de eversão versus rotação medial do joelho para os adultos $(A)$ e idosos (B) analisados.

\section{DISCUSSÃO}

No presente estudo foi investigado as características cinemáticas do membro inferior em adultos e idosos durante a corrida. $O$ interesse por este assunto partiu da carência de informação a respeito do comportamento dos movimentos de idosos durante a corrida. Apesar do aumento do número de idosos praticando atividade física, em especial a corrida de rua, relatada em seções anteriores deste estudo, ainda é desconhecido o comportamento desta população durante esta atividade.

Algumas variáveis analisadas demonstraram grande variabilidade no presente estudo. Os movimentos de EV, ADU/ABD, RIJ e RIT foram os que apresentaram maior variação. A dificuldade de mensuração por se tratar de movimentos de pequena amplitude contribuiu para o aparecimento desses achados. Apesar dessa grande variabilidade, foi observada a existência de um padrão entre os sujeitos do mesmo grupo. Estudos que investigaram essas mesmas variáveis em 
adultos corredores também reportaram variabilidade de magnitude semelhante (BELLCHAMBER \& VAN DEN BOGERT, 2000; MCCLAY \& MANAL, 1997,, 1998a,, 1999; NAWOCZENSKI, SALTZMAN \& COOK, 1998; REINSCHMIDT, 1996; REINSCHMIDT, VAN DEN BOGERT, LUNDBERG, NIGG, MURPHY, STACOFF \& STANO, 1997a; REINSCHMIDT et al., 1997c; STACOFF et al., 2000b). No presente estudo todos os cuidados foram tomados para que as medições fossem as mais acuradas possíveis e se aproximassem dos modelos internacionais utilizados, minimizando possíveis erros inerentes em estudos que utilizam técnicas não invasivas de medição.

\subsection{Cinemática da corrida em adultos e idosos}

Os idosos exibiram maior grau de flexão do joelho no contato inicial, e menor excursão FLXJ durante o apoio, com média de $33^{\circ}$ contra $27^{\circ}$. No estudo conduzido por BUS (2003) foram encontrados comportamentos similares em sujeitos com idade entre 55 e 65 anos. A diminuição da excursão nos idosos pode ser explicada pelo aumento da rigidez articular com o processo de envelhecimento biológico que já foi relatado em outros estudos (SUCH, UNSWORTH, WRIGHT \& DOWSON, 1975; VANDERVOORT et al., 1992). BUS (2003) atribuiu o maior grau de FLXJ do joelho durante o contato inicial em corredores mais velhos ao fato que a rigidez articular do joelho limita a extensão do joelho prévia ao contato inicial. Além disso, tal flexão do joelho serviria para reduzir a carga no sistema musculoesquelético logo após o impacto inicial. A diminuição da excursão do movimento de FLXJ poderia ser explicada pelo padrão de marcha precavida adotada pelos idosos para fornecer maior estabilidade e menor risco de quedas durante a corrida (BUS, 2003).

A única mudança de padrão de movimento notável entre os grupos investigados foi no movimento de ADU/ABD, embora nenhuma diferença significativa foi encontrada para as variáveis deste ângulo. Os adultos jovens exibiram um padrão de pequena adução, próximo da posição neutra na maior parte da fase de apoio, enquanto os idosos aterrissaram em posição neutra e rapidamente abduziram o joelho. Embora interessantes estes resultados devem ser analisados com cautela, pois esta medida foi a que apresentou menor amplitude de movimento (menos do 
que $5^{\circ}$ ) e a maior variabilidade como demonstrados pelos valores de dispersão deste ângulo. Sabe-se que a ADU/ABD é uma das medidas menos confiáveis quando utilizados análise cinemática com uso de marcadores superficiais. (RAMSEY \& WRETENBERG, 1999).

$\mathrm{Na}$ articulação do tornozelo não houve diferenças entre os grupos para os padrões de movimento estudados. Embora algumas diferenças fossem observadas, as médias das variáveis analisadas como o pico de DFT $\left(20^{\circ}\right.$ para os adultos e $18^{\circ}$ para os idosos), não apresentaram alterações significativas. OKADA et al. (1993), também não encontraram correlações significantes entre a idade e a diminuição da amplitude de movimento do tornozelo em corredores competitivos. No estudo realizado por BUS (2003), resultados similares ao presente estudo foram encontrados. Os sujeitos desse foram avaliados em uma velocidade controlada e em condições onde eles poderiam adotar uma velocidade de escolha própria. A ausência de diferenças no comportamento cinemático do tornozelo em relação ao joelho pode ser explicada por que o aumento da rigidez articular, devido ao envelhecimento, seja maior no joelho em relação ao tornozelo, embora esse fato não tenha sido reportado pela literatura. Além disso, as estratégias adaptativas do joelho dos idosos podem ter sido mais importantes do que as do tornozelo em resposta ao impacto que é submetido durante o período de apoio da corrida (BUS, 2003). Alguns estudos têm demonstrado que, ao adotar uma maior magnitude de flexão do joelho durante o contato inicial, o impacto inicial é reduzido (GERRITSEN, VAN DEN BOGERT \& NIGG, 1995; MCMAHON, VALIANT \& FREDERICK, 1987; NIGG, 1986). Porém, os efeitos causados pela mudança do comportamento angular do tornozelo durante esta fase da marcha e da corrida não são bem compreendidos. Dessa forma, os idosos podem alterar o padrão da corrida no joelho e não no tornozelo, intuitivamente, com esta finalidade.

Curiosamente, o pico de EV da articulação subtalar no presente estudo apresentou-se maior nos idosos $\left(-12^{\circ}\right)$ em relação aos adultos $\left(-10^{\circ}\right)$. Entretanto, tais diferenças não foram significantes. Apesar do valor de pico se apresentar maior nos idosos, este achado não significa que esta população apresentou maior mobilidade em relação aos adultos, já que os idosos apresentaram menor excursão de EV que os adultos. Os idosos realizaram o contato inicial já em eversão, ao contrário dos 
adultos, resultando em menor excursão de EV. Os achados de BUS (2003) corroboram com os achados deste estudo já que o autor não encontrou diferenças significativas no pico de EV, nem da amplitude de movimento da articulação subtalar. As principais metas no desenvolvimento de calçados para corrida são proporcionar controle de movimento do retropé, bem como, amortecimento durante o período de apoio. Essa tendência existe por que a pronação excessiva pode resultar em lesões do membro inferior (CLARKE, FREDERICK \& HAMILL, 1983; JAMES, BATES \& OSTERNIG, 1978). A melhora nas propriedades de amortecimento dos calçados, necessária para os idosos, ocorre em função da estabilidade do retropé. Os resultados apresentados pelo presente estudo demonstram que esta preocupação não é tão importante visto que nenhuma diferença significante no pico de EV e na excursão de EV foi encontrada. Estudos que investiguem as características cinéticas dos idosos são necessários para melhor compreensão das propriedades de amortecimento durante a corrida.

Como descrito anteriormente, durante o apoio, em cadeia cinética fechada e o pé fixo no solo, ocorre uma rotação da tíbia no plano transversal. No presente estudo a excursão de RIT foi menor nos idosos. Devido a ligação mecânica existente entre o pé e a perna demonstrado primeiramente por INMAN (STIEHL \& INMAN, 1991); a excursão de RIT pode ter sido influenciada pela excursão de EV que também apresentou-se menor nos idosos. Além disso, essa diminuição de mobilidade pode ser devida ao aumento da rigidez articular nos idosos relatados em outros estudos. Não foram encontrados estudos que investigaram especificamente estes movimentos em idosos, dificultando qualquer comparação com os resultados do presente estudo.

Ambos os grupos apresentaram razão de EV/RIT maior do que um. Sendo que na análise comparativa demonstraram valores similares $(p=0,26)$. Isso demonstra que tanto os adultos quanto os idosos apresentaram maior excursão de EV do que de RIT, corroborando com alguns achados da literatura. (MCCLAY \& MANAL, 1997; STACOFF, NIGG, REINSCHMIDT, VAN DEN BOGERT \& LUNDBERG, 2000a; STACOFF et al., 2000b; STACOFF, REINSCHMIDT, NIGG, VAN DEN BOGERT, LUNDBERG, DENOTH \& STUSSI, 2000c). No presente estudo 
a menor excursão de RIT dos idosos não foi suficiente para mudar significativamente a razão de EV/RIT em relação aos adultos.

Tanto os adultos quanto os idosos atingiram o pico de EV mais precocemente que o pico de FLXJ. Padrões semelhantes de assincronia foram encontrados em outros estudos (HAMILL, BATES \& HOLT, 1992; MCCLAY \& MANAL, 1997). O pico de EV também ocorreu antes do pico de RIJ no presente estudo em ambos os grupos. MCCLAY e MANAL (1997) também relataram que o pico de EV antecede o pico de RIJ em corredores com pisada normal e em hiperpronadores. Se o pico de EV ocorre antes, o pé começa a inverter mais cedo, causando uma adução do tálus e uma rotação lateral da tíbia; porém o joelho continua flexionando e rodando medialmente. Portanto, a magnitude desta assincronia de movimentos pode resultar em lesões articulares. Apesar da análise comparativa não ter demonstrado diferença significativa entre os grupos, foi notado maior assincronia de movimentos nos idosos no presente estudo. Estudos que investigam um maior número de sujeitos podem considerar significativa esta diferença.

A interpretação dos ciclogramas que representam o acoplamento entre os movimentos de FLXJ-EV para os dois grupos separadamente sugere que os picos de ambas as curvas ocorreram quase ao mesmo tempo com uma pequena diferença inter-grupo. Os idosos atingiram o pico de EV mais precocemente que o pico de FLXJ em relação aos adultos. Já o ciclograma que representou o acoplamento entre a RIJ-EV demonstrou uma discrepância maior ainda entre os grupos analisados. Isso aconteceu por que os idosos apresentaram um pico de EV maior e um pico de RIJ menor que os adultos. Ambos os ciclogramas demonstraram a curva dos idosos com um contorno mais aberto que a dos adultos, evidenciando uma diferença de tempo maior entre os picos de EV-FLXJ e EV-RIJ. A EV do retropé e a RIT demonstraram um padrão aproximado de correlação linear, observado no ciclograma em ambos os grupos analisados. Esse comportamento foi observado em outros estudos com adultos (BELLCHAMBER \& VAN DEN BOGERT, 2000; NIGG, COLE \& NACHBAUER, 1993). Todos os ciclogramas demonstraram que os idosos apresentavam menor excursão dos movimentos do que os adultos, sugerindo uma menor mobilidade. A inexistência de estudos anteriores que utilizaram essa técnica 
para observar o comportamento cinemático dos idosos impossibilitou a comparação com os achados do presente estudo.

\subsection{Cinemática da corrida em diferentes velocidades}

\subsubsection{Adultos}

Poucos estudos investigaram a influência da velocidade no padrão cinemático dos membros inferiores durante a corrida. Os estudos que foram realizados se preocuparam mais com os movimentos realizados no plano transversal, negligenciando os movimentos realizados em outros planos de movimento. Isso dificultou a comparação dos resultados do presente estudo com os achados de estudos anteriores.

No presente estudo foi realizado análise comparativa da corrida dentro do grupo dos sujeitos adultos em duas velocidades distintas: 11 e $14 \mathrm{~km} / \mathrm{h}$. Apesar de subjetivo, a eleição destas velocidades para os adultos foi realizada seguindo um critério onde a velocidade máxima $(14 \mathrm{~km} / \mathrm{h})$ não causasse grande esforço para a população estudada e a velocidade mínima $(11 \mathrm{~km} / \mathrm{h})$, que coincidia com a máxima dos idosos, exigisse um esforço leve dos adultos.

Houve uma diminuição da excursão de FLXJ com o aumento da velocidade da corrida. Aparentemente isso foi causado pela maior FLXJ adotado pelos adultos durante o contato inicial, resultando em menor excursão. NOVACHECK (1998), SINNING e FORSYTH (1970) e SEGERS et al. (no prelo) mostraram que o ângulo de FLXJ no contato inicial aumenta a medida que a velocidade da corrida aumenta. Sabe-se que o aumento da velocidade causa aumento do impacto inicial (MUNRO, MILLER \& FUGLEVAND, 1987). Os sujeitos do presente estudo podem ter flexionado mais o joelho no contato inicial na tentativa de reduzir a carga no sistema musculoesquelético, pois tal estratégia já foi observada em alguns estudos (GERRITSEN, VAN DEN BOGERT \& NIGG, 1995; MCMAHON, VALIANT \& FREDERICK, 1987).

Houve aumento do pico de RIJ, com o aumento da velocidade da corrida nos adultos $(p<0,001)$, apesar da excursão de RIJ permanecer inalterada. Aparentemente esse aumento se deve a posição do joelho no contato inicial, sendo que quando a velocidade aumentava o joelho exibia menor grau de rotação lateral 
comparada à velocidade mais baixa. A carência de estudos que pesquisaram a influência das velocidades nos movimentos secundários do joelho dificultou as comparações. Acrescido a isto, a grande variabilidade desses resultados que se devem as dificuldades de mensuração dos movimentos atrapalha análises mais conclusivas.

O pico de FLXJ ocorreu mais precocemente na velocidade de $14 \mathrm{~km} / \mathrm{h}$. Estudos anteriores que investigaram os movimentos do joelho em diferentes velocidades também encontraram diminuição progressiva do tempo para o pico de FLXJ com o aumento da velocidade da corrida (BATES, OSTERNIG, MASON \& JAMES, 1979; DE WIT, DE CLERCQ \& AERTS, 2000). Isso se deve a diminuição do tempo de apoio em resposta ao aumento da velocidade, como verificado por MUNRO et al. (1987). Quando comparada a simultaneidade entre os movimentos nas diferentes velocidades, foi notado que os adultos apresentaram maior sincronia entre os picos de EV e de FLXJ durante a velocidade de $14 \mathrm{~km} / \mathrm{h}$, ainda que diferenças não foram significativas $(p=0,03)$.

\subsubsection{Idosos}

Houve aumento da excursão de DF nos idosos devido ao aumento da velocidade da corrida. POHL et al. (2007) apresentaram resultados semelhantes para esta variável investigada, entretanto este trabalho investigou pessoas jovens. $O$ ângulo de DFT pode ter sido influenciado pelo ângulo de FLXJ que também teve acréscimo (pico e excursão) com o aumento da velocidade de corrida, devido a dependência das duas articulações em movimentos onde o pé está apoiado no chão (FITZGERALD, 1997). O aumento do impacto inicial resultante do aumento de velocidade (MUNRO, MILLER \& FUGLEVAND, 1987); pode ter causado maior FLXJ nos idosos na tentativa de atenuação da carga. Essa estratégia já foi evidenciada pela literatura (GERRITSEN, VAN DEN BOGERT \& NIGG, 1995; MCMAHON, VALIANT \& FREDERICK, 1987).

Quando observado as excursões dos outros movimentos analisados, os idosos não apresentaram alterações significativas quando a velocidade foi aumentada. Isso pode ser devido a maior rigidez articular presente nesta população como demonstraram alguns estudos (SUCH et al., 1975; VANDERVOORT et al., 
1992; VANDERVOORT \& MCCOMAS, 1986). Em especial a articulação do joelho demonstrou comportamento diferente dos adultos. Enquanto a excursão de FLXJ diminuiu significativamente nos adultos com o aumento da velocidade, nos idosos esse movimento não apresentou mudanças significativas, evidenciando a falta de mobilidade articular.

Os idosos também apresentaram maior excursão de EV do que de RIT em ambas as velocidades analisadas, resultando na razão EV/RIT maior do que um. Resultados similares foram encontrados nos adultos analisados no presente estudo e na literatura, apesar dos trabalhos investigarem apenas os adultos jovens (MCCLAY \& MANAL, 1998a; STACOFF et al., 2000a; STACOFF et al., 2000c). Com o aumento da velocidade houve diminuição do valor dessa razão, ao contrário dos adultos, porém não significativa. Essa diminuição pode ser explicada pelo menor aumento da excursão de EV, comparada ao aumento da excursão de RIT. Além disso, a influência da velocidade nos parâmetros analisados pode ter sido diferente entre os grupos, visto que as velocidades mínima e máxima para cada grupo foram diferentes.

Da mesma forma que os adultos, os picos dos movimentos analisados foram alcançados em um tempo menor para todas as variáveis analisadas. Como o tempo de apoio diminui conforme o aumento da velocidade da corrida esses resultados eram esperados (MUNRO, MILLER \& FUGLEVAND, 1987). Apesar da diminuição do tempo, os sujeitos atingiram esse pico mais tardiamente em relação à porcentagem do período de apoio na velocidade de $11 \mathrm{~km} / \mathrm{h}$. Essa tendência existiu também nos adultos do presente estudo e em outro trabalho, contudo as velocidades utilizadas nesses casos foram diferentes (POHL, MESSENGER \& BUCKLEY, 2007). Assim como os adultos analisados, o pico de EV acontecia antes do pico de FLXJ e de RIJ nos idosos. Resultados similares podem ser encontrados na literatura em trabalhos que analisaram adultos (HAMILL, BATES \& HOLT, 1992; VAN WOENSEL \& CAVANAGH, 1992). Na análise comparativa entre as velocidades, os idosos apresentaram maior coordenação entre os movimentos de EV e FLXJ na velocidade mais alta $(11 \mathrm{~km} / \mathrm{h})$, observado pela diferença do tempo entre os picos desses movimentos $(p<0,001)$. A sincronia entre os movimentos de EV e de RIJ também foi maior na velocidade de $11 \mathrm{~km} / \mathrm{h}$ nos idosos, porém sem diferença significativa $(p=0,03)$, demonstrando que os idosos apresentaram maior coordenação de 
movimentos nessa velocidade. Esses achados podem ser explicados pelo fato que a velocidade de $11 \mathrm{~km} / \mathrm{h}$ é mais próxima da velocidade que os idosos estão acostumados a correr em seus treinos, desta maneira estão mais familiarizados e conseguem desempenhar os movimentos de forma mais coordenada. A comparação dos resultados do presente estudo foi dificultada pela carência de trabalhos que investigaram a população idosa em diferentes velocidades da corrida.

\section{CONCLUSÃO}

Com base nos resultados do presente estudo é possível concluir-se que os idosos apresentaram comportamento cinemático diferente dos adultos nos seguintes aspectos:

- Uma menor excursão do movimento de flexão e rotação medial da tíbia comparada a dos adultos, o que sugere uma menor mobilidade para os idosos. Vale ressaltar que o achado da rotação da tíbia é inédito, uma vez que não existiam relatos na literatura sobre esses movimentos em idosos.

- Os idosos foram menos sensíveis a mudanças na velocidade da corrida. Talvez a maior rigidez articular tenha contribuído para este resultado, apesar do presente estudo não ter investigado esta questão.

O presente estudo sugere que talvez seja desnecessária a preocupação em fornecer maior estabilidade ao calçado do idoso atleta, uma vez que não foi observado diferenças de mobilidade na região do retropé em relação aos adultos para os idosos atletas investigados. No entanto, mais estudos devem ser conduzidos com idosos sedentários para que esses achados possam ser generalizados.

Os resultados do presente estudo sugerem que estratégias para prevenção de lesões em idosos corredores possam se concentrar na melhora da mobilidade articular, principalmente da articulação do joelho. O treinamento de força muscular poderia ser outro aspecto a ser prescrito, especialmente para o aparelho extensor do joelho.

Estudos futuros que investiguem as características cinéticas como os impactos e momentos articulares em idosos durante a corrida são necessários para a 
melhor compreensão de como as alterações degenerativas modificam a mecânica da corrida nesta população. 


\section{REFERÊNCIAS}

ABDEL-AZIZ, Y. I.; KARARA, H. M. Direct Linear Transformation from Comparator Co-ordinates Into Object Space Co-ordinates. In: Proc. ASP/UI Symposium on Closerange Photogrammetry. Am. Soc. of Photogrammetry, 1971. Falls Church, VA Falls Church, VA. p. 1-18.

ANDRIACCHI, T. P.; ANDERSSON, G. B.; FERMIER, R. W.; STERN, D.; GALANTE, J. O. A study of lower-limb mechanics during stair-climbing. J Bone Joint Surg Am, v. 62, p. $749-757,1980$.

AREBLAD, M.; NIGG, B. M.; EKSTRAND, J.; OLSSON, K. O.; EKSTROM, H. Threedimensional measurement of rearfoot motion during running. J Biomech, v. 23, p. 933-940, 1990.

BATES, B. T.; OSTERNIG, L. R.; MASON, B. R.; JAMES, S. L. Functional variability of the lower extremity during the support phase of running. Med Sci Sports, v. 11, p. 328-331, 1979.

BELLCHAMBER, T. L.; VAN DEN BOGERT, A. J. Contributions of proximal and distal moments to axial tibial rotation during walking and running. J Biomech, v. 33, p. 1397-1403, 2000.

BRANCH, T. P.; HUNTER, R.; DONATH, M. Dynamic EMG analysis of anterior cruciate deficient legs with and without bracing during cutting. Am J Sports Med, v. 17, p. 35-41, 1989.

BRANCH, T. P.; HUNTER, R. E. Functional analysis of anterior cruciate ligament braces. Clin Sports Med, v. 9, p. 771-797, 1990.

BUS, S. A. Ground reaction forces and kinematics in distance running in older-aged men. Med Sci Sports Exerc, v. 35, p. 1167-1175, 2003.

CAPPOZZO, A.; CAPPELLO, A.; DELLA CROCE, U.; PENSALFINI, F. Surfacemarker cluster design criteria for $3-D$ bone movement reconstruction. IEEE Trans Biomed Eng, v. 44, p. 1165-1174, 1997.

CAPPOZZO, A.; CATANI, F.; CROCE, U. D.; LEARDINI, A. Position and orientation in space of bones during movement: anatomical frame definition and determination. Clin Biomech (Bristol, Avon), v. 10, p. 171-178, 1995.

CAVANAGH, P. R. Biomechanics of distance running. Champaign, IL: Human Kinetics Books, 1990.

CLARKE, T. E.; FREDERICK, E. C.; HAMILL, C. The study of rearfoot movement in running. In: FREDERICK, E. C. (Eds.). Sport shoes and playing surfaces : biomechanical properties. Champaign, III.: Human Kinetics, 1984, p. 166-189. 
CLARKE, T. E.; FREDERICK, E. C.; HAMILL, C. L. The effects of shoe design parameters on rearfoot control in running. Med Sci Sports Exerc, v. 15, p. 376-381, 1983.

CZERNIECKI, J. M. Foot and ankle biomechanics in walking and running. A review. Am J Phys Med Rehabil, v. 67, p. 246-252, 1988.

DE WIT, B.; DE CLERCQ, D.; AERTS, P. Biomechanical analysis of the stance phase during barefoot and shod running. J Biomech, v. 33, p. 269-278, 2000.

DELEO, A. T.; DIERKS, T. A.; FERBER, R.; DAVIS, I. S. Lower extremity joint coupling during running: a current update. Clin Biomech (Bristol, Avon), v. 19, p. 983-991, 2004.

EDINGTON, C.; FREDERICK, E. C.; CAVANAGH, P. Rearfoot motion in distance running. In: CAVANAGH, P. R. (Eds.). Biomechanics of distance running. Champaign, III.: Human Kinetics, 1990, p. 135-161.

ENGSBERG, J. R.; ANDREWS, J. G. Kinematic analysis of the talocalcaneal/talocrural joint during running support. Med Sci Sports Exerc, v. 19, p. 275-284, 1987.

ESLAMI, M.; BEGON, M.; FARAHPOUR, N.; ALLARD, P. Forefoot-rearfoot coupling patterns and tibial internal rotation during stance phase of barefoot versus shod running. Clin Biomech (Bristol, Avon), v. 22, p. 74-80, 2007.

FITZGERALD, G. K. Open versus closed kinetic chain exercise: issues in rehabilitation after anterior cruciate ligament reconstructive surgery. Phys Ther, v. 77, p. $1747-1754,1997$.

FRANK, C.; SHRIVE, N. Biomaterials: ligament. In: NIGG, B.; HERZOG, W. (Eds.). Biomechanics of the musculo-skeletal system. New York: Wiley, 1994, p. 106132.

GERRITSEN, K. G.; VAN DEN BOGERT, A. J.; NIGG, B. M. Direct dynamics simulation of the impact phase in heel-toe running. J Biomech, v. 28, p. 661-668, 1995.

GOSWAMI, A. A new gait parameterization technique by means of cyclogram moments: Application to human slope walking. Gait \& Posture, v. 8, p. 15-36, 1998.

GREINER, T. M. The jargon of pedal movements. Foot Ankle Int, v. 28, p. 109-125, 2007. 
GROOD, E. S.; SUNTAY, W. J. A joint coordinate system for the clinical description of three-dimensional motions: application to the knee. J Biomech Eng, v. 105, p. 136$144,1983$.

HAMILL, J.; BATES, B. T.; HOLT, K. G. Timing of lower extremity joint actions during treadmill running. Med Sci Sports Exerc, v. 24, p. 807-813, 1992.

HINTERMANN, B.; NIGG, B. M. Pronation in runners. Implications for injuries. Sports Med, v. 26, p. 169-176, 1998.

HOGAN, D. B.; CAPE, R. D. Marathoners over sixty years of age: results of a survey. J Am Geriatr Soc, v. 32, p. 121-123, 1984.

HRELJAC, A.; MARSHALL, R. N.; HUME, P. A. Evaluation of lower extremity overuse injury potential in runners. Med Sci Sports Exerc, v. 32, p. 1635-1641, 2000.

HSU, T. C.; WANG, C. L.; TSAI, W. C.; KUO, J. K.; TANG, F. T. Comparison of the mechanical properties of the heel pad between young and elderly adults. Arch Phys Med Rehabil, v. 79, p. 1101-1104, 1998.

INMAN, V. T. The joints of the ankle. Baltimore: Williams \& Wilkins, 1976.

JAMES, S. L.; BATES, B. T.; OSTERNIG, L. R. Injuries to runners. Am J Sports Med, v. 6, p. 40-50, 1978.

LAFORTUNE, M. A.; CAVANAGH, P. R.; SOMMER, H. J., 3RD; KALENAK, A. Threedimensional kinematics of the human knee during walking. J Biomech, v. 25, p. 347357, 1992.

LARSSON, L.; GRIMBY, G.; KARLSSON, J. Muscle strength and speed of movement in relation to age and muscle morphology. J Appl Physiol, v. 46, p. 451-456, 1979.

LYSHOLM, J.; WIKLANDER, J. Injuries in runners. Am J Sports Med, v. 15, p. 168171, 1987.

MANAL, K.; MCCLAY, I.; STANHOPE, S.; RICHARDS, J.; GALINAT, B. Comparison of surface mounted markers and attachment methods in estimating tibial rotations during walking: an in vivo study. Gait Posture, v. 11, p. 38-45, 2000.

MARANS, H. J.; JACKSON, R. W.; GLOSSOP, N. D.; YOUNG, C. Anterior cruciate ligament insufficiency: a dynamic three-dimensional motion analysis. Am J Sports Med, v. 17, p. 325-332, 1989.

MARTI, B.; VADER, J. P.; MINDER, C. E.; ABELIN, T. On the epidemiology of running injuries. The 1984 Bern Grand-Prix study. Am J Sports Med, v. 16, p. 285294, 1988. 
MCCLAY, I.; MANAL, K. Coupling parameters in runners with normal and excessive pronation. J Appl Biomech, v. 13, p. 109-124, 1997.

. A comparison of three-dimensional lower extremity kinematics during running between excessive pronators and normals. Clin Biomech (Bristol, Avon), v. 13, p. 195-203, 1998a.

. The influence of foot abduction on differences between two-dimensional and three-dimensional rearfoot motion. Foot Ankle Int, v. 19, p. 26-31, 1998b.

Three-dimensional kinetic analysis of running: significance of secondary planes of motion. Med Sci Sports Exerc, v. 31, p. 1629-1637, 1999.

MCCLAY, I. S. A comparison of tibiofemoral and patellofemoral joint motion in runners with and without patellofemoral pain. 1990. Thesis (Ph.D.) -, Pennsylvania State University.

MCKEAN, K. A.; MANSON, N. A.; STANISH, W. D. Musculoskeletal injury in the masters runners. Clin J Sport Med, v. 16, p. 149-154, 2006.

MCMAHON, T. A.; VALIANT, G.; FREDERICK, E. C. Groucho running. J Appl Physiol, v. 62, p. 2326-2337, 1987.

MESSIER, S. P.; PITTALA, K. A. Etiologic factors associated with selected running injuries. Med Sci Sports Exerc, v. 20, p. 501-505, 1988.

MUNRO, C. F.; MILLER, D. I.; FUGLEVAND, A. J. Ground reaction forces in running: a reexamination. J Biomech, v. 20, p. 147-155, 1987.

NAWOCZENSKI, D. A.; SALTZMAN, C. L.; COOK, T. M. The effect of foot structure on the three-dimensional kinematic coupling behavior of the leg and rear foot. Phys Ther, v. 78, p. 404-416, 1998.

NEUMANN, D. A. Foot and Ankle. In: NEUMANN, D. A. (Eds.). Kinesiology of the musculoskeletal system : foundations for physical rehabilitation. New York: Elsevier Inc, 2002, p. 480-524.

NIGG, B. M. Biomechanics of running shoes. Champaign, III.: Human Kinetics, 1986.

NIGG, B. M.; COLE, G. K.; NACHBAUER, W. Effects of arch height of the foot on angular motion of the lower extremities in running. J Biomech, v. 26, p. 909-916, 1993.

NOEHREN, B.; DAVIS, I.; HAMILL, J. ASB clinical biomechanics award winner 2006 prospective study of the biomechanical factors associated with iliotibial band syndrome. Clin Biomech (Bristol, Avon), v. 22, p. 951-956, 2007. 
NOVACHECK, T. F. The biomechanics of running. Gait Posture, v. 7, p. 77-95, 1998.

OKADA, H.; AE, M.; KOTOH, T.; ASANO, K. Biomechanical study on changes in running kinematics with aging in master's distance runners. In: XIVth Congress of the International Society of Biomechanics, 1993. Paris Paris. p. 982-983.

POHL, M. B.; MESSENGER, N.; BUCKLEY, J. G. Forefoot, rearfoot and shank coupling: Effect of variations in speed and mode of gait. Gait \& Posture, v. 25, p. 295-302, 2007.

RAMSEY, D. K.; WRETENBERG, P. F. Biomechanics of the knee: methodological considerations in the in vivo kinematic analysis of the tibiofemoral and patellofemoral joint. Clin Biomech (Bristol, Avon), v. 14, p. 595-611, 1999.

REINSCHMIDT, C. Three-dimensional tibiocalcaneal and tibiofemoral kinematics during human locomotion - measured with external and bone markers. 1996. 1996.

REINSCHMIDT, C.; VAN DEN BOGERT, A. J.; LUNDBERG, A.; NIGG, B. M.; MURPHY, N.; STACOFF, A.; STANO, A. Tibiofemoral and tibiocalcaneal motion during walking: external vs. skeletal markers. Gait \& Posture, v. 6, p. 98-109, 1997a.

REINSCHMIDT, C.; VAN DEN BOGERT, A. J.; MURPHY, N.; LUNDBERG, A.; NIGG, $B$. M. Tibiocalcaneal motion during running, measured with external and bone markers. Clin Biomech (Bristol, Avon), v. 12, p. 8-16, $1997 \mathrm{~b}$.

REINSCHMIDT, C.; VAN DEN BOGERT, A. J.; NIGG, B. M.; LUNDBERG, A.; MURPHY, N. Effect of skin movement on the analysis of skeletal knee joint motion during running. J Biomech, v. 30, p. 729-732, 1997c.

RIGGS, B. L.; MELTON, L. J., 3RD. Involutional osteoporosis. N Engl J Med, v. 314, p. 1676-1686, 1986.

ROBERTSON, D. G. E. Research methods in biomechanics. Champaign, III.: Human Kinetics, 2004.

SEGERS, V.; LENOIR, M.; AERTS, P.; DE CLERCQ, D. Kinematics of the transition between walking and running when gradually changing speed. Gait \& Posture, v. In Press, Corrected Proof, p.

SINNING, W. E.; FORSYTH, H. L. Lower-limb actions while running at different velocities. Med Sci Sports, v. 2, p. 28-34, 1970.

SLOCUM, D. B.; JAMES, S. L. Biomechanics of running. Jama, v. 205, p. 721-728, 1968. 
SOUTAS-LITTLE, R. W.; BEAVIS, G. C.; VERSTRAETE, M. C.; MARKUS, T. L. Analysis of foot motion during running using a joint co-ordinate system. Med Sci Sports Exerc, v. 19, p. 285-293, 1987.

STACOFF, A.; NIGG, B. M.; REINSCHMIDT, C.; VAN DEN BOGERT, A. J.; LUNDBERG, A. Tibiocalcaneal kinematics of barefoot versus shod running. J Biomech, v. 33, p. 1387-1395, 2000a.

STACOFF, A.; NIGG, B. M.; REINSCHMIDT, C.; VAN DEN BOGERT, A. J.; LUNDBERG, A.; STUSSI, E.; DENOTH, J. Movement coupling at the ankle during the stance phase of running. Foot Ankle Int, v. 21, p. 232-239, $2000 \mathrm{~b}$.

STACOFF, A.; REINSCHMIDT, C.; NIGG, B. M.; VAN DEN BOGERT, A. J.; LUNDBERG, A.; DENOTH, J.; STUSSI, E. Effects of foot orthoses on skeletal motion during running. Clin Biomech (Bristol, Avon), v. 15, p. 54-64, 2000c.

STERGIOU, N.; BATES, B. T. The relationship between subtalar and knee joint function as a possible mechanism for running injuries. Gait \& Posture, v. 6, p. 177185, 1997.

STERGIOU, N.; BATES, B. T.; JAMES, S. L. Asynchrony between subtalar and knee joint function during running. Med Sci Sports Exerc, v. 31, p. 1645-1655, 1999.

STIEHL, J. B.; INMAN, V. T. Inman's joints of the ankle. 2nd. Baltimore: Williams \& Wilkins, 1991.

STOVITZ, S.; COETZEE, J. Hyperpronation and Foot Pain. The Physician and Sportsmedicine, v. 32, p. 19-26, 2004.

SUCH, C. H.; UNSWORTH, A.; WRIGHT, V.; DOWSON, D. Quantitative study of stiffness in the knee joint. Ann Rheum Dis, v. 34, p. 286-291, 1975.

TAKEDA, Y.; XEROGEANES, J. W.; LIVESAY, G. A.; FU, F. H.; WOO, S. L. Biomechanical function of the human anterior cruciate ligament. Arthroscopy, v. 10, p. $140-147,1994$.

TAUNTON, J. E.; RYAN, M. B.; CLEMENT, D. B.; MCKENZIE, D. C.; LLOYD-SMITH, D. R.; ZUMBO, B. D. A retrospective case-control analysis of 2002 running injuries. Br J Sports Med, v. 36, p. 95-101, 2002.

TIBERIO, D. Evaluation of functional ankle dorsiflexion using subtalar neutral position. A clinical report. J Orthop Sports Phys Ther, v. 9, p. 161-165, 1987.

TYLKOWSKI, C. M.; SIMON, S. R.; MANSOUR, J. M. Internal rotation gait in sapastic cerebral palsy in the hip. In: 10th Open Scientific Meeting of the Hip Society, 1982. St. Louis St. Louis: Mosby. p. 89-125. 
VAILAS, J. C.; PINK, M. Biomechanical effects of functional knee bracing. Practical implications. Sports Med, v. 15, p. 210-218, 1993.

VAN MECHELEN, W. Running injuries. A review of the epidemiological literature. Sports Med, v. 14, p. 320-335, 1992.

VAN WOENSEL, W.; CAVANAGH, P. R. A perturbation study of lower extremity motion during running. International Journal of Sport Biomechanics, v. 8, p. 30-47, 1992.

VANDERVOORT, A. A.; CHESWORTH, B. M.; CUNNINGHAM, D. A.; PATERSON, D. H.; RECHNITZER, P. A.; KOVAL, J. J. Age and sex effects on mobility of the human ankle. J Gerontol, v. 47, p. M17-21, 1992.

VANDERVOORT, A. A.; MCCOMAS, A. J. Contractile changes in opposing muscles of the human ankle joint with aging. J Appl Physiol, v. 61, p. 361-367, 1986.

WANG, B. W.; RAMEY, D. R.; SCHETTLER, J. D.; HUBERT, H. B.; FRIES, J. F. Postponed development of disability in elderly runners: a 13-year longitudinal study. Arch Intern Med, v. 162, p. 2285-2294, 2002.

WILLSON, J. D.; DAVIS, I. S. Lower extremity mechanics of females with and without patellofemoral pain across activities with progressively greater task demands. Clinical Biomechanics, v. In Press, Corrected Proof, p.

WU, G.; SIEGLER, S.; ALLARD, P.; KIRTLEY, C.; LEARDINI, A.; ROSENBAUM, D.; WHITTLE, M.; D'LIMA, D. D.; CRISTOFOLINI, L.; WITTE, H.; SCHMID, O.; STOKES, I. ISB recommendation on definitions of joint coordinate system of various joints for the reporting of human joint motion--part I: ankle, hip, and spine. International Society of Biomechanics. J Biomech, v. 35, p. 543-548, 2002.

YOUNG, A.; DINAN, S. Activity in later life. Bmj, v. 330, p. 189-191, 2005. 
ANEXO 1 - QUESTIONÁRIO COM DADOS PESSOAIS DOS SUJEITOS

\section{Dados Pessoais}

Nome:

DN:

Altura:

Peso:

\section{Dados sobre a Corrida:}

Tempo de Prática: treinos/sem:

Tipo de Piso:

Marca e Modelo do Calçado:

Tempo de uso: Freqüência:

Km por treino: $\mathrm{Min} / \mathrm{Km}$ :

Tipo de Prova: Melhor Desempenho:

3. Histórico de Lesões:

Lesão Atual:

( ) $\operatorname{sim}$ ( ) não Qual?

Há quanto tempo: Tempo de Afastamento:

Lesões Pregressas: 


\section{ANEXO 2- CARTA DE APROVAÇÃO DO COMITÊ DE ÉTICA}

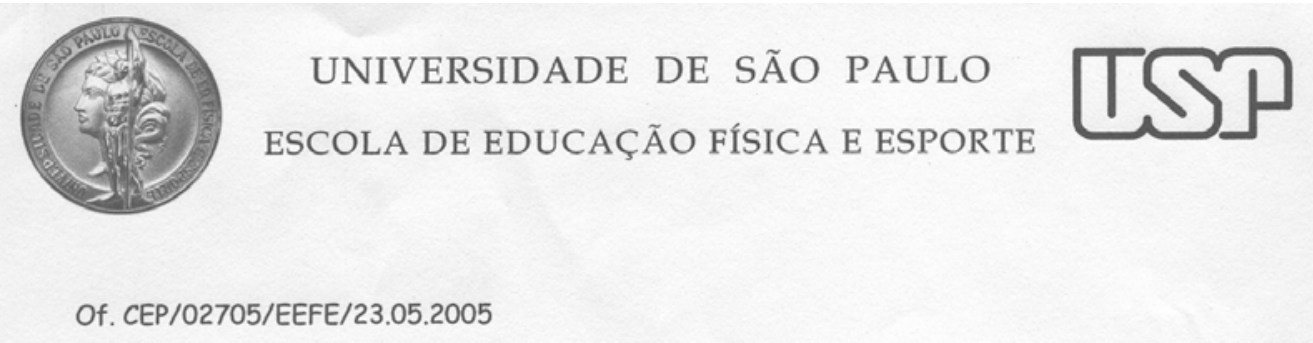

Parecer CEP - Projeto $N^{\circ} 95$

Senhor Professor

Pelo presente, informo que o Comitê de Ética em Pesquisa da EEFE-USP, em reunião ordinária realizada em 06 de maio de 2005, apreciou o projeto de pesquisa intitulado "Análise Cinemática do Pé durante a Fase de Apoio da Corrida em Adultos Jovens e Idosos", sob sua responsabilidade, e considerou-o aprovado.

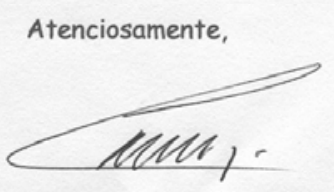

Prof. Dr. Carlos Eduardo Negrão Presidente do Comitê de Ética em Pesquisa

Ilmo. Sr.

Prof. Dr. Marcos Duarte

Departamento de Biodinâmica do Movimento do Corpo Humano EEFE-USP

Av. Professor Mello Moraes, 65 Săo Paulo - SP - Brasi Fax: $55113812-4141$ 


\section{ANEXO 3- TERMO DE CONSENTIMENTO LIVRE E ESCLARECIDO

\author{
ESCOLA DE EDUCAÇÃO FÍSICA E ESPORTE \\ UNIVERSIDADE DE SÃO PAULO
} \\ TERMO DE CONSENTIMENTO LIVRE E ESCLARECIDO}

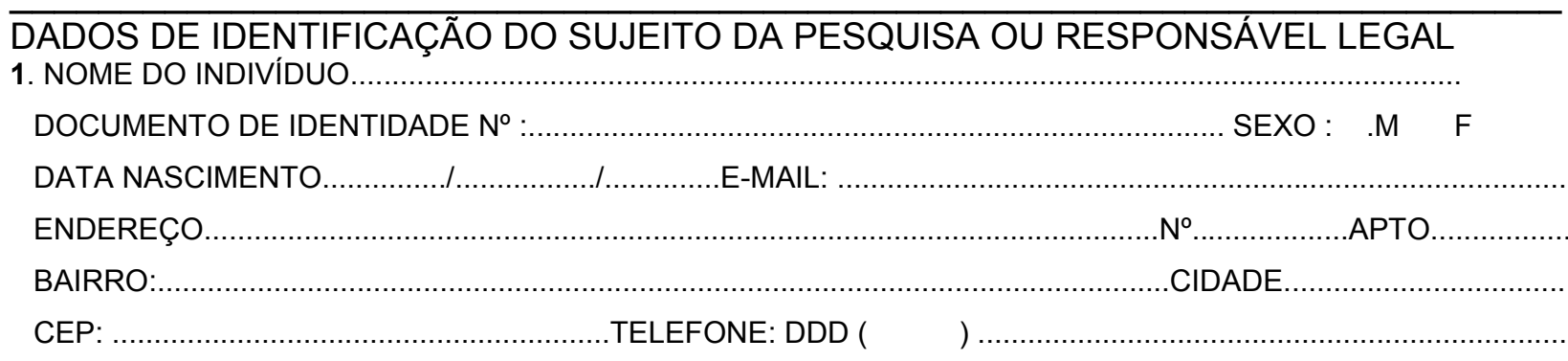

2 NOME DO RESPONSÁVEL LEGAL:

DOCUMENTO DE IDENTIDADE N ${ }^{\circ}$ : SEXO : .M F

DATA NASCIMENTO ./.

ENDEREÇO

$\mathrm{N}^{\circ}$

APTO.

BAIRRO: CIDADE

CEP:

TELEFONE: DDD (

) .

\section{II - DADOS SOBRE A PESQUISA CIENTÍFICA}

1. TítUlO dO PROJETO DE PESQUISA : Análise Cinemática do Pé durante a Fase de Apoio da Corrida em Adultos Jovens e Idosos.

2. PESQUISADOR RESPONSÁVEL: Reginaldo Kisho Fukuchi

3. CARGO/FUNÇÃO: Aluno de Mestrado

4. AVALIAÇÃO DO RISCO DA PESQUISA:

$\begin{array}{lll}\text { RISCO MÍNIMO } & & \text { RISCO MÉDIO } \\ \text { RISCO BAIXO } & \mathbf{X} & \text { RISCO MAIOR }\end{array}$

(probabilidade de que o indivíduo sofra algum dano como consequência imediata ou tardia do estudo)

5. DURAÇÃO DA PESQUISA: 1 hora

\section{III - EXPLICAÇÕES DO PESQUISADOR AO INDIVÍDUO OU SEU REPRESENTANTE LEGAL SOBRE A PESQUISA, CONSIGNANDO:}

Este estudo faz parte do projeto de mestrado desenvolvido no Laboratório de Biofísica da Escola de Educação Física e Esporte da USP. O estudo tem como objetivo principal observar como se comporta os movimentos dos seus pés durante a fase de apoio da corrida (pisada). Para isso, durante o teste você irá correr em uma esteira ergométrica em duas velocidades diferentes por 5 minutos cada uma utilizando bolinhas de isopor que serão colados em alguns pontos do seu corpo com uma fita adesiva antialérgica. A coleta de dados terá duração de aproximadamente 60 minutos. Os resultados, 
guardadas as devidas identificações, serão analisados e utilizados única e exclusivamente para fins científicos.

\section{IV - ESCLARECIMENTOS DADOS PELO PESQUISADOR SOBRE GARANTIAS DO SUJEITO DA PESQUISA:}

1. O voluntário terá acesso, a qualquer tempo, às informações sobre procedimentos, riscos e benefícios relacionados à pesquisa, inclusive para dirimir eventuais dúvidas;

2. Terá a liberdade de retirar seu consentimento a qualquer momento e de deixar de participar do estudo, sem que isto traga prejuízo à continuidade da assistência;

3. Os resultados serão confidenciais de uso exclusivo para fins científicos, e;

4. Estará disponível assistência médica no HU (Hospital Universitário da USP), por eventuais danos à saúde, decorrentes dessa pesquisa.

\section{V - INFORMAÇÕES DE NOMES, ENDEREÇOS E TELEFONES DOS RESPONSÁVEIS PELO ACOMPA- NHAMENTO DA PESQUISA, PARA CONTATO EM CASO DE INTERCORRÊNCIAS CLÍNICAS E REAÇÕES ADVERSAS.}

Pesquisador Responsável:

Nome:

RG:

CPF:

Profissão:

Endereço:

CEP:

Telefone:

Pesquisador Gerente:

Nome:

RG:

CPF:

Profissão:

Endereço:

CEP:

Telefone:

\section{OBSERVAÇÕES COMPLEMENTARES:}

\section{VII - CONSENTIMENTO PÓS-ESCLARECIDO}

Declaro que, após convenientemente esclarecido pelo pesquisador e ter entendido o que me foi explicado, consinto em participar do presente Projeto de Pesquisa .

São Paulo, de de 20 


\section{INSTRUÇÕES PARA PREENCHIMENTO}

(Resolução Conselho Nacional de Saúde 196, de 10 outubro 1996)

1. Este termo conterá o registro das informações que o pesquisador fornecerá ao sujeito da pesquisa, em linguagem clara e accessível, evitando-se vocábulos técnicos não compatíveis com o grau de conhecimento do interlocutor.

2. A avaliação do grau de risco deve ser minuciosa, levando em conta qualquer possibilidade de intervenção e de dano à integridade física do sujeito da pesquisa.

3. O formulário poderá ser preenchido em letra de forma legível, datilografia ou meios eletrônicos.

4. Este termo deverá ser elaborado em duas vias, ficando uma via em poder do paciente ou seu representante legal e outra deverá ser juntada ao prontuário do paciente.

5. A via do Termo de Consentimento Livre e Esclarecido submetida à análise do Comitê de Ética em Pesquisa - CEP deverá ser idêntica àquela que será fornecida ao sujeito da pesquisa. 


\section{ANEXO 4 - MARCAS ANATÔMICAS}

A definição de eixos e planos articulares é de extrema importância na Biomecânica e em situações clínicas. O Virtual Animation of the Kinematics of the Human for Industrial, Educational and Research Purposes - VAKHUM (http://www.ulb.ac.be/project/vakhum/) é um projeto europeu que se preocupou em padronizar protocolos de análise cinemática para os membros inferiores dentro dos modelos internacionais propostos, procurando diminuir a variabilidade destes entre os diferentes estudos.

A análise cinemática proposta aqui neste trabalho, utiliza marcas retrorefletivas em proeminências anatômicas. A localização de tais proeminências é um fator problemático, pois a palpação envolvida nesta localização não é fácil e está sujeita a erros. Assim, este estudo utiliza a padronização proposta no projeto VAKHUM para localização das proeminências anatômicas onde as marcas refletivas são colocadas.

\section{Segmento coxa}

Pontos utilizados: centro da cabeça femoral, epicôndilo lateral e epicôndilo medial (FIGURA 28). O centro da cabeça femoral foi determinado a partir da localização do centro articular do quadril pelo método híbrido reportado por TYLKOWSKI et al.(1982) e ANDRIACCHI et al. (1980).

Os planos e eixos podem ser visualizados na FIGURA 28.

Plano coronal: este plano é definido pelos pontos do: epicôndilo lateral, epicôndilo medial e centro da cabeça do fêmur.

Plano sagital: este plano é ortogonal ao plano anterior e contém os pontos: ponto médio entre os epicôndilos, e centro da cabeça femoral.

Plano transverso: este plano é mutuamente ortogonal aos dois anteriores. 


\section{ANEXO 4 - MARCAS ANATÔMICAS (cont.)}

Origem do sistema da coxa: ponto médio entre o epicôndilo lateral e o epicôndilo medial.

Eixo Y: este eixo é orientado sobre a linha que passa sobre a origem do sistema da coxa e o centro da cabeça femoral, com direção positiva apontando para cima.

Eixo Z: este eixo está sobre o plano coronal do fêmur e é perpendicular ao eixo $\mathrm{Y}$, com direção positiva apontando para a direita.

Eixo X: este eixo é mutuamente ortogonal aos dois anteriores e é positivo no sentido anterior.

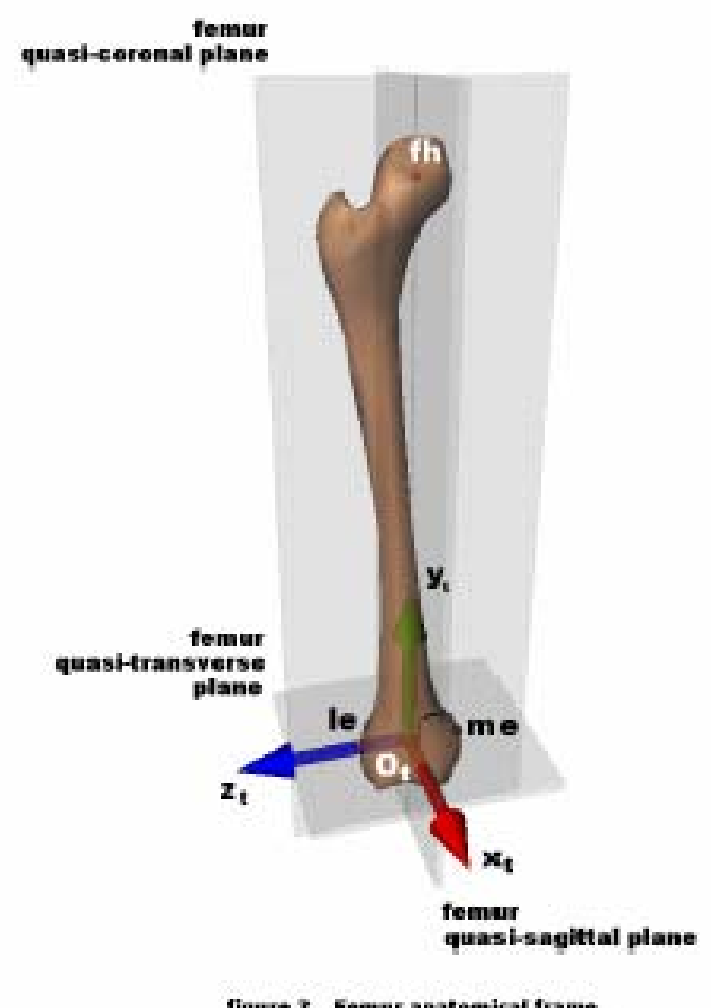

FIGURA 28. Marcas anatômicas utilizadas no segmento coxa. 


\section{ANEXO 4 - MARCAS ANATÔMICAS (cont.)}

\section{Segmento perna}

Pontos utilizados: Ápice da cabeça da fíbula, tuberosidade da tíbia, ápice distal do maléolo lateral e ápice distal do maléolo medial (FIGURA 29).

Os planos e eixos podem ser visualizados na FIGURA 29.

Plano coronal: este plano é definido pelos pontos do: cabeça da fíbula, maléolo lateral e o ponto médio entre os maléolos.

Plano sagital: este plano é ortogonal ao plano anterior e contém os pontos: tuberosidade da tíbia e o ponto médio entre os maléolos.

Plano transverso: este plano é mutuamente ortogonal aos dois anteriores.

Origem do sistema da perna: ponto médio entre o maléolo lateral e o maléolo medial.

Eixo Y: é definido pela interseção entre os planos coronal e sagital da tíbia, sendo positivo para cima.

Eixo Z: este eixo está sobre o plano coronal da perna e é perpendicular ao eixo $\mathrm{Y}$, com direção positiva apontando para a direita.

Eixo X: este eixo é mutuamente ortogonal aos dois anteriores e é positivo no sentido anterior.

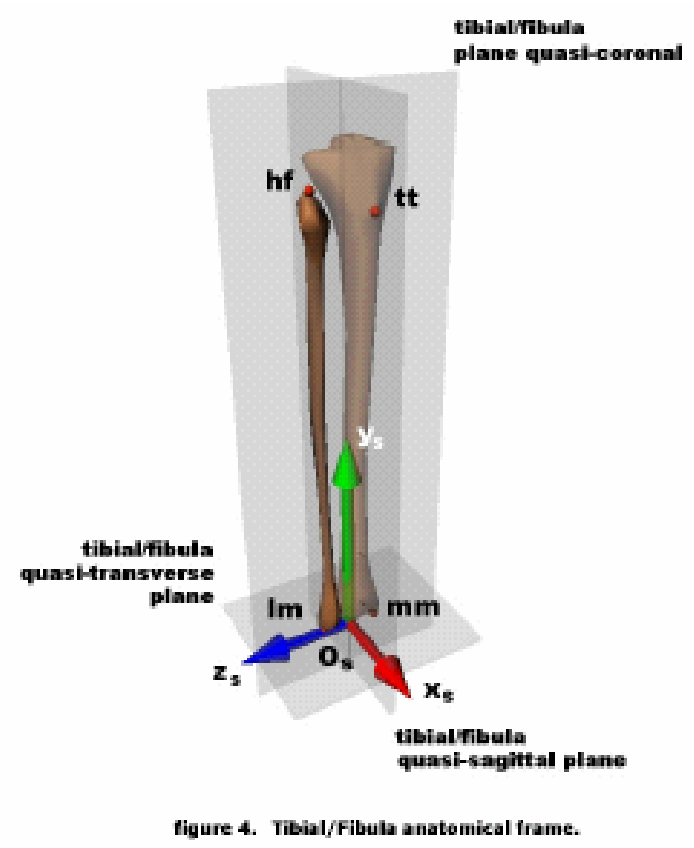

FIGURA 29. Marcas anatômicas utilizadas no segmento perna. 


\section{ANEXO 4 - MARCAS ANATÔMICAS (cont.)}

\section{Segmento pé}

Pontos utilizados: calcâneo, cabeça do quinto metatarso, cabeça do segundo metatarso e cabeça do primeiro metatarso (FIGURA 30).

Os planos e eixos podem ser visualizados na FIGURA 30.

Plano transverso: este plano é definido pelos pontos do: calcâneo, primeiro metatarso e quinto metatarso.

Plano sagital: este plano é ortogonal ao plano anterior e contém os pontos: calcâneo e segundo metatarso.

Plano coronal: este plano é mutuamente ortogonal aos dois anteriores.

Origem do sistema do pé: ponto do calcâneo.

Eixo Y: definido pela interseção entre os planos coronal e sagital do pé, sendo positivo para cima.

Eixo Z: este eixo está sobre o plano transverso do pé e é perpendicular ao eixo $\mathrm{Y}$, com direção positiva apontando para a direita.

Eixo X: este eixo é mutuamente ortogonal aos dois anteriores e é positivo no sentido anterior.

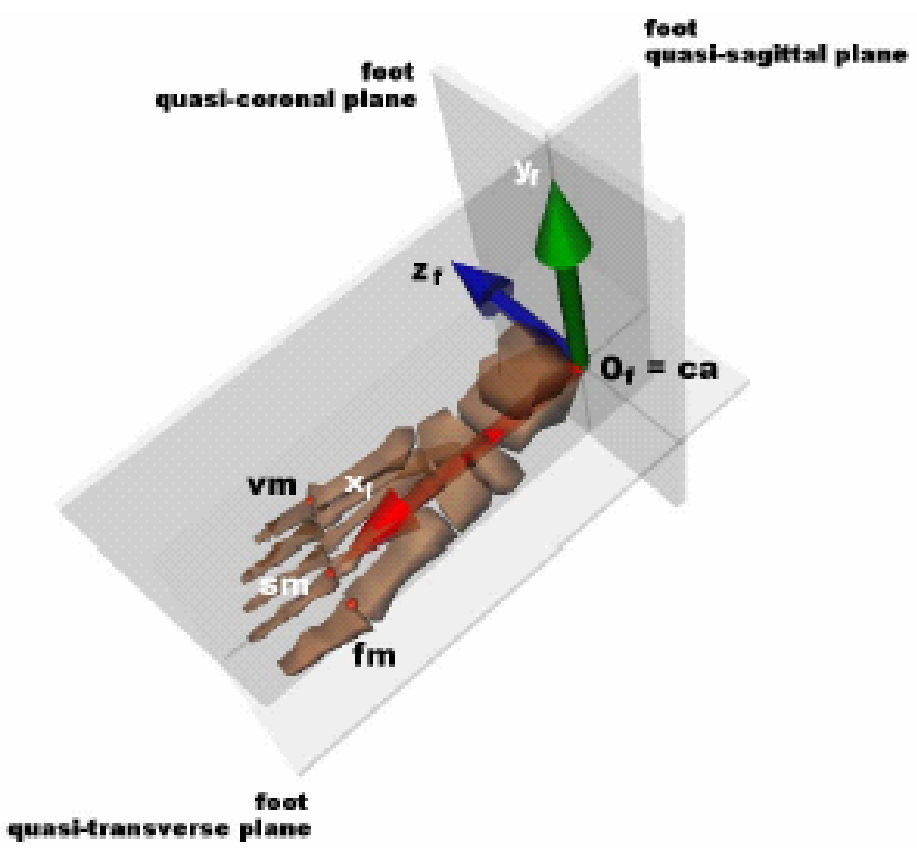

FIGURA 30. Marcas anatômicas utilizadas no segmento pé. 


\section{ANEXO 5 - SISTEMA DE REFERÊNCIA}

Para descrever a posição de um corpo no espaço, é necessário definir alguns termos importantes. O primeiro dele é o Sistema de referência global (SRG), onde as leis de Newton são válidas e que pode também ser chamado de sistema inercial, sendo que este esteja parado ou em velocidade constante. Este tipo de sistema é construído a partir de uma origem e três eixos unitários e mutuamente ortogonais passando pela origem, também chamada de base ortonormal, (FIGURA 31).

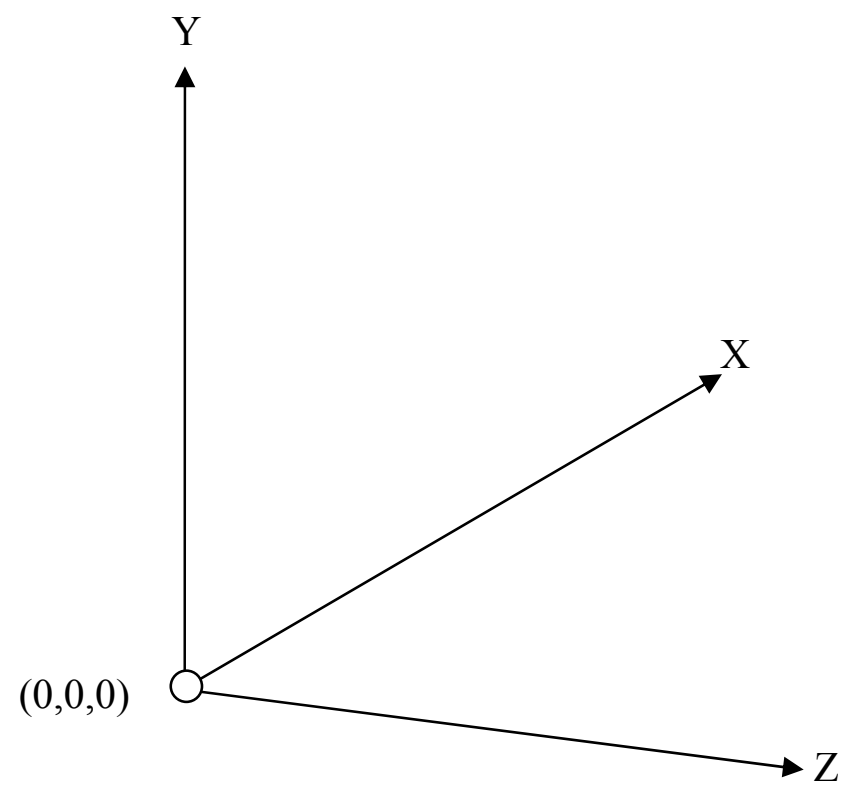

FIGURA 31 - Exemplo de um Sistema de Referência Global (SRG).

Neste estudo, o plano XY corresponde aproximadamente ao plano sagital do indivíduo durante do movimento, o $\mathrm{YZ}$ ao frontal do indivíduo e o $\mathrm{XZ}$ ao plano transversal do indivíduo.

Outro termo importante a ser definido é o Sistema de Referência Local (SRL). Este sistema está em movimento acelerado em relação ao SRG, e geralmente em biomecânica, esse sistema está acoplado ao segmento, de modo que qualquer ponto deste segmento não se move em relação ao seu respectivo SRL (FIGURA 32). 


\section{ANEXO 5 - SISTEMA DE REFERÊNCIA (cont.)}

Para determinar o SRL, é necessário conhecer no mínimo a posição de 3 pontos não colineares fixos a este segmento, o que permite construir uma base ortonormal fixa ao segmento.

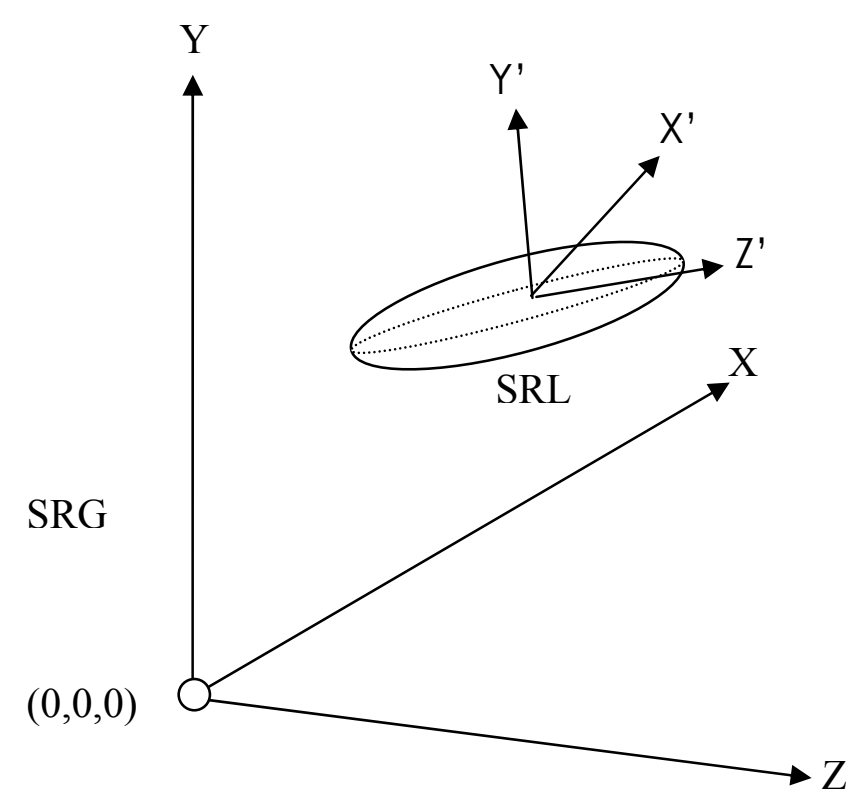

FIGURA 32 - Sistema de referência local (SRL) localizado dentro de um Sistema de referência global (SRG).

Fixado um SRG, é possível descrever a posição de qualquer ponto de interesse, como a posição de marcadores fixados ao sujeito durante o movimento analisado, em relação a esse SRG. Porém, na biomecânica, estamos interessados na maioria das vezes, em descrever a posição de um segmento no espaço, não de apenas um ponto.

A posição segmentar é impossível de ser determinada a partir de apenas um ponto localizado no corpo. $\mathrm{Na}$ análise do movimento, para determinarmos a posição de um segmento corporal no espaço, aproximamos os segmentos corporais a corpos rígidos, que corresponde a um conceito limite ideal de um corpo que não 


\section{ANEXO 5 - SISTEMA DE REFERÊNCIA (cont.)}

sofre deformações em nenhum momento quando forças externas são aplicadas a ele. Assim, segmentos corporais são considerados rígidos quando seu tamanho não muda, o que na verdade não acontece. Porém, assumindo que esses corpos são rígidos, o procedimento matemático para estudar o comportamento deste corpo torna-se muito mais viável, além de ser é uma boa aproximação da realidade e que não compromete o entendimento do fenômeno como o que está sendo estudado.

Para especificar completamente a posição de um corpo rígido em relação a um dado referencial, são necessárias no mínimo seis informações. Três destas informações são obtidas a partir da posição (três coordenadas) de um ponto $\mathrm{P}$ do corpo no espaço. Associando um ponto A nesse mesmo corpo, distante $r$ de $\mathrm{P}$, podemos retirar mais duas informações: latitude e longitude do segmento AP. Por ultimo, temos que saber a rotação sobre o eixo AP, para isso, é necessário um outro ponto $\mathrm{B}$ não colinear a AP informando assim o ângulo de rotação em torno do eixo AP. Essas seis informações (três coordenadas do ponto $P$, latitude e longitude do segmento $A P$ e ângulo de rotação do segmento $A P$ ) denotam os graus de liberdade do sistema, sendo esse, o número de parâmetros que é preciso especificar para determinar a posição do corpo (FIGURA 33). 


\section{ANEXO 5 - SISTEMA DE REFERÊNCIA (cont.)}

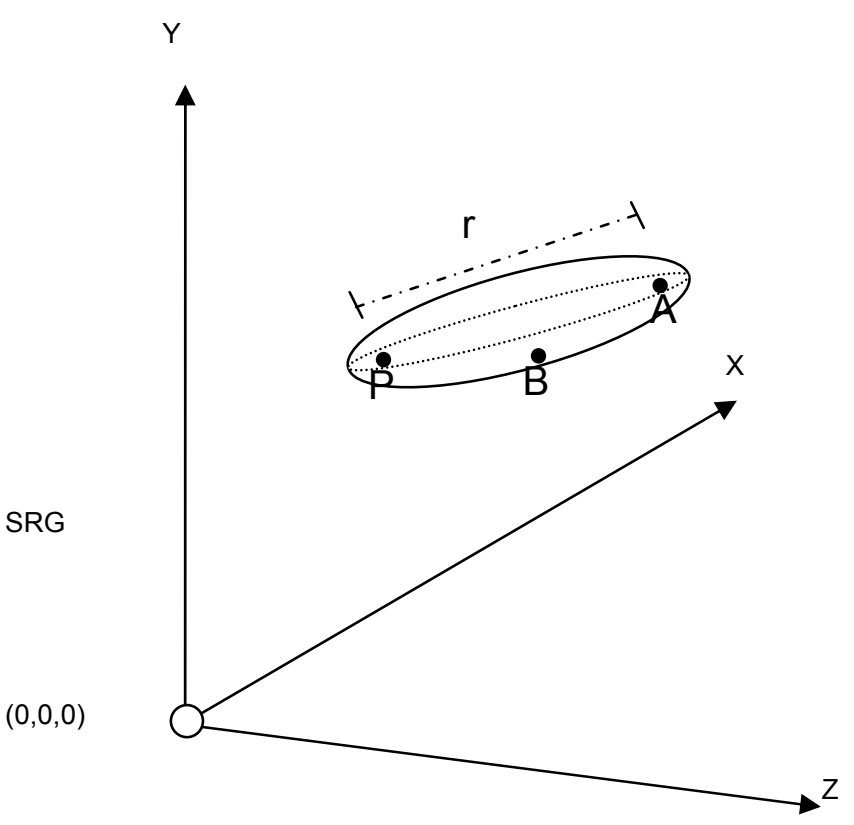

FIGURA 33 - Graus de liberdade de um corpo.

Assumindo que os segmentos coxa, perna e pé são corpos rígidos e que os clusters não se mexem em relação às marcas do respectivo segmento, o vetor posição das marcas em relação ao respectivo cluster, onde é determinado o SRL do segmento, não muda em função do movimento analisado.

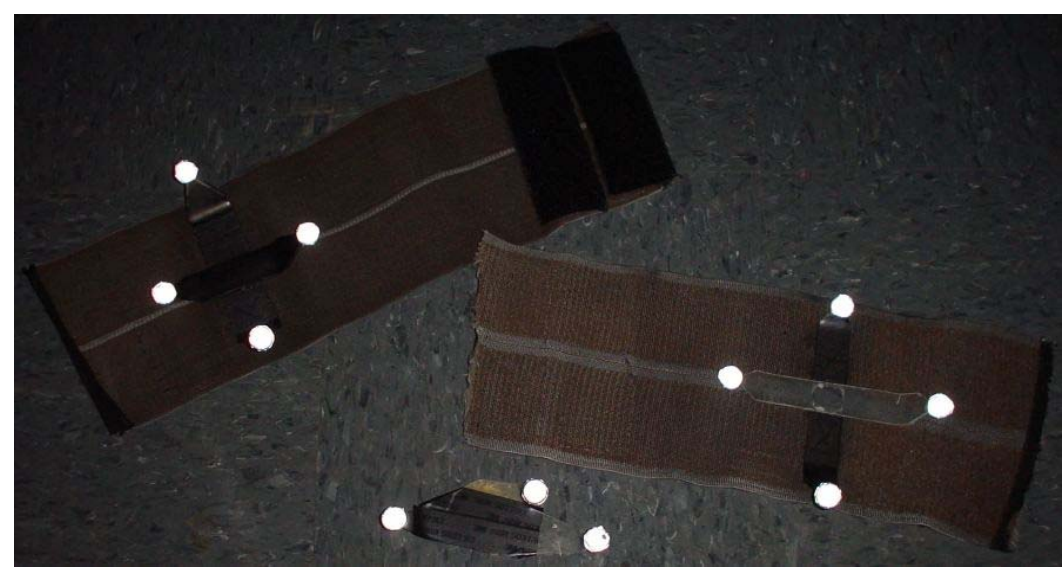

FIGURA 34 - Cluster de marcas. 


\section{ANEXO 5 - SISTEMA DE REFERÊNCIA (cont.)}

CAPPOZZO et al (1997) utilizaram a técnica de calibração do sistema anatômico (CAST), (CAPPOZZO et al., 1995), para reconstruir a posição das marcas anatômicas dos segmentos durante o movimento. O sujeito utilizado no estudo havia sofrido uma fratura de fêmur e estava utilizando um fixador ósseo ligado neste membro. A reconstrução a partir do CAST apresentou bons resultados na reconstrução das marcas anatômicas em comparação às marcas do fixador externo. Esse procedimento de utilização do CAST (FIGURA 34) melhorou a acurácia na determinação da posição óssea quando comparada à colocação de marcas diretamente sobre a pele.
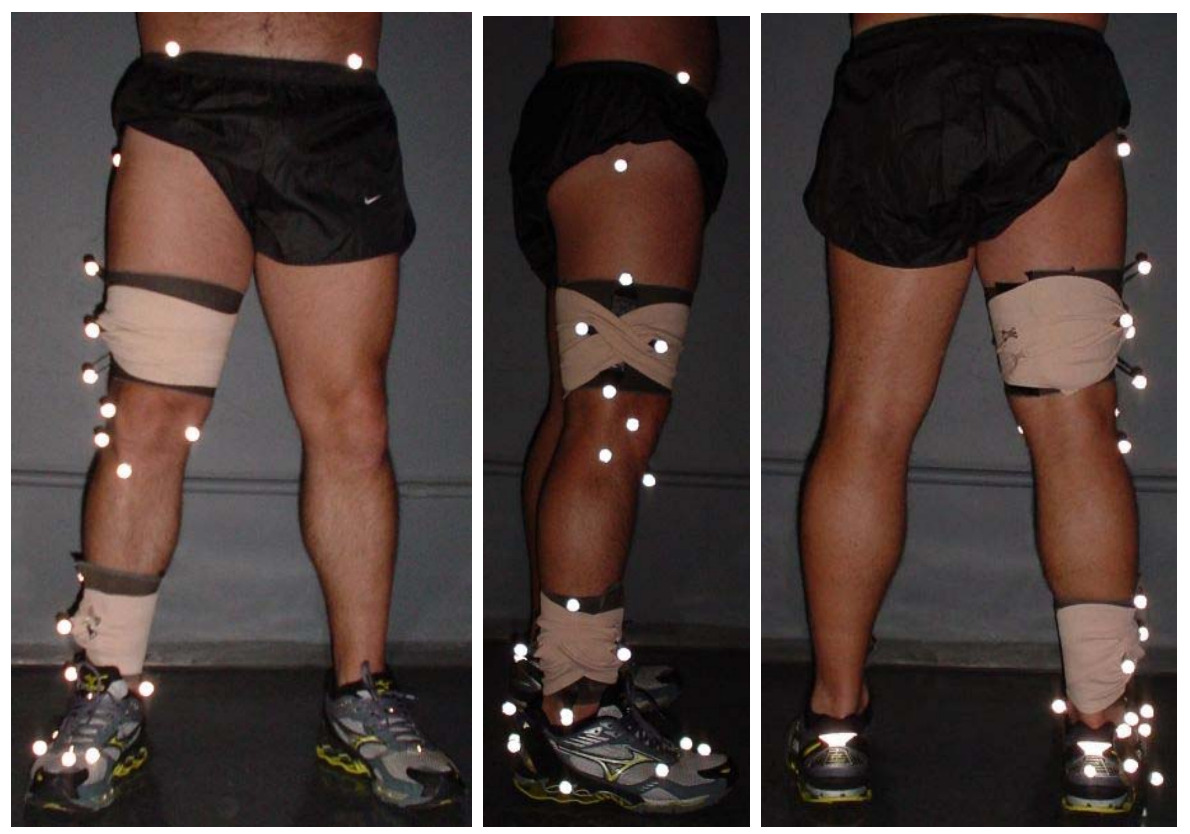

FIGURA 35 - Colocação das marcas anatômicas sobre os segmentos e os respectivos clusters para utilização do CAST.

Definições importantes sobre a posição e orientação espacial de ossos durante o movimento são reportadas por CAPPOZZO, et al (1995). Neste artigo, os autores se preocuparam em reconstruir a posição e orientação da pélvis humana e os ossos do membro inferior durante a execução da locomoção e exercícios físicos usando um sistema estereofotogramétrico. Foram definidos os termos "anatomical landmarks" (proeminências anatômicas), "bone-embedded anatomical reference 


\section{ANEXO 5 - SISTEMA DE REFERÊNCIA (cont.)}

system" (sistema de referência anatômica ligado ao osso) e "anatomical landmark calibration" (calibração das proeminências anatômicas).

A partir do cluster, é determinado um SRL no segmento em que esse cluster está fixado. A posição $\vec{V}^{\prime}$ de cada marca no respectivo segmento é expressa, neste primeiro momento, em relação a este SRL. Como essa posição não muda em função do tempo (já que o segmento é assumido como rígido), é necessário determinar essa posição em um único instante $t$. O vetor $\vec{V}^{\prime}$ pode ser então definido como:

$$
\overrightarrow{V^{\prime}}=\left[\begin{array}{c}
V_{x} i^{\prime} \\
V_{y} j^{\prime} \\
V_{z} k^{\prime}
\end{array}\right]
$$

onde i',j' e k' são os vetores unitários do SRL X'Y'Z'.

Porém, o que nos interessa é saber a posição desses vetores posição no SRG. Deste modo, é necessário achar a matriz de transformação $T$ para transformar um vetor de um sistema de referência para outro. Neste caso, é achar $\boldsymbol{T}$ que transforme um vetor do SRL para o SRG.

$$
T_{G / L}=\left[\begin{array}{lll}
i . i^{\prime} & i . j^{\prime} & i . k^{\prime} \\
j . i^{\prime} & j \cdot j^{\prime} & j . k^{\prime} \\
k . i^{\prime} & k . j^{\prime} & k . k^{\prime}
\end{array}\right]
$$

onde: onde $i, j, k$ e i',j', $k^{\prime}$ são os vetores unitários do SRG e SRL respectivamente e $\mathbf{T}_{G / L}$ é a matriz de transformação para o SRL do SRG. 


\section{ANEXO 5 - SISTEMA DE REFERÊNCIA (cont.)}

Para obtermos o $\vec{V}$, que representa a posição das marcas no SRG, a seguinte operação matricial deve ser feita:

$$
\left[\begin{array}{c}
V_{x} i \\
V_{y} j \\
V_{z} k
\end{array}\right]=\left[\begin{array}{ccc}
i . i^{\prime} & i \cdot j^{\prime} & i . k^{\prime} \\
j \cdot i^{\prime} & j \cdot j^{\prime} & j \cdot k^{\prime} \\
k \cdot i^{\prime} & k \cdot j^{\prime} & k \cdot k^{\prime}
\end{array}\right]\left[\begin{array}{c}
V_{x} i^{\prime} \\
V_{y} j^{\prime} \\
V_{z} k^{\prime}
\end{array}\right]
$$

Na prática, o CAST funciona da seguinte forma:

Coleta estática. Nesta fase, todas as marcas anatômicas são utilizadas, inclusive os 'clusteres' (FIGURA 35). Nesta coleta, todos os vetores posição das marcas da coxa, perna e pé são determinados e descritos a partir do SRL (cluster). Para cada marca existe apenas um único valor para o vetor posição, já que é assumido que as marcas não se movem durante a execução do movimento, pois faz parte de um corpo rígido (FIGURA 36).

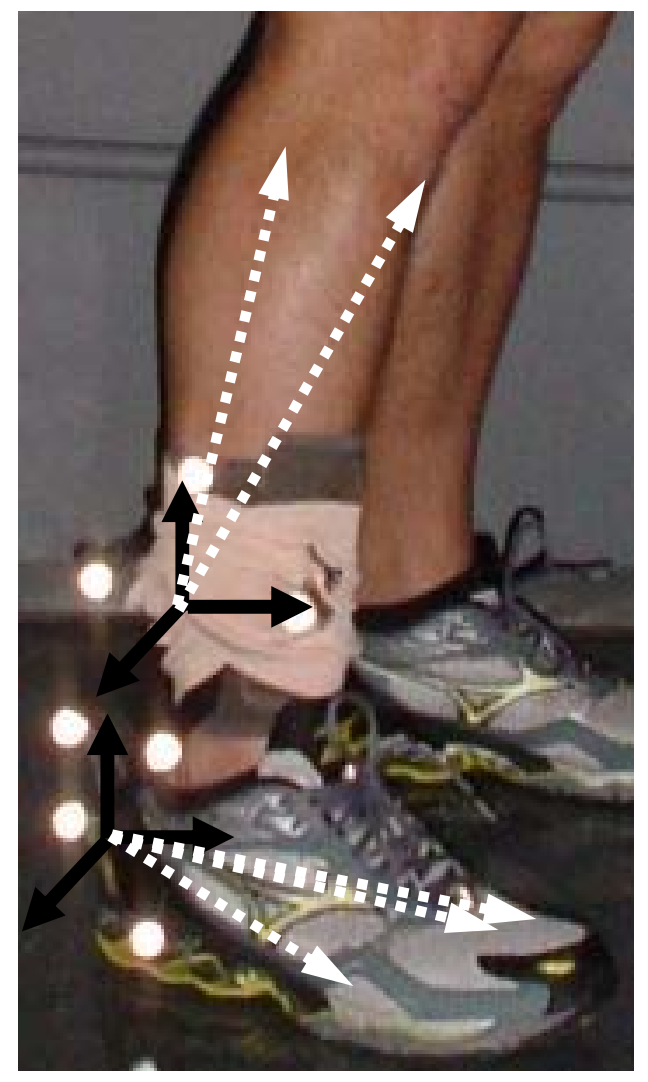

FIGURA 36 - Vetores-posição (em branco) das marcas anatômicas em relação ao SRL da perna (preto). 


\section{ANEXO 5 - SISTEMA DE REFERÊNCIA (cont.)}

(a) Coleta dinâmica. Nesta fase, somente os 'clusteres' de marcas são digitalizados, determinando assim a matriz de rotação $\mathbf{T}$ entre o cluster (SRL) e o sistema do laboratório (SRG) em cada instante (FIGURA 37).

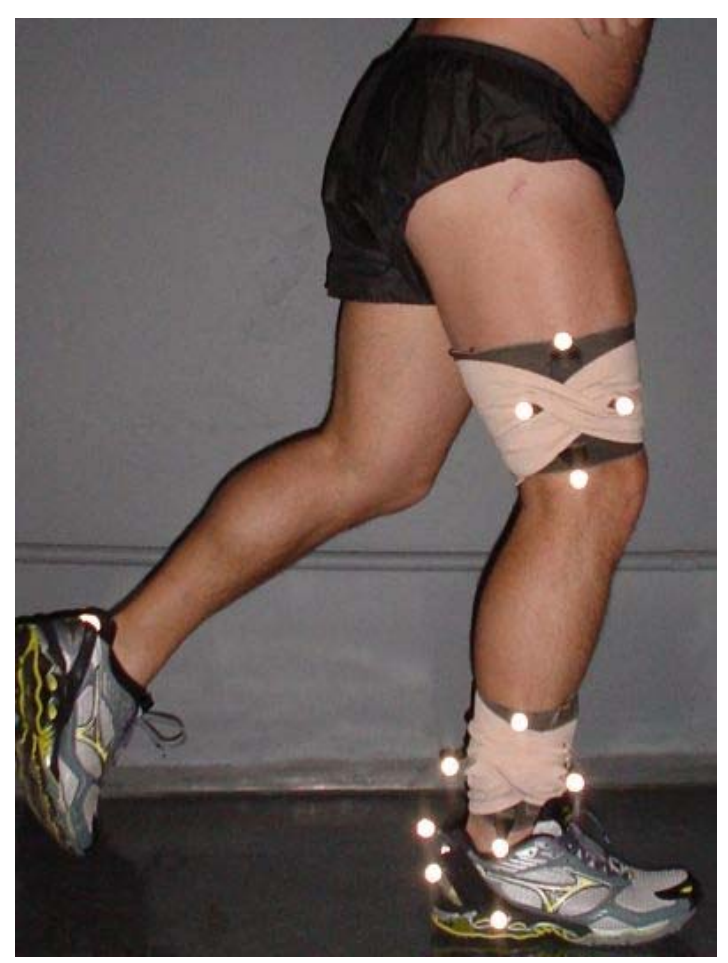

FIGURA 37 - Coleta Dinâmica.

(b) Reconstrução das Marcas. Nesta fase, em ambiente computacional, são determinadas virtualmente as posições das marcas no SRG. 
ANEXO 6 - CENTRO ARTICULAR DO QUADRIL

Neste item, será abordado o método utilizado no presente estudo para determinar o centro articular do quadril.

\section{Determinação do centro articular do quadril}

Foi utilizado o método híbrido de TYLKOWSKI et al. (1982) e ANDRIACCHI et al. (1980) para estimar o centro articular do quadril (CAQ). O CAQ direito encontra-se a $14 \%$ da distância entre a espinha llíaca ântero-superior direita (EIASD) e a espinha llíaca ântero-superior esquerda (EIASE), medial à EIASD e 30\% deste comprimento inferiormente às EIAS no plano frontal (ANDRIACCHI et al., 1980; TYLKOWSKI, SIMON \& MANSOUR, 1982) enquanto a posição ântero-posterior do quadril no plano sagital é determinada pela posição do trocânter maior do fêmur direito (TMFD) (ANDRIACCHI et al., 1980). As posições relativas do CAQ e das outras marcas anatômicas de referência são demonstradas na FIGURA 38.

Visão Frontal

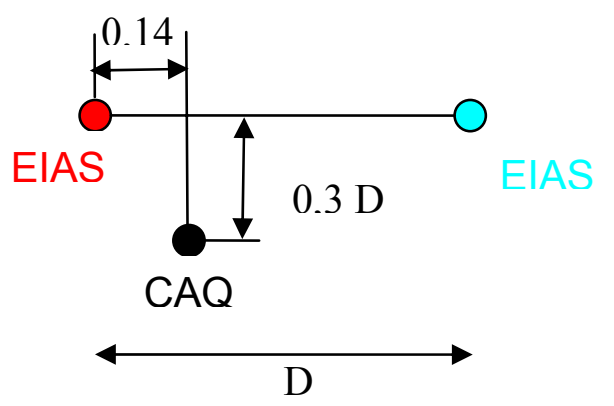

Vista Sagital

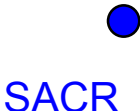

EIAS

- CAQ

O TMF

FIGURA 38. Posição relativa do Centro Articular do Quadril

Este método híbrido apresenta um problema: quando a coxa roda, a posição ântero-posterior do trocânter maior flutua. Então, a posição ântero-posterior do quadril flutua também. Uma solução para isto é registrar a posição relativa do quadril dentro da origem do sistema de coordenadas da pelve na posição neutra (posição neutra com os pés unidos e alinhados paralelamente) e utilizar isto no registro das situações dinâmicas. 